NBER WORKING PAPER SERIES

\title{
WEIGHT GAINS FROM TRADE IN FOODS: EVIDENCE FROM MEXICO
}

\author{
Osea Giuntella \\ Matthias Rieger \\ Lorenzo Rotunno \\ Working Paper 24942 \\ http://www.nber.org/papers/w24942
NATIONAL BUREAU OF ECONOMIC RESEARCH 1050 Massachusetts Avenue
Cambridge, MA 02138
August 2018, Revised April 2019

Previously circulated under the title "Trade in unhealthy foods and obesity: Evidence from Mexico." We thank the editor and two anonymous referees for their constructive comments and advice. We are grateful to Nicolas Berman, John Cawley, Amitabh Chandra, Eleonora Fichera, Jessie Handbury, Sergi Jimenez, Fabrizio Mazzonna, Janneke Pieters, Brandon Restrepo and participants at the 2019 CSAE Conference, 2018 FIW International Economics Conference, 2018 ISS-Wageningen Health Economics Workshop, IFPRI Workshop on Food Industries, Trade and Agriculture NBER Conference, 2018 ASSA meetings, 2017 HCHE Workshop on Risky Healthy Behaviors, 2017 ETSG Conference, 2017 FREIT Sardinia Conference, 2017 American-European Health Study Group Workshop, 2017 DIAL Conference, 2017 IRDES Workshop, 2017 Policy Evaluation in Health Workshop, and seminars at IMT Lucca, G ottingen, Bocconi, PSE, AixMarseille School of Economics, TSE, and International Institute of Social Studies (ISS), Erasmus University, for their comments and suggestions. We thank Sarah Elven and Alessia Mortara for their able research assistance. Part of the research was funded through the project "Trade liberalisation, nutrition transition, and health" (LED0938) by the John Fell Fund (Oxford University Press). The views expressed herein are those of the authors and do not necessarily reflect the views of the National Bureau of Economic Research.

NBER working papers are circulated for discussion and comment purposes. They have not been peer-reviewed or been subject to the review by the NBER Board of Directors that accompanies official NBER publications.

(C) 2018 by Osea Giuntella, Matthias Rieger, and Lorenzo Rotunno. All rights reserved. Short sections of text, not to exceed two paragraphs, may be quoted without explicit permission provided that full credit, including $(\odot$ notice, is given to the source. 
Weight gains from trade in foods: Evidence from Mexico

Osea Giuntella, Matthias Rieger, and Lorenzo Rotunno

NBER Working Paper No. 24942

August 2018, Revised April 2019

JEL No. F60,F61,I10,I12

\section{ABSTRACT}

In this paper, we investigate the effects of trade in foods on obesity in Mexico. To do so, we match data on Mexican food imports from the U.S. with anthropometric and food expenditure data. Our findings suggest that exposure to food imports from the U.S. explains about ten percent of the rise in obesity prevalence among Mexican women between 1988 and 2012. Pro-obesity effects are driven by areas more exposed to unhealthy food imports. We also find evidence in favour of a price mechanism. By linking trade flows to obesity, the paper sheds light on an important channel through which globalisation may affect health.

Osea Giuntella

University of Pittsburgh

Department of Economics

Posvar Hall

230 S Bouquet Street

Pittsburgh 15213

osea.giuntella@gmail.com

Matthias Rieger

International Institute of Social Studies (ISS)

Erasmus University

Kortenaerkade 12

The Hague

2518

The Netherlands

matthias.rieger@graduateinstitute.ch
Lorenzo Rotunno

Aix-Marseille University

Aix-Marseille School of Economics (AMSE)

CNRS \& EHESS

Chemin du Chateau Lafarge

13290

Les Milles

France

lorenzo.rotunno@univ-amu.fr 


\section{Introduction}

The prevalence of obesity, overweight and other diet-related chronic diseases has increased rapidly in the global south. Today, an estimated 62 percent of obese individuals live in developing countries ( $\mathrm{Ng}$ and et al., 2014). And the number of overweight or obese people living in the developing world has tripled between 1980 and 2008 (Keats and Wiggins, 2014). Over the same period many emerging economies have opened up their food markets to international competition. In response, policy makers have paid more attention to the implications of globalisation and international trade for population health and diets. The World Health Organization (WHO, 2015), for instance, has adopted a clear mandate to help member states better align trade and health policies. Despite the perceived association between trade liberalisation and diet-related health outcomes (see the review by Barlow et al. (2017b)), the causal effects of trade in foods on obesity and their quantitative importance are not well established. ${ }^{1}$

The rise in obesity observed in emerging economies has been associated with a "nutrition transition" whereby diets become richer in animal fats, sugars, and processed foods as average income increases (Popkin and Gordon-Larsen, 2004). These nutritional changes are intertwined with an epidemiological transition in which populations suffer more from obesity, diabetes and cardiovascular diseases rather than infectious diseases and undernutrition (Omran, 1971).

Greater openness to trade in foods can affect the nutrition transition and hence obesity prevalence through changes in prices, income, norms, and tastes. Lower relative prices of imported and import-competing foods can raise food consumption and the incidence of obesity, especially if such price effects are concentrated in more unhealthy, 'obesity-prone' foods. By affecting individuals' income, trade liberalisation can shape the nutrition transition and obesity prevalence. Finally, globalisation and trade openness can induce changes in food tastes and consumption, resulting in persistent and self-reinforcing effects on nutritional outcomes (Atkin, 2013; Dragone and Ziebarth, 2017).

In this paper, we examine the effects of U.S. exports of foods and beverages (F\&B or 'food' for short) on obesity in Mexico. Over the last decades, Mexico has recorded spectacular increases in diabetes and obesity rates, becoming a prime example of a country in the nutrition transition (Popkin et al., 2012). According to the latest WHO data from 2016, it ranks among the thirty most obese countries in the world, with an estimated 28.9

\footnotetext{
${ }^{1} \mathrm{~A}$ recent literature in public health has studied the association between trade liberalisation and availability of calories (Barlow et al., 2018), supply of products containing high-fructose corn syrup (Barlow et al., 2017a), and sugar-sweetened beverages (Lopez et al., 2017).
} 
percent of the adult population being obese. Trade flows between the U.S. and Mexico have also boomed since the 1980s and in particular following the North American Free Trade Agreement (NAFTA) in 1994. ${ }^{2}$ This is especially true for the F\&B industry, where U.S. products represent around 75 percent of total Mexican imports and 8 percent of Mexican households' food expenditure in 2012 (see section 4.1 for details). These concurrent trends beg the question: has the U.S. 'exported' its high obesity prevalence (the highest among OECD countries (OECD, 2017)) to Mexico through trade in foods?

To identify the effect of U.S. food exports within Mexico, we allocate trade flows across Mexican states - i.e., the lowest spatial unit at which data are representative. We measure each state's 'exposure' with its historical expenditure by food product. The general idea is that national trade shocks affect regions and individuals differentially; depending on, for instance, their access to trade routes (Atkin and Donaldson, 2015) and their sectors of employment (Topalova, 2007, 2010; Autor et al., 2013; Dix-Carneiro and Kovak, 2017). In our paper, the share of total national expenditure of a given food product in each state at the start of the period measures exposure to trade shocks. In a shift-share design, this pre-determined and time-invariant measure of food consumption is used to predict changes in state-level food imports over time. The empirical approach implies that a Mexican state where expenditure in, say, processed foods, was higher at the beginning of the period will receive a larger share of a given increase in U.S. exports of processed foods. Reassuringly, the imputed changes in state-level food imports from the U.S. correlate strongly with actual changes in state food imports from the U.S., for which data are available only starting from 2006.

We focus on the import side of food trade between Mexico and the U.S. because of its immediate link with food consumption. While Mexican food exports to the U.S. and elsewhere also increased dramatically (a sixteen-fold increase in exports to the U.S.), lack of detailed production and employment data by product at the regional level hinders proper identification of their possible influences on obesity. Our analysis nonetheless checks for effects of increased Mexican food exports operating through relative food prices.

We document a positive and robust effect of U.S. food exports on changes in obesity prevalence across Mexican states. ${ }^{3}$ Our analysis is based on anthropometric data for adult women collected through four surveys in 1988, 1999, 2006 and 2012, as data for men were

\footnotetext{
${ }^{2} \mathrm{~A}$ large literature has examined the implications of Mexican economic liberalisation for economic growth (Hanson, 2010), labour markets and wage inequality (e.g, Hanson, 2007; Verhoogen, 2008), as well as retail prices and household welfare (Atkin et al., 2018).

${ }^{3}$ Obesity status is derived from the Body-Mass Index (BMI, equal to weight (in $\mathrm{kg}$ ) over height squared (in meters)), commonly used as a measure of body fat.
} 
only collected in later surveys (2006 and 2012). ${ }^{4}$ The pro-obesity effect is confirmed in both long-difference and stacked first-difference specifications. The relationship between rising exposure to U.S. foods and obesity prevalence is statistically significant, also when controlling for state-level trends in obesity, exposure to foods from other countries (negatively and less strongly associated with obesity changes), and other state-level characteristics.

To bolster a causal interpretation of our findings, we follow Autor et al. (2013) and implement an instrumental variable (IV) strategy that aims at identifying supply-side shifters of U.S. food exports. Changes in U.S. food exports to other destinations than Mexico are used as instrument in order to isolate variation in U.S. food exports stemming from U.S. comparative advantage and market access to third countries across food products. Similar to the ordinary least squares (OLS) estimates, the IV results point to a sizeable causal effect of exposure to U.S. foods on the rise of obesity prevalence in Mexico. The supply-driven rise in U.S. food exports to Mexico can explain about ten percent of the spectacular increase in obesity prevalence among Mexican adult women observed between 1988 and 2012. The findings are confirmed when we replace U.S. food exports to Mexico with differenced residuals from regressions of U.S. and Mexican food exports on product and destination fixed effects, which explicitly net out demand-side influences (Autor et al., 2013).

Counterfactual calculations using IV estimates illustrate that in the absence of food imports from the U.S. between 1988 and 2012, there would have been one million fewer obese women in Mexico. While suggestive, these numbers point to a quantitatively important impact of food imports on obesity in Mexico, which is comparable to the effects of other changes in the local food environment found in the U.S. (see Courtemanche and Carden (2011) on obesity and Walmart supercenters expansions).

We submit our baseline findings to several robustness checks and extensions. In a temporal placebo test, we find that current changes in obesity prevalence are not related to future changes in food imports. Another falsification test using imports of apparel as an alternative measure of states' exposure to trade dismisses spuriousness due to overall trade with the U.S. The findings are also robust to controlling for Mexican food exports, the use of food imports statistics for final demand only, dropping specific states, and employing alternative dependent variables (BMI, overweight).

The strong obesity effect of American foods (relative to the lower and downward influence of those from other sources) hints at their unhealthiness, so we further categorize foods using the USDA Dietary Guidelines for Americans (DGA (2010); see also Alcott et al. (2018); and

\footnotetext{
${ }^{4}$ We do confirm our baseline results using obesity data for men in the 2012 - 2006 difference (see footnote no. 29).
} 
Volpe et al. (2013) for recent applications). While U.S. food exports to Mexico increased more than seven-fold between 1989 and 2012, exports of unhealthy foods featured the highest increases (e.g., exports of "food preparations" are 23 times higher in 2012 than in 1989). In the empirical analysis, this unhealthy component of changes in U.S. food exports drives our baseline findings. Moreover, the obesity effect of trade in unhealthy foods is amplified by low levels of education, potentially widening the already large disparities in obesity risk between women with different levels of education.

We explore mechanisms behind our baseline findings guided by standard neoclassical models of obesity (e.g., Philipson and Posner (2003); Cutler et al. (2003); Lakdawalla and Philipson (2009)). In these settings, individuals' utility increases with food consumption and with body weight up to a target weight level above which utility decreases with weight. Holding the ideal weight and the level of physical activity fixed, the reduction in relative food prices and the higher income potentially associated with greater trade integration might (at least initially) increase food consumption and body weight.

Greater import penetration in final goods can lower consumer prices through various theoretical channels - e.g., lower prices of imported goods, pro-competitive pressure on domestic producers, and elimination of policy distortions. As Goldberg and Pavcnik (2016) argue, the quantitative importance of the price-reducing effect of import liberalisation is however less clear and hinges on the specific market conditions. Using Mexican consumer price micro data (1995-2010) from Gagnon (2009) and Gagnon et al. (2013), we test for this mechanism in reduced-form by regressing national food prices on U.S. food exports to other countries - i.e., our instrument for foreign supply shocks. The results point to a negative and significant effect of U.S. export supply shocks on consumer food prices, whose magnitudes are in line with those found in previous studies (Topalova, 2010; De Loecker et al., 2016). While prices of foods (and of other consumer products) went up in Mexico during the sample period (Gagnon, 2009), the evidence suggests that greater exposure to U.S. foods curbed food inflation - an effect that is concentrated in unhealthy food products. Mexican food prices did not respond to U.S. demand-driven shocks to Mexican food exports (as proxied by U.S. food imports from other countries than Mexico), suggesting that the rise of Mexican food exports did not have a significant effect on relative consumer prices.

Greater trade openness could affect food consumption and body weight by changing average income through increased competitiveness and market opportunities. This income channel should however pertain to overall trade rather than food imports only. On the import side, greater import competition can lead to reductions in wages (e.g., Topalova (2010); and Dix-Carneiro and Kovak (2017)), which could be partly mitigated by productivity increases 
through greater access to cheaper inputs (e.g., Kis-Katos and Sparrow (2015)). Our empirical strategy, exploiting differential exposure across food products (and hence within a single industry), is geared towards identification of consumption channels and cannot capture exposure through industry employment, which is normally adopted to identify income effects. In our empirical analysis at the state-level, we find no strong support for a systematic relationship between obesity rates and average income changes, providing little evidence that the obesity-inducing effect of greater penetration of U.S. foods is operating through changes in income.

Increased availability of U.S. foods over time can shift tastes for different types of foods. Consumers' preferences exhibit taste formation when the marginal utility of current consumption increases with past consumption (Dragone and Ziebarth (2017); similar to what Atkin (2013) refers to as "habit" formation). Since higher U.S. food exports are significantly correlated with lower food prices, Mexican households could develop a stronger taste for foods that were relatively cheaper in the past because of exposure to U.S. supply. We test for this channel by regressing household budget shares on lags of U.S. food exports, while controlling for current state-level prices and household characteristics (including real expenditure). Results are overall consistent with habit formation, but the evidence is rather weak.

This paper provides the first causal evidence on trade in foods and obesity. It expands recent conceptual studies (WHO, 2015; Thow, 2009) linking trade liberalisation to the nutrition transition and to the related rise in obesity, diabetes and other cardiovascular diseases in the global south. Existing cross-country studies provide mixed evidence Miljkovic et al. (2015) and Vogli et al. (2014) report a positive and significant effect of trade openness on obesity and BMI, whereas the findings in Oberlander et al. (2017) and Costa-Font and Mas (2016) suggest that social (rather than economic) globalisation matters. We use detailed data from a single country, Mexico, and contribute to this nascent line of empirical work by identifying the impact of trade in foods (rather than total trade flows).

Our study also complements recent work on the adverse effects of trade liberalisation on health through income and labour market channels (Colantone et al., 2018; Adda and Fawaz, 2017; Pierce and Schott, 2017; Hummels et al., 2016; Lang et al., 2019; McManus and Schaur, 2016). Our paper applies a comparable shift-share identification strategy, but it is the first one to focus on obesity and on a demand-side channel operating through food consumption (Popkin and Gordon-Larsen, 2004; Rivera et al., 2004).

More broadly, we add to a large body of work on the economic determinants of obesity and dietary habits (Cawley, 2015). Courtemanche et al. (2016) find that the local economic 
environment (e.g., retailers and restaurants) explains a significant portion of the observed rise in obesity in the U.S.. ${ }^{5}$ Alcott et al. (2018), however, find that spatial differences in access to healthy foods explain only a small fraction of the differences in nutritional intake across people from different socioeconomic groups (e.g., across people with different levels of education). In our analysis, we find no evidence of a significant association between changes in obesity prevalence and the local food retail environment, as measured by food expenditure by place of purchase and consumption, and by state penetration of Walmart in Mexico. When controlling for these additional factors, the pro-obesity effect of U.S. foods remains unaltered. Our paper therefore highlights the role of international trade in foods as an independent economic driver of obesity.

The rest of the paper proceeds as follows. Sections 2 and 3 describe the empirical strategy and the data used in the analysis. Section 4 discusses the results, focusing on a descriptive analysis first (subsection 4.1), and then delving into the econometric results and extensions thereof (subsection 4.2). Section 5 discusses findings and some evidence of mechanisms. Section 6 concludes.

\section{Empirical strategy}

The empirical analysis follows three steps. First, we present some descriptive patterns in obesity and U.S. food exports to Mexico. Second, we estimate the effect of greater exposure to food imports from the U.S. on obesity prevalence. Third, we investigate possible mechanisms.

Our baseline specification relates obesity prevalence to exposure to U.S. food exports allocated to the 32 Mexican states - the lowest level of aggregation at which the health surveys are representative -, controlling for state-level characteristics. In particular, we estimate the following regression:

$$
\Delta \text { Obesity }_{s, t}=\beta_{1} \Delta U \operatorname{Simp}_{s, t}+\beta_{2} \Delta R O W i m p_{s, t}+\beta_{3} X_{s, t-1}+\beta_{4} \Delta W_{s, t}+\theta_{t}+\epsilon_{s, t}
$$

The ' $\Delta$ ' operator denotes the difference between the value of the variable at time $t$ and and its value at $t-1$. The empirical specification in differences attenuates concerns of serial correlation in the error term and is standard in shift-share designs used to study the local labour market impact of import competition (e.g., Autor et al. (2013)). Our data spans four periods $(1988,1999,2006$, and 2012), which correspond to the years of the health survey containing anthropometric information (individuals are not followed over time). We estimate

\footnotetext{
${ }^{5}$ See also Currie et al. (2010) on the effects of fast food restaurants on obesity.
} 
regression (1) in a long-difference specification, where the $\Delta$ operator indicates state-level differences between 2012 and 1988, and in a specification pooling the first differences in the sample (1999 - 1988, 2006 - 1999, and 2012 - 2006).

The $\Delta$ Obesity variable equals the change in the share of adult women living in state $s$ who have a BMI greater than or equal to 30 between $t$ and $t-1$. The main covariate of interest is $\Delta U$ Simp - imputed changes in food imports (PPP-adjusted) coming from the U.S. at the state level between $t$ and $t-1$.

The coefficient $\beta_{1}$ identifies the effect of food imports from the U.S. on obesity in 'reduced-form'. The variable $\Delta U$ Simp measures variation in states' exposure to food imports as predicted by expenditure specialisation in different food products at $t-1$. Specifically, differences in imputed food imports from the U.S. of state $s$ over time are defined as:

$$
\Delta U \operatorname{Simp}_{s, t}=\sum_{g} \frac{E_{g, s, t-1}}{E_{g, t-1}} \frac{\Delta M_{g, t}^{U S}}{E_{s, t-1}}
$$

where the subscript $g$ identifies a food product. Changes in imports from the U.S. for each Mexican state at the product level are imputed from national trade statistics - imports at the state level are available only starting from $2006 .^{6}$

In practice, we first convert U.S. food exports to Mexico from nominal US\$ to local Mexican consumer prices by multiplying the export values by the yearly PPP conversion factor for private consumption - in changes, this gives the variable $\Delta M_{g, t}^{U S}$ in equation (2). We then use the state's expenditure share for a given product at $t-1$ (i.e., the state expenditure for a product relative to total national expenditure for the same product, $\left.\frac{E_{g, s, t-1}}{E_{g, t-1}}\right)$ to allocate changes in (PPP-adjusted) imports across states. Imputed changes in state-level food imports from the U.S. $\left(\sum_{g} \frac{E_{g, s, t-1}}{E_{g, t-1}} \Delta M_{g, t}\right)$ are finally normalized by state food expenditures at $t-1\left(E_{s, t-1}\right)$. The resulting variable, $\Delta U \operatorname{Simp}_{s, t}$ measures changes in exposure to U.S. foods over time relative to household food expenditure (on both domestic and foreign foods) at baseline.

Variation in expenditure shares across states and products, as well as changes in trade flows over time identify our coefficient of interest, $\beta_{1}$, in the regression equation (1). If the food expenditure on each product is equally distributed across states, the $\Delta U$ Simp variable does not vary across states as well, and the $\beta_{1}$ coefficient cannot be identified separately from period dummies $\theta_{t}$ (or a constant term in the long-difference specification). More generally, time dummies absorb the influence of variation in national food imports from the U.S. as

\footnotetext{
${ }^{6}$ We show below that there is a strong correlation between our imputed and actual changes in Mexican state imports.
} 
well as of other national shocks.

Our empirical design is borrowed from the literature on the local labour market impact of import competition (see, e.g., Autor et al., 2013), which has recently been applied to investigate the effects of imports on workers' health (Colantone et al., 2018). In this line of work, the objective is to investigate trade effects in the labour market and hence imports are allocated within countries according to sub-national and sectoral employment shares. In our analysis, we focus on a nutrition channel - expenditure shares are thus the relevant measure of trade exposure at the local level. ${ }^{7}$

The imputed import variable $\Delta U$ Simp can be thought of as an instrument for variation in the actual consumption of foods from the U.S. - which is unobserved until 2006 and likely to be endogenous to obesity prevalence. However, a causal interpretation of the $\beta_{1}$ coefficient further requires that U.S. exports to Mexico vary across food categories and over time $\left(\Delta M_{g, t}^{U S}\right.$ in equation (2)) with supply-side determinants of U.S. food production that are not affected by Mexican demand. We thus follow Autor et al. (2013) and exploit variation in U.S. food exports to other countries (except Mexico) in order to generate plausibly exogenous variation. ${ }^{8}$ Our instrument is constructed as in equation (2) with changes in U.S. food exports to other destinations replacing U.S. food exports to Mexico. As a further check on our identification assumption, we also compute differences in residuals from panel regressions of U.S. and Mexico food exports on product and destination dummies (other than Mexico and the U.S.), and use these instead of U.S. food exports in our definition of Mexican states' exposure to U.S. foods (equation (2)). ${ }^{9}$ As Autor et al. (2013) argue, variation in these gravity residuals should only come from changes in the patterns of U.S. comparative advantage relative to Mexico in the food sector, and from any differential changes in trade costs. In particular, the product and destination fixed effects in the auxiliary regressions control for dietary shifts during the nutrition transition that are common to Mexico and

\footnotetext{
${ }^{7}$ The coefficient $\beta_{1}$ in equation (1) could still capture the influence of labour market channels (e.g., changing physical activity due to import competition) if the pre-determined expenditure shares correlate with initial employment shares.

${ }^{8}$ In previous versions of the paper, we considered U.S. food exports to the ten largest upper middle-income destination countries (UMIC) other than Mexico: China, Colombia, Costa Rica, Dominican Republic, Algeria, Malaysia, Russia, Thailand, Turkey and Venezuela. Using food exports to all other destinations, including countries at different stages of economic development and hence of the nutrition transition, alleviates concerns of cross-country correlation in food demand patterns. Results available upon request are nonetheless similar when using U.S. food exports to the ten major UMIC destinations to build the instrument.

${ }^{9}$ We employ a PPML (Pseudo-Poisson Maximum likelihood) estimator in the estimation of the gravity equations to account for the zeros (pervasive mainly in Mexican food exports) and heteroskedasticity in trade data (Silva and Tenreyro, 2006). The difference in the residuals from the two gravity equations (one for U.S. food exports and one for Mexican food exports) is further differenced over the time periods in our estimation sample, and averaged across destinations by product.
} 
other countries.

By using initial expenditure shares to project variation in food imports over time, we are assigning more imports to states that were already on an upward trend in food consumption, and possibly in obesity prevalence. To control for such pre-existing patterns, the specification in (1) includes the changes in obesity prevalence during the previous period $\left(\Delta\right.$ Obesityt $y_{t-1}$. For the long-difference specification and for the first time window in our sample (1999 1988), we set the value of $\Delta$ Obesity $_{t-1}$ equal to obesity prevalence in 1988 because of lack of data on obesity before then. With this pre-trend control, the coefficient $\beta_{1}$ is identified off deviations in imputed food imports from states' trends in obesity. Its sign and size help assessing the role of exposure to U.S. foods in shaping the underlying and upward obesity trends observed in Mexico (and similar to those observed in other countries going through a nutrition transition). To make sure that the identifying variation in our variable of interest, $\Delta U$ Simp, comes from variation in food imports, we also control for the food share of states' expenditure at $t-1 .^{10}$

Our preferred empirical specification controls for changes in exposure to food imports from countries other than the U.S. $\left(\triangle R O W i m p_{s, t}\right)$ and for changes in other states' characteristics (collected in $\Delta W_{s, t}$ ) that can shape obesity patterns and correlate with exposure to U.S. foods. State-level food imports from other countries are computed as for imports from the U.S. (see equation (2)), with $\Delta M^{U S}$ being replaced with changes in aggregate product-level imports from countries other than the U.S. (in PPP). The associated coefficient $\beta_{2}$ is however likely to be biased for the same reasons that can bias the OLS coefficient on the U.S. food imports variable. Lack of a credible exclusion restriction that can identify global exogenous variation in food supply leads us to treat this variable as a control in our empirical analysis, in order to isolate the contribution of U.S. supply shocks to obesity in Mexico.

The matrix $W$ controls for economic development as proxied by GDP per capita, measures of economic and cultural openness to the U.S. - the state's stock of inward Foreign Direct Investments (FDI) (relative to the state's GDP) and a measure of returning migration from the U.S. normalized the state's population. ${ }^{11}$ We further control for changes in the share of women in our sample with at least a high school diploma (a signal of high education

\footnotetext{
${ }^{10}$ This is equivalent to controlling for initial manufacturing share of local employment in the similar shift-share design of Autor et al. (2013).

${ }^{11}$ We use data from the EMIF, an annual survey starting from 1995, to obtain the number of Mexicans living in the U.S. who came back to Mexico in a given year, by Mexican state of birth. This flow is normalized by the state's population. For the first period of our sample (1988), we use the Mexico population census in 1990 and compute the share of people living in a state who reported having lived in the U.S. during the preceding five years.
} 
attainment in our empirical setting) and in the unemployment share, both proxies for the socioeconomic composition of the sample. The state shares of total female population in the initial period (1990) are used as weights in the regressions to correct for sampling error in computing state-level variables and to ensure that our results are nationally representative. Standard errors in (1) are clustered at the state level.

\section{Data}

We use data on anthropometrics, expenditure and trade. The former come from the Encuesta Nacional de Nutricion (ENN, 1988 and 1999) which then became the Encuesta Nacional de Salud y Nutricion (ENSA, 2006 and 2012). ${ }^{12}$ The survey changed structure and expanded its content over time. However and importantly for our study, the surveys are representative at the state level. The ENN collected anthropometrics data only for children and women between 20 and 49 years of age. For this reason, we restrict our baseline analysis to this sample of adult women, and check the robustness of our results using men and other age groups surveyed in the ENSA (2006 and 2012). In each survey year, we compute obesity prevalence as the share of surveyed women between 20 and 49 years of age who are classified as obese. Due to lack of anthropometric data for five states in $1999,{ }^{13}$ we linearly interpolate (by state) using the preceding (1988) and subsequent observation (2006) to impute obesity prevalence for those observations. ${ }^{14}$ It should be noted that this data issue does not affect the 2012 - 1988 changes in obesity prevalence or our results as we control for the added noise with an indicator for those five states with missing data in 1999.

The heath surveys contain information on individual socioeconomic risk factors (education, employment status, household type) linked to obesity. We aggregate the education and employment variable at the state-level to control for the share of women in our sample with at least a high school diploma (measure of high education) and for the unemployed share of women. In individual-level extensions of our baseline model (equation (1)), we add a broader set of individual controls, including an index for the position of each

\footnotetext{
${ }^{12}$ We use these data rather than the individual panel data of the Mexican Family Life Survey (MXFLS) because the MXFLS is not representative at the state level (the smallest spatial unit at which the expenditure data are representative) and because it goes back only to 2002. Hence, using it would miss the major changes in U.S. food exports to Mexico that occurred in the 1990's.

13 The 1999 wave of the ENN survey does not include four states and the state of Chihuahua has very few anthropometric measurements.

${ }^{14}$ As an alternative solution, we assign the average change in obesity prevalence across states in 1999 1988 and in 2006 - 1999 to those five states with missing data. Results (available upon request) are virtually identical to those presented here.
} 
household in the sample wealth distribution. ${ }^{15}$

Data on household expenditure are drawn from waves of the Encuesta Nacional de Ingresos y Gastos de los Hogares (ENIGH), the Mexican household-level survey on expenditure by detailed product categories, covering the period of the obesity data (from 1989 to 2012). State expenditures in 1989, 1998 and 2006 are used to compute changes in exposure to food imports (e.g., $\Delta U$ Simp in (2)) over the 1988 - 1999, 2006 - 1999, and 2012 - 2006 periods, respectively.

Mexican imports from the U.S. and other trade variables starting from 1989 are sourced from UN COMTRADE. After harmonizing the product classification of the trade (SITC, revision 3) and expenditure data, we obtain a sample of 152 foods and beverages with a full time series of expenditures and imports. ${ }^{16}$ Trade values in current US $\$$ are converted into local Mexican consumer prices by using the yearly PPP conversion factor for private consumption from the World Development Indicators.

Variation in $\Delta U$ Simp across states and over time comes from the interaction of pre-determined expenditures shares and time-varying U.S. food exports to Mexico (see equation 2). In order to identify the demand channel going from exposure to U.S. foods to obesity, these imputed imports should correlate with actual values. To verify this, we use data from the TransBorder Freight Database, reporting U.S. exports by broad sector to each Mexican state starting from 2006. A different sector classification and the inclusion of both final and intermediate goods in the TransBorder Database make it difficult to ensure a good match between imputed and actual food imports. ${ }^{17}$ In spite of these data shortcomings, Figure A2 in the Appendix shows a strong correlation between actual and imputed food imports. Partialling out year fixed effects in Panel (a) delivers a positive and significant slope coefficient on imputed imports, whose variation can explain $71 \%$ of the residual variance in actual imports, as denoted by the partial $\mathrm{R}^{2}$. In Panel (b), we control for both state and year fixed effects, exploiting the within-state variation in imports over time that also helps identifying the obesity empirical model. The estimates imply that, after netting out the

\footnotetext{
${ }^{15}$ We perform a principal component analysis of different household asset variables for each year (e.g., whether the house has walls made of concrete, a TV, a fridge) and use the first component as an index of household wealth. We then allocate households to quintiles of the index in order to mitigate sampling error.

${ }^{16}$ We exclude 16 products for which the matching with the trade or health (USDA) classifications was highly problematic, because of imprecise definitions (e.g. "loose seeds", "packaged seeds", "packed chillis") or because there was no clear international (e.g., "Pueblan chillis for stuffing", "unpasteurized milk") or health (e.g., "Cinnamon") category. They represent, on average, 4.5 percent of state imputed imports from the U.S. and 2 percent of state household expenditure.

${ }^{17}$ We define food imports in the TransBorder Freight Database as the sum of the product codes 16 to 22 in the classification available here: https://www.bts.gov/sites/bts.dot.gov/files/docs/browsestatistical-products-and-data/transborder-freight-data/220171/codes-north-americantransborder-freight-raw-data.pdf.
} 
influence of year dummies, changes in imputed imports over time can explain up to $38 \%$ of the within-state variation in actual imports. These results suggest that our allocation of national food imports to states can explain a substantial part of the variation over time in actual states' food imports from the U.S.. ${ }^{18}$

When investigating plausible mechanisms underlying our main findings, we make extensive use of the micro data on Mexican prices that form the official Consumer Price Index (CPI) ${ }^{19}$ These data, made available by Gagnon (2009), provide monthly price quotes identified by store, city and product category, between 1993 and 2010 (see also Atkin et al. (2018) for an application using similar price data). Although the time series do not cover the full set of health surveys with obesity data (seven Mexican states had no prices collected before 1995$)^{20}$, the CPI microdata are representative of Mexican households' consumption basket, and the monthly quotes provide an accurate measure of annual food prices. ${ }^{21}$ For these reasons, we adopt the CPI data to test for the price effects of exposure to U.S. foods starting from 1995, when all Mexican states where included in the sample. Most of the food product categories can be easily matched with the ENIGH products - we could find the prices of around 110 out of the 152 food products considered in the obesity regressions. The set of product categories is roughly constant over time, while product varieties (defined at the level of price quotes) changed substantially after 2002, which makes it impossible to track the price of the same variety throughout the sample. We follow Gagnon (2009) and drop implausible prices values and prices of products for which quantity units changed over time. Annual prices are obtained as averages of monthly price quotes (in logs). These are further averaged at the ENIGH product level, thus providing our measure of (log) prices of foods, aggregated at the country or state level. Importantly, we have no information on purchases at the level of price quotes (equivalent to varieties of the same food product). ${ }^{22}$

Part of the analysis tries to distinguish expenditure and trade in healthy and unhealthy

\footnotetext{
${ }^{18}$ If deviations from actual state food imports in our imputed import variable $\Delta U$ Simp are correlated with obesity prevalence, they would lead to non-classical measurement error and bias our estimates. Univariate regressions of the difference between $\Delta U$ Simp and the 2012 - 2006 change in actual food imports (normalized by the state's food expenditure, as for $\Delta U$ Simp) on obesity changes over the 2012 - 2006 period or on obesity prevalence in 2006 yield insignificant coefficients (point estimate $=-0.03$, std. error $=0.13$; and point estimate $=-0.004$; std. error $=0.15$ ), thus going against endogeneity due to non-classical measurement error.

${ }^{19}$ We thank an anonymous referee for pointing us to these data.

${ }^{20}$ Eleven Mexican states (out of 32) have more than one city (at most three) where prices are recorded. In our aggregation procedure, we average $(\log )$ prices of the same product across cities in the same state.

${ }^{21}$ The CPI microdata are of better quality than the self-reported unit values from the ENIGH expenditure surveys. ENIGH unit values at the household level do not capture the price of new and different varieties of a food product, and are recorded by monitoring households' purchases for one week only.

${ }^{22}$ This type of information is normally available in consumer panel microdata collected by market research companies (see Atkin et al. (2018)). Moreover, the price microdata cannot be used to construct store-specific price indexes because the store identifier changes with the product category.
} 
foods. To identify these categories, we follow Volpe et al. (2013) (see also Hut and Oster (2018), and (Alcott et al., 2018) for recent applications) and aggregate food products in the 52 groups used by the Quarterly Food-at-Home Price Database (QFAHDP). We classify these as healthful or unhealthful following USDA Dietary Guidelines for Americans (DGA (2010); also in Volpe et al., 2013). Healthy foods are those recommended for increased consumption (e.g., "dark green vegetables"), whereas unhealthy foods are those recommended for limited consumption (e.g., "refined flour and mixes"). We assign the food items from the trade and expenditure data to the 52 USDA food categories on the basis of their text description. Table A1 in the Appendix lists the food products and their USDA category. In the last column, we report a more conservative classification that restricts the healthy category to vegetables, fruits, fish and poultry.

\section{Results}

Before discussing the results of the econometric analysis, we provide some descriptive evidence on the evolution of obesity and U.S. food exports to Mexico in our sample, running from 1988 to 2012 and with data on obesity available at four points in time.

\subsection{Descriptive evidence}

Our anthropometric data replicate the spectacular rise in obesity that is documented in other work on Mexico (Rtveladze et al., 2014). Average BMI of women is 19 percent higher in 2012 than in 1988, and the rate of obesity prevalence dramatically increased during the same period, going from 10 to 35 percent. $^{23}$ The share of women who are overweight or obese (i.e. with a BMI of at least 25) doubled from 35 to 70 percent.

Obesity among adult women increased nationally, yet the rate of change varies across Mexican states as shown in Figure 1 (showing the variable $\Delta$ Obesity used in the long-difference specification). The state of Nayarit experienced the smallest increase (19 percentage points), while the biggest increase (37 percentage points) is recorded in Quintana Roo.

\footnotetext{
${ }^{23}$ Survey weights are used for the 1999, 2006 and 2012 waves to compute these statistics. We use state-level weights equal to the number of adult women respondents divided by the relevant state population in 1990 for the 1988 survey, where survey weights are missing or have implausible values. Using an alternative measure of obesity based on the waist-to-height (WTH) ratio (women with a WTH over 0.58 are normally classified as obese), we find that obesity prevalence went from 18 to 48 percent between 1999 and 2012. We do not have data on waist in 1988.
} 
Figure 1: Changes in obesity prevalence across Mexican states between 1988 and 2012

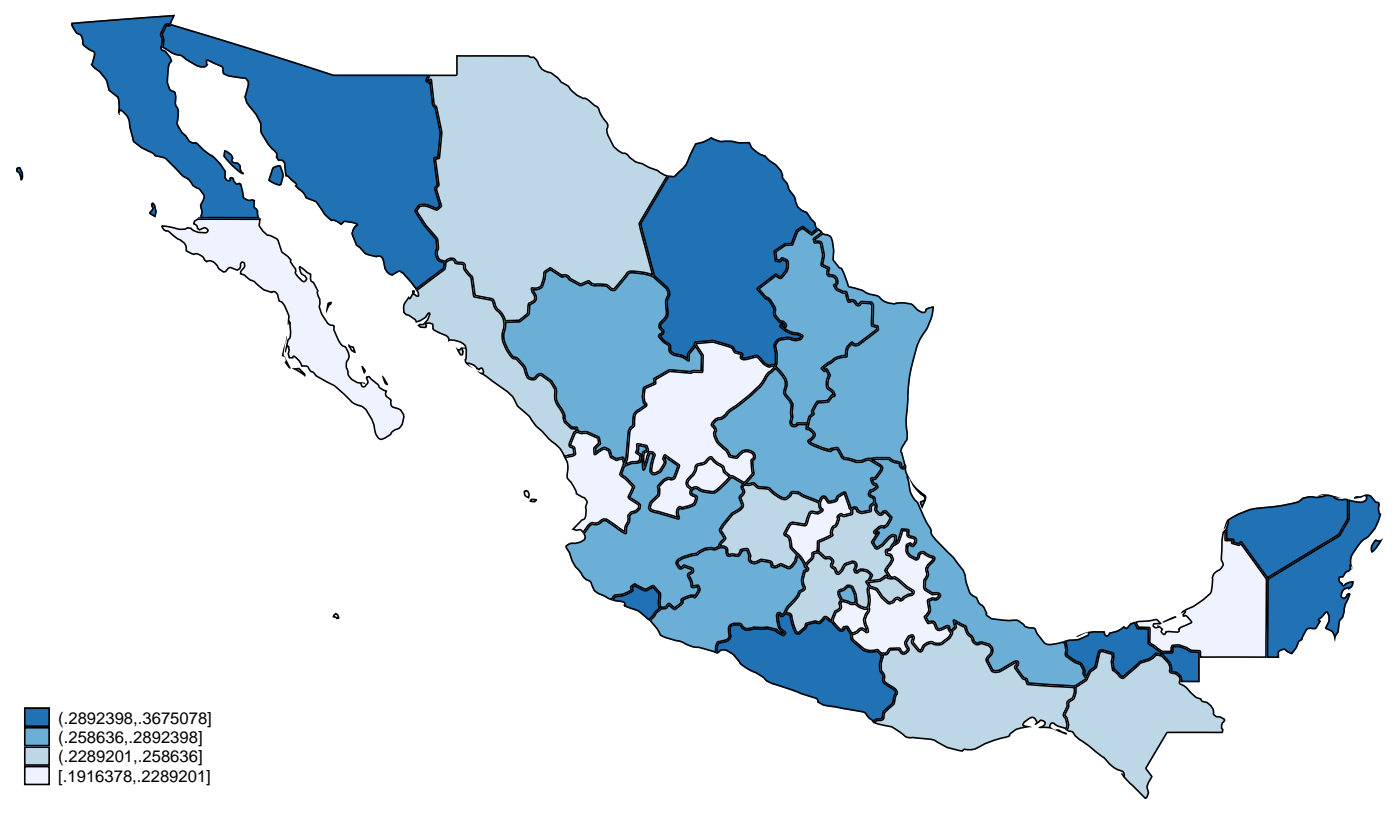

At the same time, trade flows between Mexico and the U.S. have been rising steadily, following economic liberalisation policies adopted by the Mexican government and the formation of NAFTA in 1994. This trend is particularly visible in the F\&B sector. Figure 2 shows that the U.S. are by far Mexico's largest source of imports of F\&B, whereas their importance in Mexican imports of other manufacturing goods has declined during the 2000s mainly because of heightened competition from emerging economies like China (Mendez, 2015). Figure 2 also portrays how the share of imports from the U.S. in total Mexican household expenditure in F\&B ('import penetration') tripled between 1989 and 2012, going from 2.5 to 8 percent. $^{24}$ In comparison, food imports from other countries (ROW) have played a smaller role in Mexican food consumption over the same period - their share in total food expenditure went from 1.9 to 3 percent.

\footnotetext{
${ }^{24}$ These shares are lower if we consider only imports classified for final consumption (see section 4 ). Under this alternative definition, import penetration in household food expenditure went from 2 to 5.5 percent between 1989 and 2012. In the graph, import penetration is computed taking only imports and total expenditures on the 152 foods that have been successfully matched in the trade data and expenditure survey - the same set of products used in the regressions. Adopting the full set of SITC food products and the total household food expenditures computed from ENIGH, import penetration goes from 6 to 12 percent between 1989 and 2012.
} 
Figure 2: U.S. share of Mexican imports and U.S. import penetration in Mexican food expenditure

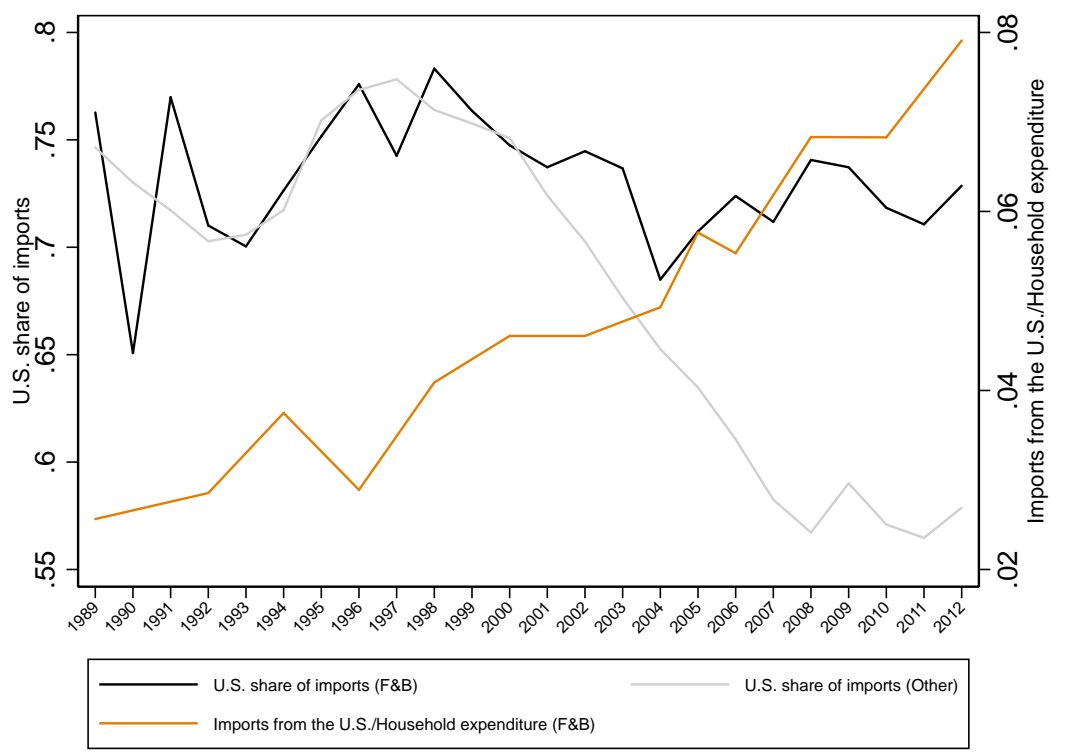

Note: Mexican food imports are those under the one-digit categories 0 and 4, and the two-digit categories 11 and 22 of the SITC Revision 3 classification. Import values in current US $\$$ are converted in Mexican consumer prices using the annual PPP conversion factor for private consumption. Mexican household food expenditures are imputed from the ENIGH surveys using the households' sampling weights.

Our empirical strategy allocates U.S. food exports to Mexican states using expenditure shares by food product in the initial period. The map in Figure A1 in the Appendix illustrates the geography of changes in imputed food imports between 1989 and 2012, normalized by state's food expenditure in 1989 - the variable $\Delta U$ Simp in (2) for the long-difference specification. While exposure to U.S. foods increased everywhere, states were exposed differentially so. The increase in imputed imports was 2.8 times higher than total food expenditure in 1989 in the state of Tabasco (the largest relative increase), while the state of Durango reported the smallest relative increase in imports of U.S. foods ( $92 \%$ of the initial level of food expenditure). States on the Gulf of Mexico experienced higher increases in the penetration of U.S. foods than other states, while states on the U.S. border, whose labour markets and production structure have been affected the most by greater market access to the U.S. (i.e., via exports - see Hanson (2003); and Chiquiar et al. (2017)), have received relatively modest inflows of U.S. foods. ${ }^{25}$

The evolution of aggregate U.S. food exports to Mexico can mask important variation across different types of products. In Figure 3, we plot U.S. food exports by main F\&B categories over time relative to their values in 1989 (in current US\$). ${ }^{26}$ Products

\footnotetext{
${ }^{25}$ Table A3 dissects this variation further and tabulates values for each state and time period used in the regression analysis.

${ }^{26}$ The absolute increase of U.S. food exports to Mexico is much larger when flows are converted into local
} 
that are generally associated with an unhealthy and obese-prone diet have been driving the overall increase in Mexican food imports from the U.S. More specifically, imports of "Food preparations" (including preparations of fats, sauces, soups, and homogenised foods) exhibited the highest relative increase among all food categories, going from 35.5 to 859 millions US\$. "Drinks" and "sugars" also displayed large rates of change, recording fifteen-fold and fourteen-fold increases, respectively. While purely illustrative, these patterns suggest that the surge of Mexican imports from the U.S. was concentrated in generally 'bad' foods, which might have accelerated the spread of the obesity epidemic.

Figure 3: Mexican imports of F\&B from the U.S. over time

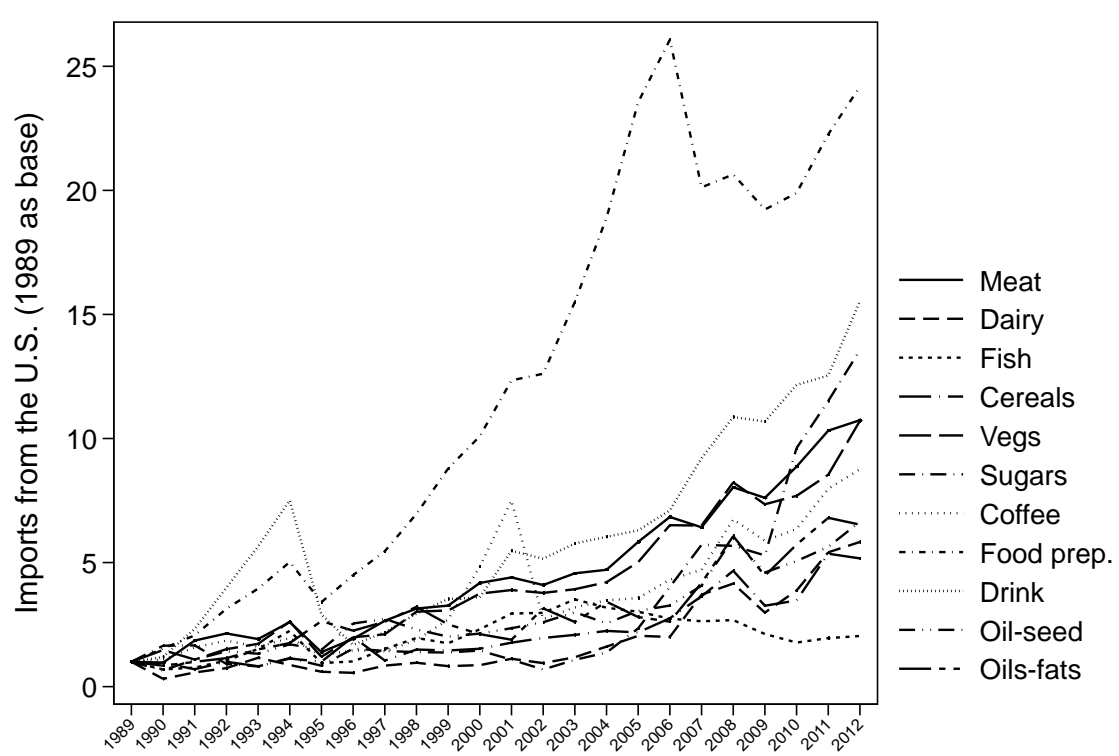

Note: U.S. exports in current US\$. Food categories are defined following the SITC Rev. 3 product classification: 'Meat' is category "01 - Meat and meat preparations"; 'Dairy' is category "02 - Dairy products and birds' eggs"; 'Fish' is category "03 - Fish (not marine mammals), crustaceans, molluscs and aquatic invertebrates, and preparations thereof"; "Cereals' is category "04 - Cereals and cereal preparations"; 'Vegs' is category "05 - Vegetables and fruit"; 'Sugars' is category "06 - Sugars, sugar preparations and honey"; 'Coffee' is category "07 - Coffee, tea, cocoa, spices, and manufactures thereof"; 'Food prep.' is category "09 - Miscellaneous edible products and preparations"; 'Drink' is category " 11 - Beverages"; 'Oil-seed' is category " 22 - Oil-seeds and oleaginous fruits"; and 'Oils-fats' is category " 4 - Animal and vegetable oils, fats and waxes".

This bias towards unhealthy American foods is even clearer after we classify the SITC products according to the 'healthy' and 'unhealthy' categories of the USDA. As shown in panel (a) of Figure 4, the latter increased faster than the former, especially starting from

Mexican consumer prices through a PPP adjustment, as the Mexican Peso underwent large devaluations during our sample period. The seven-fold increase in U.S. food exports to Mexico between 1988 and 2012 as measured in US\$ translates into a forty-two-fold increase in PPP-adjusted flows.

${ }^{27}$ Within the corresponding chapter "09 - Miscellaneous edible products and preparations", the product category "09893 - Food preparations for infant use" recorded the largest increase in imports relative to the base level in 1989 (a ninety-three-fold increase). "09899 - Miscellaneous food preparations" experienced the second largest relative increase (and the largest absolute one), followed by "09843 - Mustard preparations". 
the mid-1990's. ${ }^{28}$ Trends are similar when we use a more conservative classification that restricts the healthy category to vegetables, fruits, fish and poultry (see panel (b)).

Figure 4: Unhealthy and healthy Mexican F\&B imports from the U.S.

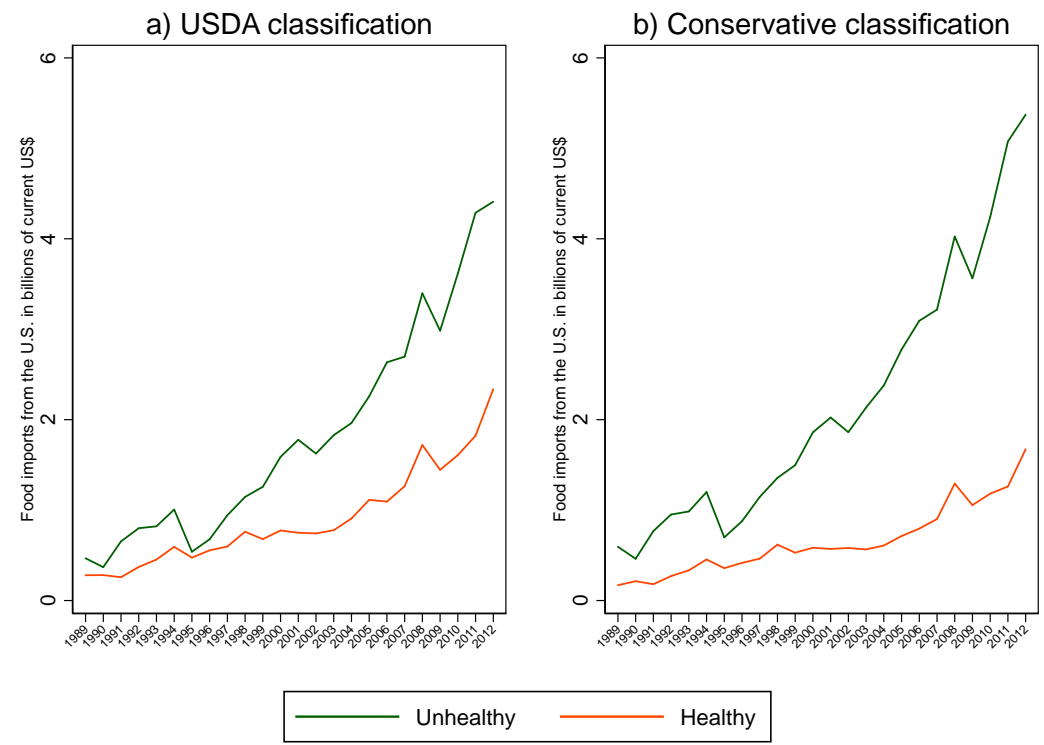

Note: The "conservative" classification considers only vegetables, fruits, fish and poultry.

\subsection{Effects of food imports on obesity}

Our benchmark specification allows us to assess the effect of changes in exposure to food imports from the U.S. - computed using pre-determined expenditure shares at the product level - on changes in obesity prevalence of adult women at the state level. We first show results using long differences (2012-1988), and then exploit all four survey rounds in the form of stacked first differences. The results from these baseline specifications are submitted to a number of checks - falsification tests, alternative measures of trade exposure, changes in the local retail environment, and other anthropometric outcome variables.

(a) Baseline results

We document a positive relationship between long-run changes in exposure to foods coming from the U.S. and changes in obesity between 2012 and 1988. Figure 5 shows the

\footnotetext{
${ }^{28}$ Opposite trends are observed for foreign non-American foods. The value of unhealthy foods from ROW increased only from 0.5 to 1.2 billions US $\$$, while healthy imports from the same countries rose from 0.07 to 1.1 billions US\$. Overall, total Mexican food imports have become increasingly unhealthy - 5.6 billions US\$ on unhealthy foods, compared to 3.4 billions US\$ on healthy foods.
} 
univariate relationship between the two changes (Panel (a)), which is robust to the inclusion of the full set of control variables (Panel (b)).

Figure 5: Long differences in obesity prevalence and trade in food imports from the U.S.

Panel (a): 2012 - 1988 changes, unconditional

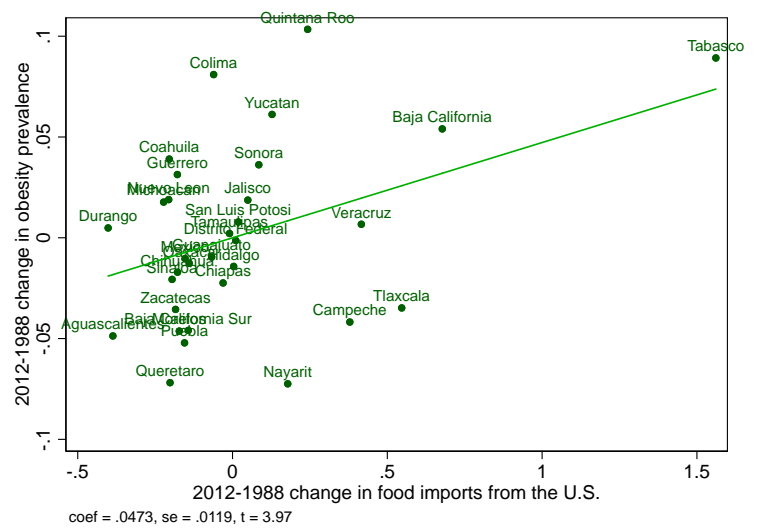

Panel (b): 2012 - 1988 changes, with covariates

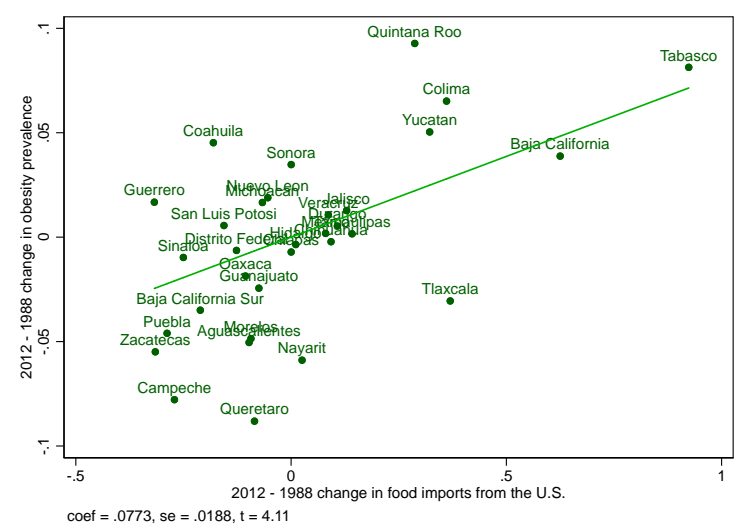

Note: Variables on the vertical and horizontal axis are 'partialled out' of the constant term and controls. Panel (a) is from estimates in Table 1, column (1), Panel (a). Panel (b) is from estimates from Table 1, column (4), Panel (a).

The corresponding OLS estimates are displayed fully in Table 1, Panel (a). The coefficient on changes in exposure to U.S. foods increases as we add controls from column (1) to (4). The unconditional point estimate of 0.0473 in Column (1) implies that a one standard deviation increase in trade exposure (0.30, see Table A2 for summary statistics on our main variables) is associated with a 1.4\%-points increase in the change in obesity prevalence (as reported in the bottom part of the panel). This amounts to $5.4 \%$ of the mean change in obesity. Adding lagged obesity, concurrent changes in food imports from other countries and other covariates in column (4) raises the effect of a one-standard-deviation increase in penetration of U.S. foods to a 2.3\%-points increase in the change of obesity (or about one tenth of its mean change).

A positive association between obesity prevalence and exposure to U.S. foods can be driven by Mexican demand-side determinants that co-shape changes in obesity. Using expenditure shares at the beginning of the period to allocate changes in national food imports can alleviate this threat, but proper identification of causal effects requires isolating U.S. food exports due to supply-side factors. To this end, we instrument Mexico's imports from the U.S. with U.S. exports to other countries, controlling for lagged obesity, concurrent changes in food imports from other countries, and changes in other covariates. Figure 6 depicts this strategy. Panel (a) reveals that U.S. exports to other countries are a strong predictor of U.S. food exports to Mexico. Panel (b) of the same figure displays the reduced form relationship, displaying a significant and positive link between changes in U.S. food exports and changes 
in obesity in Mexico. Columns (5) and (6) of Table 1 present the corresponding IV regression estimates - with and without controlling for changes in imputed imports from ROW. The IV coefficients are similar to their OLS counterparts and remain statistically significant. The causal estimates imply that if a state experienced a 0.3 higher change in penetration of U.S. foods, obesity prevalence among adult women would have risen by an additional 2.4\%-points.

Identification can however remain problematic because variation in U.S. food exports to other countries may be correlated with time-varying food preferences in these destinations - which could be similar to the ones observed in Mexico. To alleviate such concerns, we take the difference in residuals from gravity regressions of U.S. and Mexican food exports on product and destination fixed effects, and substitute this for actual changes in Mexico's imports from the U.S. $\left(\Delta M_{s, t}^{U S}\right.$ in equation (2)). The differencing nets out time-varying demand components in destination countries. The variation in the residuals should thus be only due to changes in comparative advantage and market access for U.S. products relative to Mexican ones (see Appendix B of Autor et al. (2013) for further discussions). Columns (7) and (8) of Table 1 show that the point estimate associated with changes in food imports from the U.S. stays positive and statistically significant. Note that the coefficient associated with the gravity residual is not directly comparable with and as easily interpreted as the IV and OLS coefficients. Yet, applying the point estimate in column (8) to a one standard deviation increase in the (normalized) changes in gravity residuals leads to a $2.1 \%$-points increase in obesity changes, which is very similar to the magnitudes associated with the OLS and IV estimates.

Figure 6: Instrumental Variable strategy

Panel (a): 1st stage 2012 - 1988 changes, with

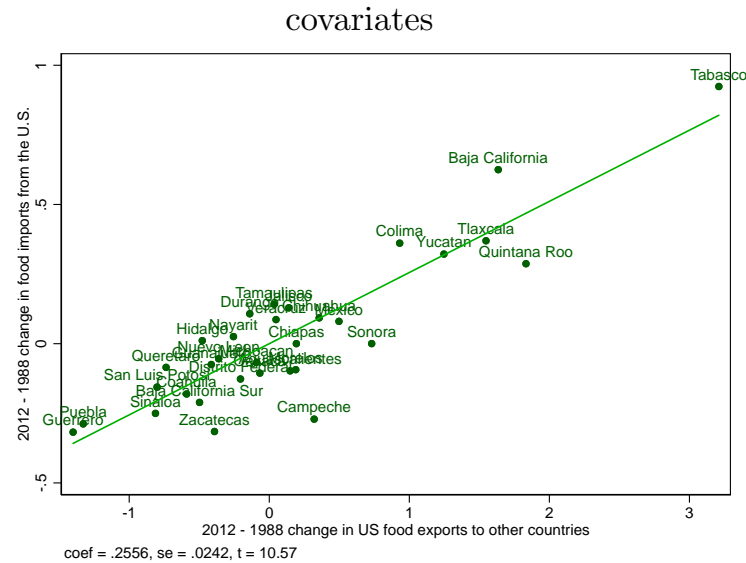

Panel (b): Reduced form 2012 - 1988 changes,

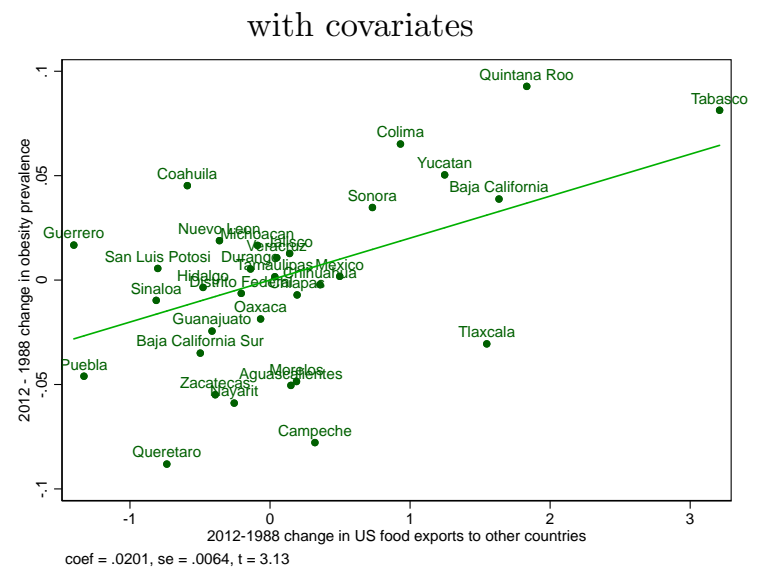

Note: Variables on the vertical and horizontal axis are 'partialled out' of the constant term and controls. Panel (a) is from estimates in Table 1, column (6), Panel (a). 
Qualitatively similar patterns emerge when we exploit all four survey rounds and estimate the specification in equation (1) with stacked first differences (2012 - 2006, 2006 - 1999, 1999 - 1988). To make the periods comparable, changes in obesity prevalence and foods imports are annualized over a six-year period. Compared to the long-difference specification, pooling first differences enlarges our sample and attenuates the influence of single observations. A limitation of this specification is that obesity data are missing for five states in the health survey of 1999 (see section 3 and footnote 13). We assign the linearly interpolated obesity prevalence by state to fill these gaps. As this adds noise to our outcome variable, in specifications with controls, we include a dummy variable for those five states.

Figure 7 displays the main obesity-U.S. imports relationship with stacked first differences in the top row. The pooled plots point to a robust, positive link with and without covariates. In Figure 8, we investigate the stability of findings in the three sub-periods. We find sizeable but statistically weaker unconditional correlations between variations in obesity prevalence and changes in normalized U.S. imports in 1999 and 2006 (Panels (a) and (c)), which however gain in strength once other state-level characteristics are controlled for (Panels (b) and (d)). Among the control variables, accounting for lagged obesity trends disciplines the correlation between obesity trends and changes in exposure to U.S. foods. All conditional plots show a strong, positive correlation of similar size. 
Figure 7: Pooled first differences in obesity prevalence and food imports from the U.S. OLS and IV strategy

Panel (a): Unconditional

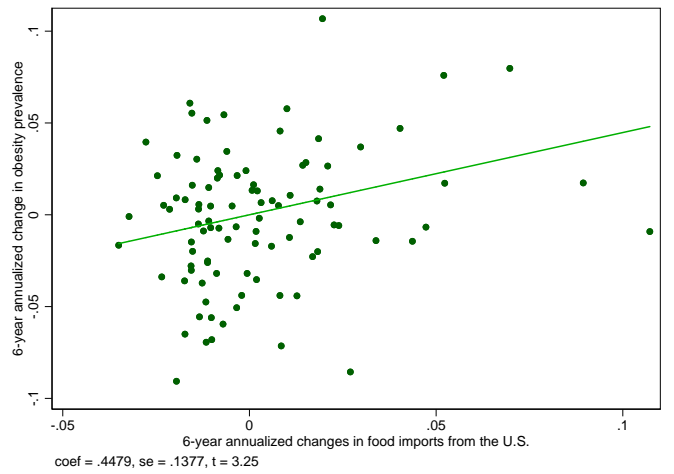

Panel (c): 1st stage, with covariates

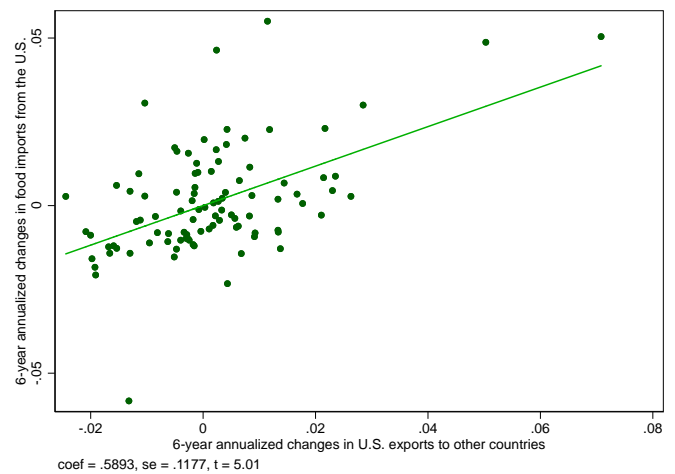

Panel (b): With covariates

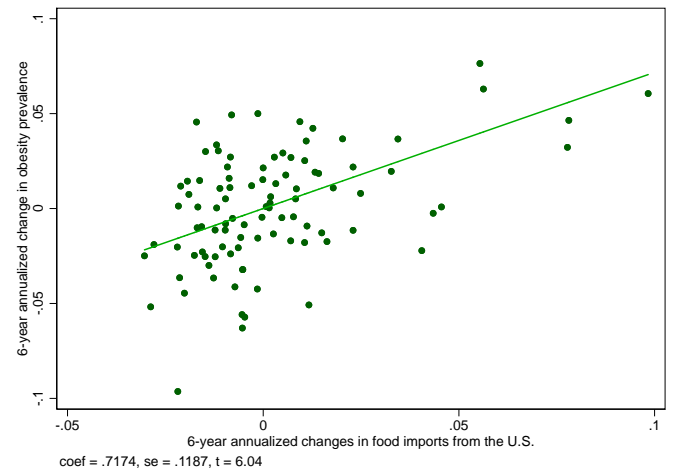

Panel (d): Reduced form, with covariates

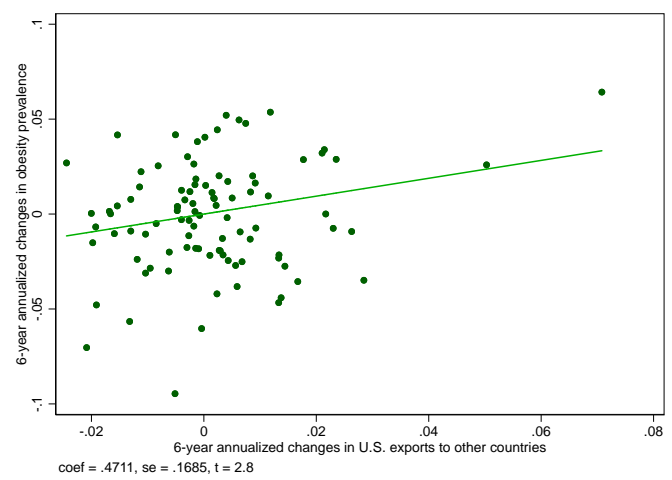

Note: Variables on the vertical and horizontal axis are 'partialled out' of the constant term, year dummies, and controls (except Panel (a)). The set of covariates is as in column (4) of Table 1. The state share of national female population between 18 and 59 years of age in 1990 is used as weight. 
Figure 8: First differences in obesity prevalence and food imports from the U.S. (2012 2006, 2006 - 1999, 1999 - 1988)

Panel (a): 1999 - 1988, unconditional

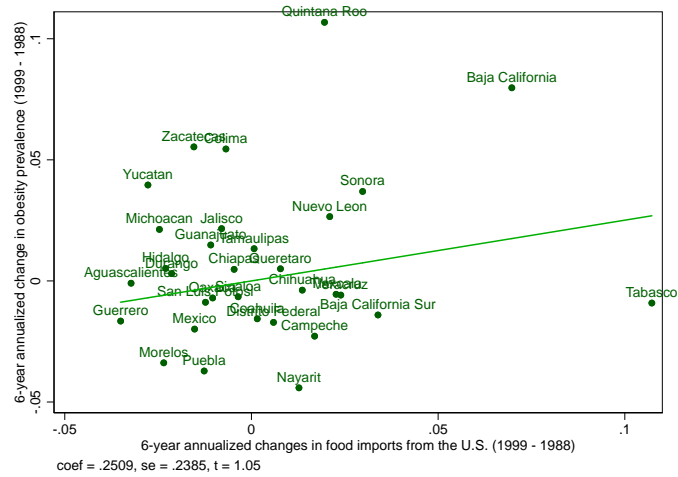

Panel (c): 2006 - 1999, unconditional

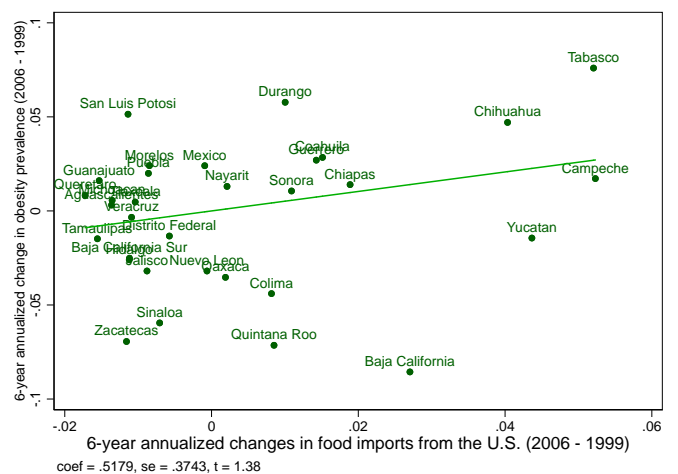

Panel (e): 2012 - 2006, unconditional

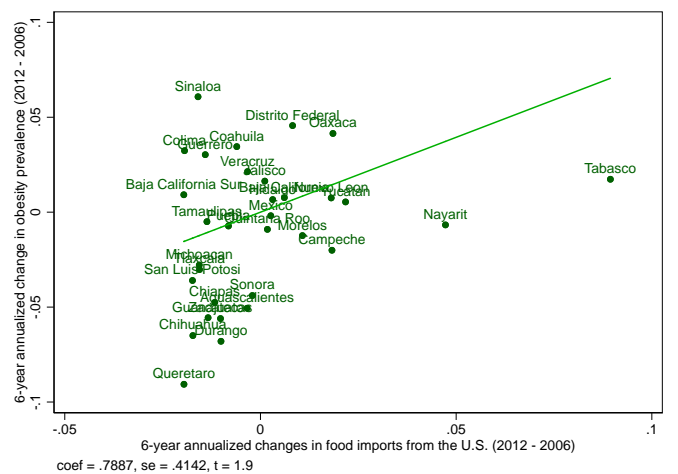

Panel (b): 1999 - 1988, with covariates

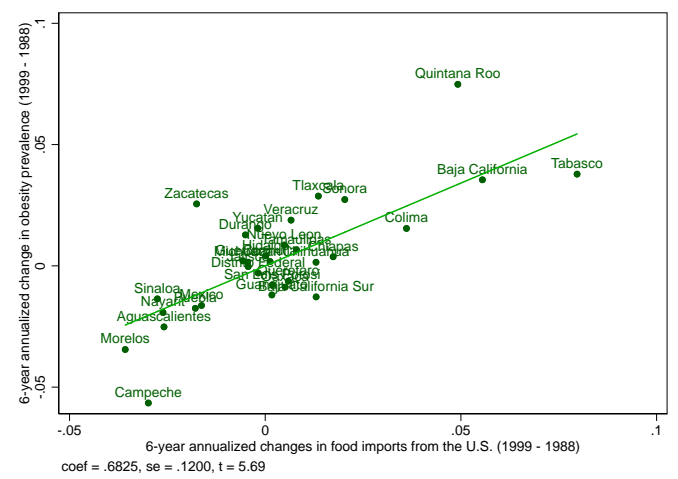

Panel (d): 2006 - 1999, with covariates

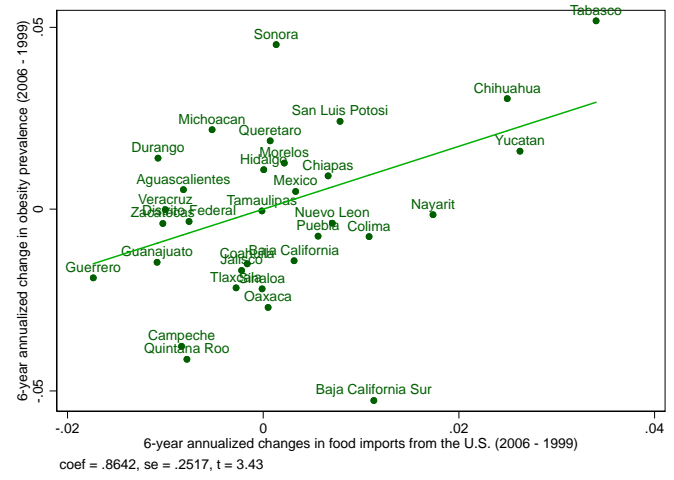

Panel (f): 2012 - 2006, with covariates

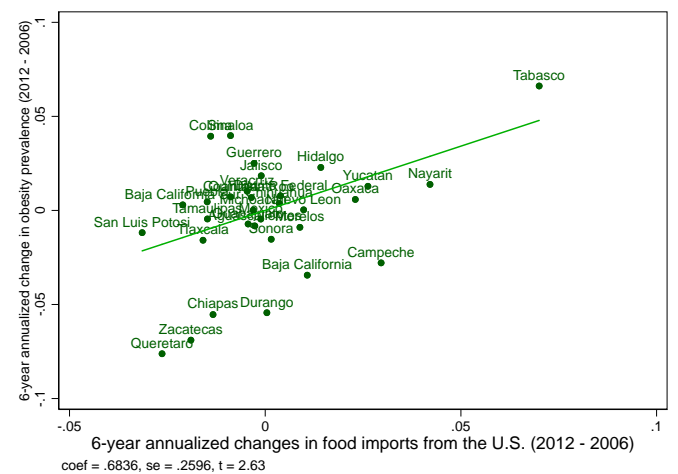

Note: Variables on the vertical and horizontal axis are 'partialled out' of the constant term (Panels (a), (c), (e)), and controls (Panels (b), (d), (f)). The set of covariates is as in column (4) of Table 1. The state share of national female population between 18 and 59 years of age in 1990 is used as weight.

Panel (b) of Table 1 reports the estimates of the stacked differences model. The point estimate in column (1) controls only for period dummies. Its value of 0.448 implies that a one standard deviation (0.038) increase in U.S. food penetration correlates with a non-negligible $1.72 \%$-points increase in obesity changes. As for the long-difference model, the point estimate of interest increases with the inclusion of covariates. In particular, the negative coefficient 
on the lagged obesity difference points to convergence in obesity rates across states (column (2)). And the inclusion of the obesity pre-trend as well as additional covariates (columns (3) and (4)) almost doubles the effect.

The final four columns based on IV and gravity residuals, in line with the long difference findings, point to an important causal effect of trade on obesity trends across Mexican states. The first-stage relationship between U.S. food exports to other countries and U.S. food exports to Mexico remains strong in first differences, as shown in Figure 7, panel (c). The IV estimate from column (6) means that a one standard-deviation increase in trade adds 2.7\%-points to the change in obesity prevalence among adult women. The pro-obesity effect of exposure to U.S. food supply also emerges in the reduced form-plot shown in Figure 7, panel (d). The coefficient on the $\Delta U$ Simp variable is qualitatively lower in the IV than in the OLS specifications, which could be interpreted as demand-side factors inflating the association of interest.

In sum, results based on first differences are similar to the ones using long-run differences in Panel (a). Among the estimates on the other covariates, the negative coefficient associated with the $\triangle R O W i m p$ variable entails that food imports from other countries are associated with a lower rise in obesity prevalence among adult women. When excluding this variable, the causal impact of exposure to U.S. food imports on obesity is indeed lower, implying that some of the variation in our variable of interest, $\Delta U$ Simp, may be picking up exposure to the relatively healthy foods coming from other countries (see footnote 28). The lack of a viable empirical strategy to identify the causal effect of Mexico's food imports from the rest of the world hinders the interpretation of the total (U.S. plus ROW) impact of food imports on obesity prevalence in Mexico. With these caveats in mind, estimates from Table 1 indicate that the robust pro-obesity effect of food imports from the U.S. quantitatively dominates that linked to ROW. According to the estimates of the IV model in column (6), a one-standard-deviation higher exposure to ROW foods between 1988 and 2012 (equal to 0.08 - see Table A2 in the Appendix) is associated with 1.4\%-points reduction in obesity changes over the same period, which remains significantly lower in absolute value than the $2.4 \%$-points increase in obesity changes led by greater penetration of U.S. foods. In the pooled first difference model, the negative association between obesity prevalence and imports from ROW could potentially 'erase' $1.4 \%$-points of the $2.7 \%$-points increase in obesity changes due to exposure to U.S. foods. Overall, exposure to foreign foods has accentuated the rise in obesity, an effect stemming from the dominating role of American foods.

The estimated coefficients on the other state-level covariates do not reveal any systematic patterns. States that devoted a larger share of household expenditure on foods tend to grow 
more obese in stacked but not significantly so in long-differences. Income per capita, exposure to FDI, and the unemployment rate among the surveyed women within the state have no discernible effect on obesity rates. Table 1 further reveals a negative link between obesity changes and changes in the importance of return migration from the U.S., which is however imprecisely estimated in long differences. Similarly, states where women became relatively more educated experience lower increases in obesity rates as per our pooled first-difference model. Importantly, the pro-obesity impact of penetration of U.S. foods is robust to the inclusion of these controls. ${ }^{29}$

\footnotetext{
29 Findings are confirmed when we consider changes in obesity prevalence among men (available only between 2006 and 2012) of the same age as women in the baseline analysis (20-49 years old). The coefficient on the 2012 - $2006 \Delta U$ Simp variable equals 0.61 in an univariate regression (std. error $=0.34$; compared to the 0.79 coefficient estimated for the same period on adult women - see panel (e) of Figure 8); and goes up to 0.86 ( std. error $=0.36$ ) with controls (compared to 0.68 obtained on adult women - see panel (f) of Figure 8). We also find similar pro-obesity effects of exposure to U.S. foods when we expand the demographic group to women and men up to 60 years old - a change that affects only obesity prevalence in 2006 and 2012 . In this case, the OLS long-difference coefficient on $\Delta U$ Simp equals 0.068 (std. error=0.014), and the pooled first-difference one equals 0.625 (std. error $=0.09$ ) - both are close to their counterparts in column (4), Table
} 1 . 
Table 1: Obesity prevalence and food imports from the U.S.

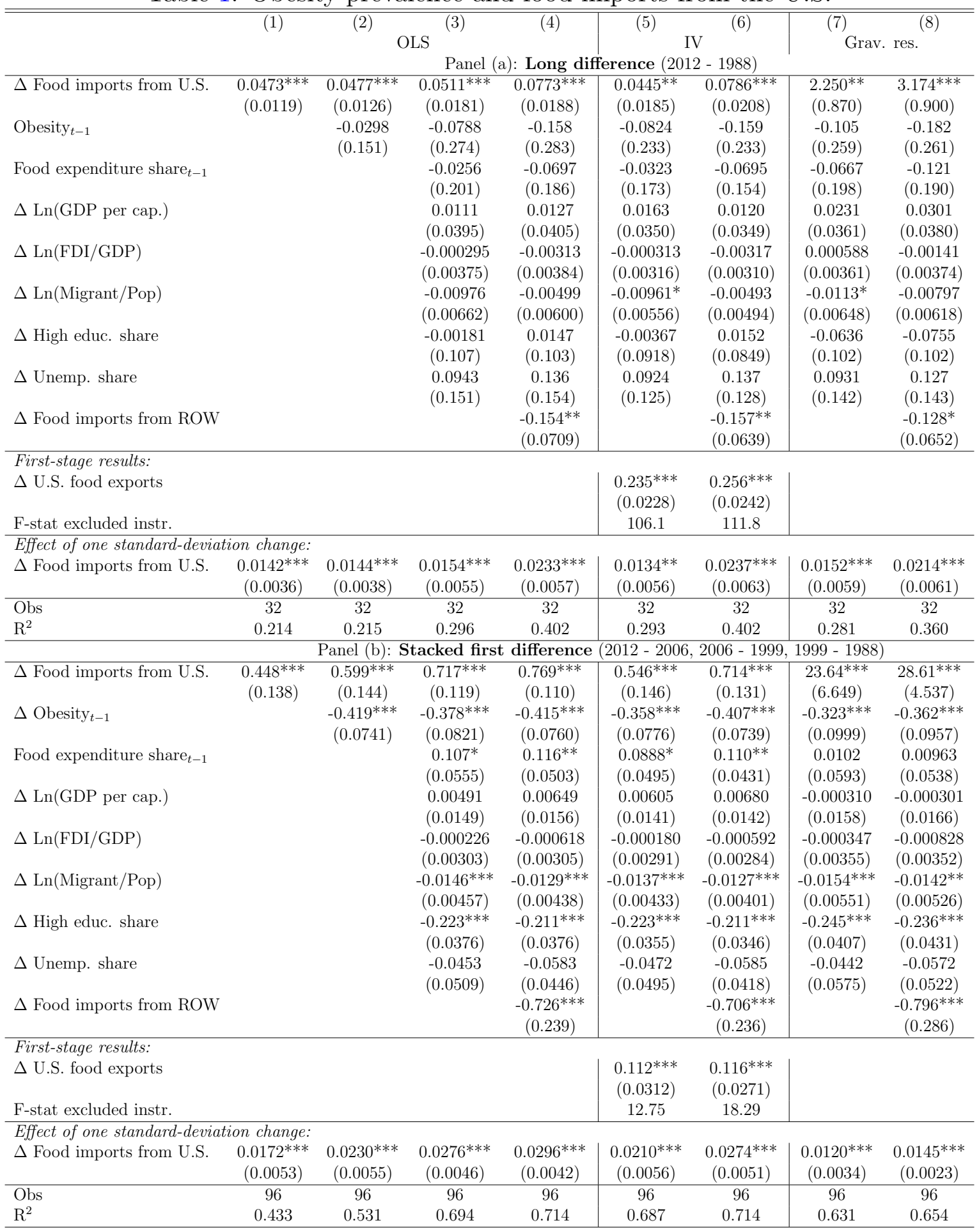

Note: All regressions include a constant term. Regressions in Panel (b) include year dummies (for 2006 and 2012) and a dummy for states with imputed obesity prevalence in 1999. The state share of national female population between 18 and 59 years of age in 1990 is used as weight. Robust standard errors clustered at the state level are in parentheses. Significant at: *10\%, $* * 5 \%, * * * 1 \%$ level. 
(b) Benchmarking the impact of U.S. food exports on obesity in Mexico

The causal effect of food imports from the U.S. can be assessed against the average observed increase of 26 percentage points in obesity prevalence across states between 1988 and 2012 (see Table A2). The positive and significant IV coefficients from the long-difference and pooled first-difference specifications in column (5) of Table 1 imply that a one-standard-deviation higher penetration of U.S. food imports in local food markets could account for as much as 7 percent ( 5 percent using long-difference estimates) of the rise in obesity observed during our sample period. Controlling for imports from ROW raises the quantitative importance of this impact to around one tenth of the average change in obesity prevalence. These magnitudes are comparable to the obesity effects found in other studies examining the role of changes in the food environment. Courtemanche and Carden (2011), for instance, find that the local penetration of Walmart Supercenters is responsible for 10.5 percent of the rise in obesity rates in the U.S. since the late 1980s.

Another way to interpret the estimated effects is to construct counterfactual changes in nation-wide obesity prevalence among adult women that would have occurred in the absence of increased penetration of U.S. food imports. To this end, we use the IV estimates from Table 1 to generate the changes in obesity rates mandated by the observed variation in instrumented food imports for each state. Autor et al. (2013) and Acemoglu et al. (2016) apply a similar procedure to back out the aggregate employment effect of U.S. manufacturing imports from China. Similar to their empirical framework, the effect of the total variation in normalised U.S. food imports can overstate the causal impact of U.S. food supply shocks, if the endogenous demand component of import exposure correlates with obesity prevalence. To isolate the supply-driven variation in our $\Delta U$ Simp variable, we adopt the method of Autor et al. (2013) and Acemoglu et al. (2016), which amounts to multiplying the observed $\Delta U \operatorname{Simp}_{s, t}$ values by the partial $\mathrm{R}^{2}$ from the first-stage regression.

While informative about the size of the estimated effects, this counterfactual exercise relies on a number of important assumptions. It applies estimates obtained from relative changes in obesity prevalence across Mexican states to quantify effects on national obesity rates. This would, for instance, under-estimate the aggregate effects if higher exposure of one state raises obesity (e.g., through greater food consumption) also in a neighbouring state that was less exposed. Moreover, our exercise implicitly assumes that all other covariates and the error term in equation (1) are unaffected by the exogenous changes in U.S. food exports to Mexico. Because of the restrictiveness of these assumptions, we view these simulations as purely suggestive of economic magnitudes. 
Using the more conservative estimates from column (5) of Table 1, Panel (a) (i.e., without controlling for ROW imports), the changes in obesity prevalence implied by greater penetration of U.S. foods $\left(\Delta \widehat{\text { Obesity }}_{s, 2012-1988} \equiv 0.87 \times \widehat{\beta}_{1} \Delta U\right.$ Simp $_{s, 2012-1988}$; with $\widehat{\beta}_{1}=0.045$, first-stage partial $\mathrm{R}^{2}=0.87$ ) are multiplied by the number of women between 18 and 59 years of age (the closest demographic group to the 20-49 age range used in the estimations) at the beginning of the period for each state. Summing these numbers across states, we impute that 1.03 million women became obese as a result of changes in food imports from the U.S. relative to the state's food expenditure between 1988 and 2012. To put these numbers into perspective, we divide them by the observed increases in the number of Mexican obese women. Changes in U.S. food penetration in Mexican markets can account for as much as 10.7 percent of the observed rise in obesity prevalence among Mexican women between 1988 and 2012. Employing the larger IV coefficient from column (6) raises the role of increasing penetration of U.S. foods to 18 percent of the observed rise in the number of obese women between 1988 and 2012 - to put it differently, 1.7 million cases of obese women would have been averted with no further increases in food exports from the U.S. between 1988 and 2012.

These numbers are slightly higher when we consider the total variation in food imports from the U.S. (i.e., including part of the variation that is possibly endogenous to obesity). This amounts to multiplying the estimated IV coefficient by the observed changes in the on the $\Delta U$ Simp variable, without applying the partial $\mathrm{R}^{2}$ from the first stage. With this alternative approach, the simulated increase in the number of obese women due solely to changes in food imports amounts to 12.3 percent (or 21.6 percent when using estimates from column (6)) of the overall change in obese cases. Overall, the results from this exercise indicate that the statistically significant impact of food imports from the U.S. on obesity prevalence in Mexico is quantitatively important and similar in size to the effects of other determinants found in the literature.

(c) Robustness checks and extensions

This section investigates the robustness of our results to lead tests, to the exclusion of single states, to alternative definitions of trade exposure, to the role of the local food environment and to other anthropometric outcome variables. In extensions, we split U.S. food exports to Mexico into healthy and unhealthy in order to further assess the nutritional channel, and finally test for heterogeneous effects by socioeconomic status. 
Placebo tests using future changes. To support the causal interpretation of our results, we run falsification tests where current changes in obesity prevalence are regressed on future changes in food imports from the U.S.. Results are reported in Table 2. Leads in the $\Delta U$ Simp variable are neither significantly nor systematically linked to current changes in obesity. In columns (1) and (2), the marginal effects of changes in U.S. food imports between 2017 and 2012 on variations in obesity prevalence between 2012 and 1988 are positive but highly insignificant. When we enter non-overlapping leads in the first difference models (columns (3) and (4)), the coefficient turns negative but remains insignificant, suggesting that, if anything, states that have higher future increases in penetration of U.S. foods experience lower rises in obesity prevalence. Stacked differences with and without controls yield mixed and insignificant point estimates (columns (3) and (4)). These patterns alleviate concerns that we may be picking up spurious correlations in food consumption and secular changes in body weight.

Table 2: Obesity prevalence and future changes in food imports from the U.S.

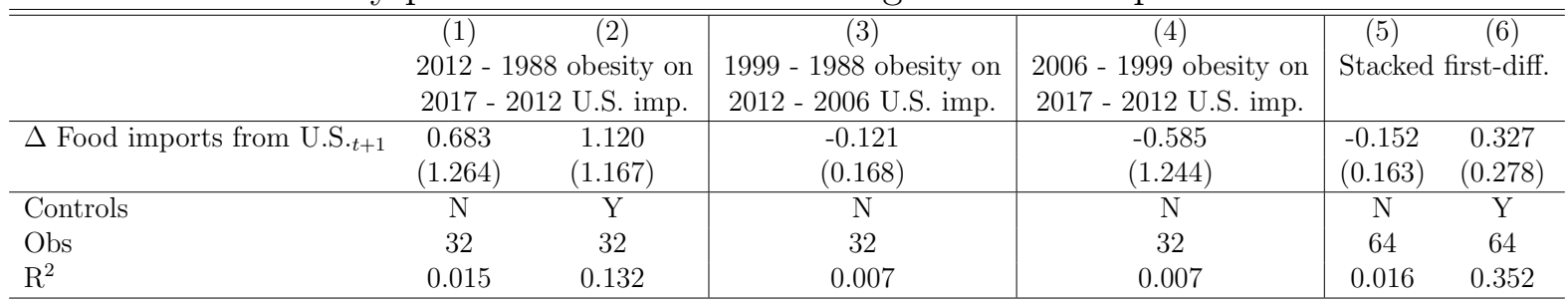

Note: All regressions include a constant term. See Table 1, column (4), for the list of controls. Columns (5) and (6) include a dummy for the 2006 period and a dummy for states with imputed obesity prevalence in 1999. The state share of national female population between 18 and 59 years of age in 1990 is used as weight. Robust standard errors clustered at the state level are in parentheses. Significant at: $* 10 \%, * * 5 \%, * * * 1 \%$ level.

Exclusion of single states. Given the small sample size, outliers may influence our key results. To counter this concern, we drop one state at a time in the estimation. Panels (a) and (b) in Figure A3 in the Appendix plot the OLS coefficient on the $\Delta U \operatorname{Simp}$ in the baseline long-difference and stacked-difference specifications (corresponding to column (4), Table 1). The limited sample size leads to some loss of precision especially in the long-difference model (e.g., when the state of Tabasco is dropped), but the coefficient is always significantly larger than zero and close in size to the one obtained in the full sample.

Alternative measures of trade exposure. Our baseline findings are equally robust to different definitions of the trade exposure variable. In columns (1) to (3) of Table 3, we single out U.S. food imports for final demand - and exclude imports for further industrial use that should not directly affect obesity. We use the Broad Economic Categories (BEC) classification for trade flows (matched with the more detailed SITC classification) to identify food products that 
are "mainly for household consumption" (BEC categories 112 and 122) and "other consumer goods" (BEC category 6). The matching between these BEC final demand categories and the SITC products is however not unique - some SITC products have multiple BEC categories -, we thus take this exercise as a robustness test of the baseline results obtained using all SITC food products. ${ }^{30}$ Using this revised food imports variable leaves us with qualitatively similar findings.

Another possible concern with the baseline specification (1) is that the effect of food imports might capture the influence of overall exposure to imports from the U.S.. To check for this, we regress obesity prevalence on apparel imports (applying equation (2) to data on apparel imports and expenditures). This important tradable product should have no direct influence on diet and nutrition. The estimated coefficients in columns (4) to (6) suggest that, if anything, exposure to American apparel is correlated with lower obesity rates, at least in long-run changes. Importantly, the coefficient on the $\Delta U$ Simp variable remains positive and significant when controlling for this variable.

Columns (7) to (9) assess the influence of exposure to Mexican food exports to the U.S. as dictated by pre-determined expenditure specialization. ${ }^{31}$ We replace the import flow variable $M$ in equation (2) with the value of Mexican exports to the U.S.. Mexican exports can correlate with Mexican imports from the U.S. in the presence of intra-product trade related, for instance, to export processing (maquiladora) food sector (Utar and Ruiz, 2013). Results however do not reveal any robust correlation between demand-based exposure to food exports and obesity prevalence, while exposure to food imports is consistently associated with higher obesity. ${ }^{32}$

\footnotetext{
${ }^{30}$ SITC products are classified for final demand if more than half of the entries fall into the BEC categories for final use.

${ }^{31}$ As further discussed in section 2, this exercise does not aim to assess the impact of market access on obesity, for instance through an income channel. Greater overall export opportunities (not necessarily confined to the food sector) should matter, and industry employment is the relevant link between changes in aggregate exports and local income (McCaig, 2011).

${ }^{32}$ Similar results are obtained if we use exposure to Mexican food exports to all countries rather than exports to the U.S. only.
} 
Table 3: Obesity prevalence and food imports from the U.S. - Alternative trade exposure

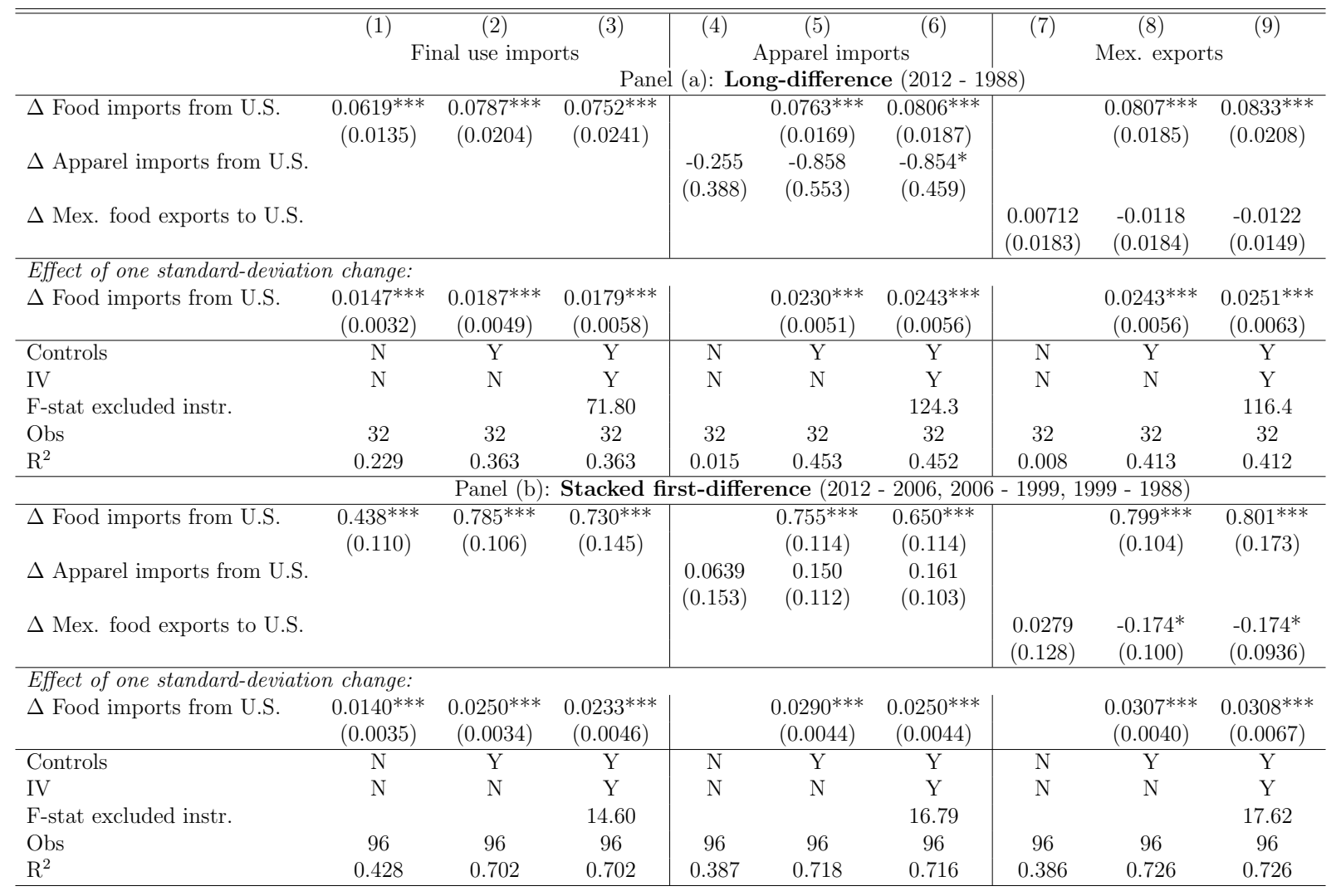

Note: All regressions include a constant term. In Panel (b), all regressions include year dummies for 2006 and 2012 . The state share of national female population between 18 and 59 years of age in 1990 is used as weight. Columns (1) to (3) use trade data only on food products classified for final consumption according to the BEC classification. Robust standard errors clustered at the state level are in parentheses. Significant at: *10\%, **5\%, ${ }^{*} * * 1 \%$ level.

Changes in the food environment and food purchases. Changes in the local food environment (other than in penetration of food imports from the U.S.) and in purchase habits can shape obesity trends and at the same time coincide with those in our import variable.

American FDI in the retail and food sector can confound the pro-obesity effect of food imports. While our baseline results are robust to controlling for changes in overall FDI, Walmart expanded throughout Mexico during our sample period and has become one of the biggest retailers in Latin America. This development can weaken the interpretation of our results, if Walmart expansion in Mexico is correlated with growing obesity (see Courtemanche and Carden (2011) for evidence on the pro-obesity effect of Walmart in the U.S.) and if states where Walmart expanded more aggressively also saw greater penetration of food imports from the U.S.. To check for this possibility, we exploit data on the number of Walmart stores by Mexican state as of 2007 from Iacovone et al. (2015). Since Walmart entered the Mexican market in the early 90's and spread mainly in the 2000's (Atkin et al., 2018), the stock of Walmart stores in 2007 (per thousands of people) equates to the change in Walmart 
presence since the beginning of our sample in 1988. Using the Walmart variable, we can provide two pieces of evidence. First, we find that it correlates negatively with 1988-2006 changes in obesity rates, indicating that, if at all, obesity prevalence has increased less rapidly in Mexican states that received more Walmart stores (see top row of Figure A4 in the Appendix). Morevoer, there is no clear relationship between the changes in $\Delta U$ Simp over the 2006 - 1988 period and Walmart penetration (see the bottom row of Figure A4). Second, in Table 4 and columns (1) to (4), we augment our regression model with the Walmart variable and the effect of U.S. food imports remains positive and significant. The coefficient on the Walmart variable is still negative but becomes weaker when considering changes in obesity rates over the long window $(2012$ - 1988). Taken together, these results suggest that Walmart penetration has no strong influence on the robust pro-obesity impact of food imports from the U.S..

That said, Walmart is not the only retailer active in the Mexican market and households more generally may buy American and other foreign foods in supermarkets and malls (rather than small markets and traditional stores, which are more likely to offer local foods), or consume them outside home (e.g., in fast food restaurants). The supermarket share in total food expenditure by state increased by a mere 3\%-points over the period 1988-2012. Meanwhile, the share of food expenditure that went to restaurants increased from about $13 \%$ in 1988 to $22 \%$ in 2012. In the remaining columns of Table 4, we thus control for these shares. In both long and stacked differences models, these proxies for changing purchasing habits are not significantly correlated with obesity (at least at this level of aggregation), and more crucially have no bearing on our coefficient of interest. ${ }^{33}$

\footnotetext{
${ }^{33}$ The aggregate measures might mask heterogeneous obesity effects depending on the type of food that is purchased in supermarkets or that is consumed away from home, which could shape obesity dynamics (see U.S.-based evidence in Todd et al. (2010)).
} 
Table 4: Obesity prevalence and food imports from the U.S. - controlling for Walmart and place of food purchase

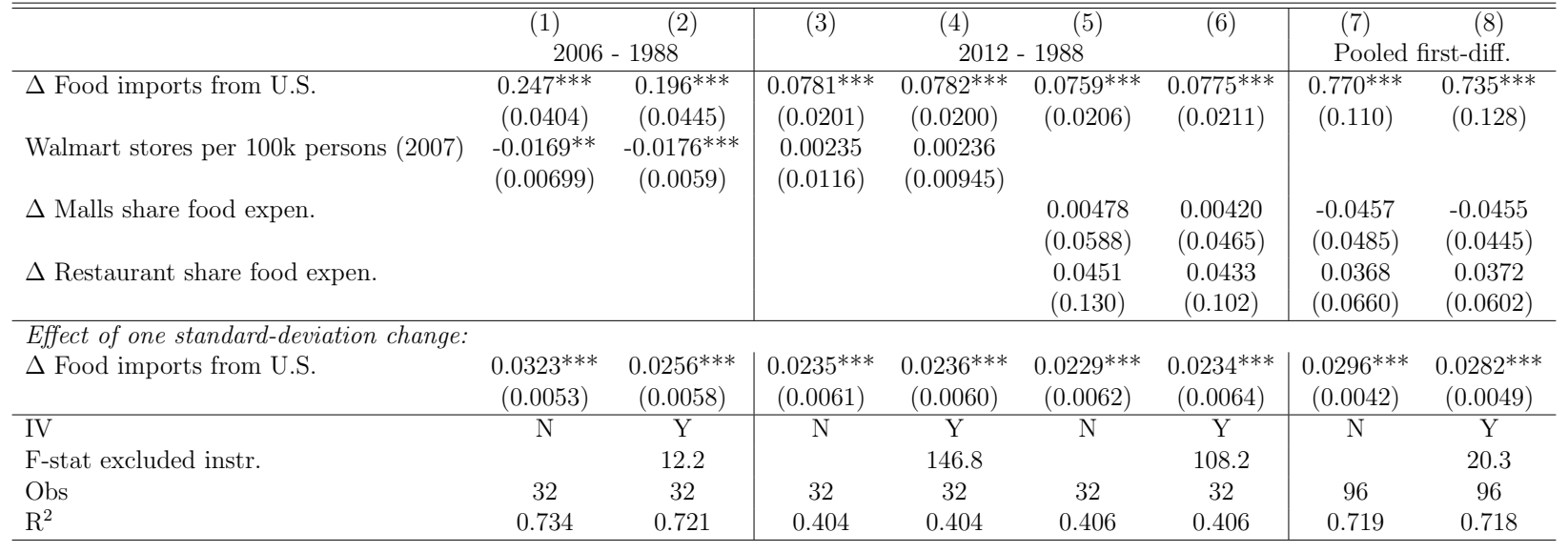

Note: All regressions include a constant term and state-level controls. Columns (7) and (8) include period dummies and a dummy for 5 states with missing and interpolated obesity rates in 1999. The state share of national female population between 18 and 59 years of age in 1990 is used as weight. Robust standard errors clustered at the state level are in parentheses. Significant at: $* 10 \%,{ }^{*} 5 \%, * * * 1 \%$ level.

Alternative measures of excess weight. As a further check on our baseline findings, we replace obesity with overweight prevalence (defined as a BMI greater or equal to 25) and additionally with the average BMI among surveyed women. Results for the long-difference and pooled first-difference models are reported in Table 5. States that are more exposed to U.S. food imports over time experience also stronger overweight rates and higher average BMI.

The positive and significant long-difference IV point estimate in column (3) implies that a one standard deviation higher penetration of U.S. foods leads to a $1.2 \%$-point increase in overweight changes, or 3 percent of the average increase in overweight prevalence observed between 1988 and 2012. In comparison, our baseline obesity effect (column (6), Table 1) is three times as large. The stacked first-difference estimate delivers a higher effect of exposure to American foods on overweight rates (6 percent of the average change in overweight), or about 80 percent of the equivalent effect on obesity prevalence.

The share of overweight women in our sample coincides with the share of women above the average level of BMI. Therefore, it is not surprising that the positive and statistically significant effect of U.S. food imports on average BMI (columns (4) to (6) of Table 5) is of similar size as the one on overweight rates. The causal estimates in column (6) indicate that a one standard deviation increase in normalized U.S. food imports raises average BMI by 0.29 points between 1988 and 2012 (or 6 percent of the average increase in BMI). Taken together, these anthropometric trends indicate that while imports of U.S. foods have shifted the entire BMI distribution, their effect is more pronounced in its right, obese tail. 
Table 5: Overweight prevalence, average BMI, and food imports from the U.S.

\begin{tabular}{|c|c|c|c|c|c|c|}
\hline & \multicolumn{2}{|r|}{ (2) } & & 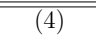 & \multicolumn{2}{|c|}{$(5) \quad(6)$} \\
\hline & \multicolumn{2}{|c|}{ Dep. var.: Overw. prevalence } & & \multicolumn{3}{|c|}{ Dep. var.: Average BMI } \\
\hline & \multicolumn{6}{|c|}{ Panel (a): Long difference $(2012-1988)$} \\
\hline$\Delta$ Food imports from U.S. & $\begin{array}{c}0.0269 \\
(0.0270)\end{array}$ & $\begin{array}{c}0.0377^{* *} \\
(0.0176)\end{array}$ & $\begin{array}{c}0.0382^{* *} \\
(0.0161)\end{array}$ & $\begin{array}{l}0.392^{*} \\
(0.204)\end{array}$ & $\begin{array}{c}1.055^{* * *} \\
(0.269)\end{array}$ & $\begin{array}{c}0.977^{* * *} \\
(0.260)\end{array}$ \\
\hline Overw $\cdot t-1$ & & $\begin{array}{c}-0.706^{* * *} \\
(0.0973)\end{array}$ & $\begin{array}{c}-0.706^{* * *} \\
(0.0798)\end{array}$ & & & \\
\hline $\mathrm{BMI}_{t-1}$ & & & & & $\begin{array}{c}-0.510^{* * *} \\
(0.119)\end{array}$ & $\begin{array}{c}-0.503^{* * *} \\
(0.0971)\end{array}$ \\
\hline \multicolumn{7}{|c|}{ Effect of one standard-deviation change: } \\
\hline$\Delta$ Food imports from U.S. & $\begin{array}{c}0.00811 \\
(0.0081)\end{array}$ & $\begin{array}{c}0.0114^{* *} \\
(0.0053)\end{array}$ & $\begin{array}{c}0.0115^{* *} \\
(0.0049)\end{array}$ & $\begin{array}{c}0.118^{*} \\
(0.0616)\end{array}$ & $\begin{array}{c}0.318^{* * *} * \\
(0.0811)\end{array}$ & $\begin{array}{c}0.294^{* * *} \\
(0.0784)\end{array}$ \\
\hline Controls & $\mathrm{N}$ & $\mathrm{Y}$ & $\mathrm{Y}$ & $\mathrm{N}$ & $\mathrm{Y}$ & $\mathrm{Y}$ \\
\hline IV & $\mathrm{N}$ & $\mathrm{N}$ & Y & $\mathrm{N}$ & $\mathrm{N}$ & Y \\
\hline F-stat excluded instr. & & & 97.94 & & & 105.64 \\
\hline Obs & 32 & 32 & 32 & 32 & 32 & 32 \\
\hline \multirow[t]{2}{*}{$\mathrm{R}^{2}$} & 0.017 & 0.899 & 0.899 & 0.042 & 0.718 & 0.710 \\
\hline & Panel (b & Stacked & irst differe & ice $(2012$ & 2006,2000 & $99,1999-1988)$ \\
\hline$\Delta$ Food imports from U.S. & $\begin{array}{l}0.243^{*} \\
(0.135)\end{array}$ & $\begin{array}{c}0.583^{* * *} \\
(0.178)\end{array}$ & $\begin{array}{c}0.592^{* * * *} \\
(0.192)\end{array}$ & $\begin{array}{c}4.485^{* * *} \\
(1.391)\end{array}$ & $\begin{array}{c}8.727^{* * *} \\
(1.666)\end{array}$ & $\begin{array}{c}7.369^{* * *} \\
(1.562)\end{array}$ \\
\hline$\Delta$ Overw.t-1 & & $\begin{array}{c}-0.277^{* * *} \\
(0.0831)\end{array}$ & $\begin{array}{c}-0.277^{* * * *} \\
(0.0780)\end{array}$ & & & \\
\hline$\Delta \mathrm{BMI}_{t-1}$ & & & & & $\begin{array}{c}-0.243^{* * *} \\
(0.0782)\end{array}$ & $\begin{array}{c}-0.234^{* * *} \\
(0.0769)\end{array}$ \\
\hline \multicolumn{7}{|c|}{ Effect of one standard-deviation change: } \\
\hline$\Delta$ Food imports from U.S. & $\begin{array}{c}0.0093^{*} \\
(0.0052)\end{array}$ & $\begin{array}{c}0.0224^{* * *} \\
(0.0068)\end{array}$ & $\begin{array}{c}0.0227^{* * *} \\
(0.0074)\end{array}$ & $\begin{array}{c}0.172^{* * *} \\
(0.0534)\end{array}$ & $\begin{array}{c}0.335^{* * *} \\
(0.0640)\end{array}$ & $\begin{array}{c}0.283^{* * *} \\
(0.0600)\end{array}$ \\
\hline Controls & $\mathrm{N}$ & $\mathrm{Y}$ & $\mathrm{Y}$ & $\mathrm{N}$ & $\mathrm{Y}$ & $\mathrm{Y}$ \\
\hline IV & $\mathrm{N}$ & $\mathrm{N}$ & Y & $\mathrm{N}$ & $\mathrm{N}$ & $\mathrm{Y}$ \\
\hline F-stat excluded instr. & & & 17.37 & & & 18.78 \\
\hline Obs & 96 & 96 & 96 & 96 & 96 & 96 \\
\hline $\mathrm{R}^{2}$ & 0.595 & 0.709 & 0.709 & 0.625 & 0.757 & 0.756 \\
\hline
\end{tabular}

Note: All regressions include a constant term. Stacked difference models include year dummies (for 2006 and 2012 ) and a dummy for states with imputed obesity prevalence in 1999. Full set of controls is as in baseline model (e.g., column (4) of Table 1), but without lagged obesity (trend). The state share of national female population between 18 and 59 years of age in 1990 is used as weight. Robust standard errors clustered at the state level are in parentheses. Significant at: ${ }^{*} 10 \%,{ }^{* *} 5 \%,{ }^{* * *} 1 \%$ level.

Unhealthy imports and obesity prevalence. U.S. food exports to Mexico have increasingly been specialised in unhealthy and possibly more obesity-prone foods (recall Figures 3 and 4). We now test whether the pro-obesity effect of increasing exposure to U.S. foods is driven by its unhealthy component. We distinguish between healthy and unhealthy foods by applying the USDA classification, and additionally, our more conservative classification that includes vegetables, fruits, fish and poultry in the 'vegs+', healthy category, and fats, drinks and foods rich in carbohydrates in the 'non-vegs', unhealthy category (see section 3 and Table A1). The $\Delta U$ Simp variable is split in its respective unhealthy and healthy components (changes in food imports from the U.S. $-\Delta M^{U S}$ in equation (2) - are divided between the two categories), which are both included in our baseline specification. In the IV regressions, U.S. exports of unhealthy and healthy foods to other countries are used as instruments. Possible collinearity between the healthy and unhealthy imports flows and between the two instruments lead us to interpret these 'horse-race' regressions with a grain of salt.

The estimates from the long-difference and stacked-difference models in Table 6 yield a stronger effect of unhealthy compared to healthy American foods. With the USDA 
classification (columns (1) to (3)), both unhealthy and healthy foods seem to foster obesity increases; that said, the effects of the unhealthy component are always larger. The patterns are even more pronounced with our conservative classification (columns (4) to (6)), where greater exposure to unhealthy foods has a large and positive impact on obesity changes, while exposure to healthy foods is weakly and even negatively associated with lower obesity. IV estimates in columns (3) and (6) imply that a one standard-deviation increase in exposure to unhealthy foods augments obesity prevalence by roughly $2 \%$-points - the same effect of a one standard-deviation increase in exposure to total food imports from the U.S. In sum, we interpret these findings in terms of a nutritional mechanism: the U.S. has contributed to the obesity epidemic in Mexico by specializing in producing and exporting unhealthy foods to Mexico.

Table 6: Obesity prevalence and unhealthy food imports from U.S.

\begin{tabular}{|c|c|c|c|c|c|c|}
\hline & 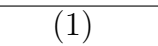 & \multicolumn{2}{|r|}{ (3) } & (4) & $(5)$ & (6) \\
\hline & \multicolumn{3}{|c|}{ USDA classification } & \multicolumn{3}{|c|}{ Conservative classification (Vegs. + ) } \\
\hline & \multicolumn{6}{|c|}{ Panel (a): Long-difference $(2012-1988)$} \\
\hline \multirow[t]{2}{*}{$\Delta$ Unhealthy imports from U.S. } & $0.0770^{* * *}$ & $0.118^{* * *}$ & $0.132^{* * *}$ & $0.0562^{* * *}$ & $0.0732^{* * *}$ & $0.0791^{* * *}$ \\
\hline & $(0.0277)$ & $(0.0364)$ & $(0.0364)$ & $(0.00986)$ & $(0.0206)$ & $(0.0203)$ \\
\hline \multirow[t]{2}{*}{$\Delta$ Healthy imports from U.S. } & 0.0309 & $0.0575^{* *}$ & $0.0531^{* *}$ & $-0.0856^{*}$ & -0.0978 & -0.0862 \\
\hline & $(0.0202)$ & $(0.0228)$ & $(0.0207)$ & $(0.0483)$ & $(0.110)$ & $(0.0927)$ \\
\hline \multicolumn{7}{|c|}{ Effect of one standard-deviation change: } \\
\hline \multirow[t]{2}{*}{$\Delta$ Unhealthy imports from U.S. } & $0.0131^{* * *}$ & $0.0200^{* * *}$ & $0.0224^{* * *}$ & $0.0164^{* * *}$ & $0.0214^{* * *}$ & $0.0231^{* * *}$ \\
\hline & $(0.0047)$ & $(0.0062)$ & $(0.0062)$ & $(0.0029)$ & $(0.0060)$ & $(0.0059)$ \\
\hline \multirow[t]{2}{*}{$\Delta$ Healthy imports from U.S. } & 0.00727 & $0.0135^{* *}$ & $0.0125^{* *}$ & $-0.0066^{*}$ & -0.0075 & -0.0066 \\
\hline & $(0.0048)$ & $(0.0054)$ & $(0.0049)$ & $(0.0037)$ & $(0.0085)$ & $(0.0071)$ \\
\hline Controls & $\mathrm{N}$ & $\mathrm{Y}$ & Y & $\mathrm{N}$ & Y & $\mathrm{Y}$ \\
\hline IV & $\mathrm{N}$ & $\mathrm{N}$ & Y & $\mathrm{N}$ & $\mathrm{N}$ & $\mathrm{Y}$ \\
\hline K-P F-stat. & & & 48.53 & & & 164.5 \\
\hline Obs & 32 & 32 & 32 & 32 & 32 & 32 \\
\hline \multirow[t]{2}{*}{$\mathrm{R}^{2}$} & 0.253 & 0.437 & 0.434 & 0.331 & 0.462 & 0.460 \\
\hline & Panel (b): & Stacked fir & st-differen & e $(2012-20$ & $06,2006-$ & , $1999-1988)$ \\
\hline \multirow[t]{2}{*}{$\Delta$ Unhealthy imports from U.S. } & $0.587^{* * *}$ & $0.814^{* * *}$ & $0.791^{* * *}$ & $0.460^{* * *}$ & $0.774^{* * *}$ & $0.718^{* * *}$ \\
\hline & $(0.130)$ & $(0.173)$ & $(0.258)$ & $(0.127)$ & $(0.112)$ & $(0.134)$ \\
\hline \multirow[t]{2}{*}{$\Delta$ Healthy imports from U.S. } & $0.265^{* *}$ & $0.713^{* * *}$ & $0.649^{* * *}$ & -0.142 & 0.505 & 0.0241 \\
\hline & $(0.111)$ & $(0.109)$ & $(0.134)$ & $(0.477)$ & $(0.507)$ & $(0.682)$ \\
\hline \multicolumn{7}{|c|}{ Effect of one standard-deviation change: } \\
\hline \multirow[t]{2}{*}{$\Delta$ Unhealthy imports from U.S. } & $0.0152^{* * *}$ & $0.0211^{* * *}$ & $0.0205^{* * *}$ & $0.0137^{* * *}$ & $0.0231^{* * *}$ & $0.0214^{* * *}$ \\
\hline & $(0.0034)$ & $(0.0045)$ & $(0.0067)$ & $(0.0038)$ & $(0.0034)$ & $(0.0040)$ \\
\hline \multirow[t]{2}{*}{$\Delta$ Healthy imports from U.S. } & $0.005^{* *}$ & $0.0135^{* * *}$ & $0.0123^{* *}$ & -0.0018 & 0.0063 & 0.0003 \\
\hline & $(0.0021)$ & $(0.0021)$ & $(0.0025)$ & $(0.0060)$ & $(0.0064)$ & $(0.0085)$ \\
\hline Controls & $\mathrm{N}$ & $\mathrm{Y}$ & $\mathrm{Y}$ & $\mathrm{N}$ & $\mathrm{Y}$ & $\mathrm{Y}$ \\
\hline IV & $\mathrm{N}$ & $\mathrm{N}$ & Y & $\mathrm{N}$ & $\mathrm{N}$ & Y \\
\hline K-P F-stat. & & & 3.84 & & & 10.32 \\
\hline Obs & 96 & 96 & 96 & 96 & 96 & 96 \\
\hline $\mathrm{R}^{2}$ & 0.441 & 0.715 & 0.714 & 0.440 & 0.715 & 0.712 \\
\hline
\end{tabular}

Note: All regressions include a constant term. Regressions in Panel (b) include year dummies and a dummy for states with imputed obesity prevalence in 1999. The state share of national female population between 18 and 59 years of age in 1990 is used as weight. Standard errors clustered at the state level are in parentheses. Significant at: $* 10 \%, * * 5 \%, * * * 1 \%$ level. 
Effects of food imports on inequalities in obesity prevalence. Local food environments and in our case exposure to U.S. foods can interact with socio-economic determinants of obesity, thereby exacerbating health inequalities (Alcott et al., 2018; Cawley, 2015). In what follows, we estimate regressions at the individual level where the outcome variable is an obesity dummy and investigate how the average effects of U.S. food penetration at the state level vary with education and employment status. Specifically, we estimate the following model at the individual level:

$$
\text { Obese }_{i, s, t}=\beta_{1} \operatorname{USimp}_{s, t} \times \operatorname{Indiv}_{i, s, t}+\beta_{2} H_{i, s, t}+\gamma_{s, t}+\epsilon_{i, s, t}
$$

The health surveys in 1988, 1999, 2006 and 2012 provide a repeated cross-section of adult women. The variable USimp is similar to equation 2, but with the PPP-converted import variable in levels at the time of the survey, and with food expenditures taken in 1989 (at the beginning of the sample). In the baseline specification, the Indiv variable is a dummy for women who have completed secondary or tertiary education ('high education') or an indicator for women currently unemployed (i.e., the individual-level counterparts of the shares included in the state-level regressions (1)), and $H$ contains individual-level controls. ${ }^{34}$ We absorb 'level' effects of time-varying state covariates by including state-year fixed effects $\gamma_{s, t}$. Table A5 in the Appendix reports the main estimates.

Exposure to U.S. foods magnifies the existing schooling gradient (of about 4\%-points) in obesity risk. The interaction effect associated with the high education indicator is negative and significant (column (1)). To better gauge the importance of this interaction effect consider Figure 9 where we plot the difference in the probability of being obese between women with low and high education against normalised state-level food imports from the U.S.. The results imply that a highly educated woman is 5\%-points less likely to be obese than a low educated one if they both live in a state with average exposure to U.S. foods echoing the stacked first-difference model where obesity correlates negatively with the share of 'high education' women (recall Table 1). If exposure to U.S. foods becomes one standard deviation (0.5) higher, the gap grows by a further percentage point and almost doubles if the USimp variable reaches its maximum at 2.9 .

Interacting the USimp variable with the unemployment indicator in column (2) does not deliver any significant effects, with employed and unemployed women in our sample showing similar obesity risks (consistent with the insignificant coefficient on the unemployment share in the state-level regression). In column (3), we control for different socio-economic

\footnotetext{
${ }^{34}$ These are individual and household characteristics such as age, being the household head, speaking indigenous languages, having chronic diseases and wealth from the health surveys (see section 3 ).
} 
interactions, including between U.S. foods and household income as proxied by indicators for women living in the central part (from 20th to 80th percentile) and top $20 \%$ of the wealth index distribution. While middle-income women face the highest risk of being obese, this gradient does not change with exposure to U.S. foods. The interaction with the unemployment dummy is now negative, but the average difference in obesity risk across employment status is still insignificant. Moreover, controlling for these socio-economic variables does not alter the education-import interaction.

The empirical patterns point to a significant (but moderately sized) interaction between exposure to U.S. foods and education in predicting the risk of being obese. The results are consistent with the well-documented link between education and health. ${ }^{35}$ The educational gradient may magnify in food environments where individuals are faced with more unhealthy food choices (Alcott et al., 2018). We find some corresponding, suggestive evidence in columns (4) and (5) of Table A5 where we split the food imports from the U.S. according to the USDA classification (patterns are even stronger with the 'vegs. vs. no-vegs' classification). Exposure to unhealthy U.S. foods exacerbates the education gradient in obesity, while the obesity gap between high and low educated women does not vary significantly with more exposure to healthy U.S. foods (and it actually narrows when we include interactions with healthy and unhealthy components - results not shown). In our setting, highly educated women in Mexico may be in a better position to assess the nutritional content of or to avoid some unhealthy imported foods.

\footnotetext{
${ }^{35}$ Theoretically, educated individuals may obtain a larger marginal return from any investment in health capital ("productive efficiency" (Grossman, 1972)) and may be more efficient at selecting inputs into health investment ("allocative efficiency" (Rosenzweig and Schultz, 1983)).
} 
Figure 9: Obesity inequality between education groups and food imports from the U.S.

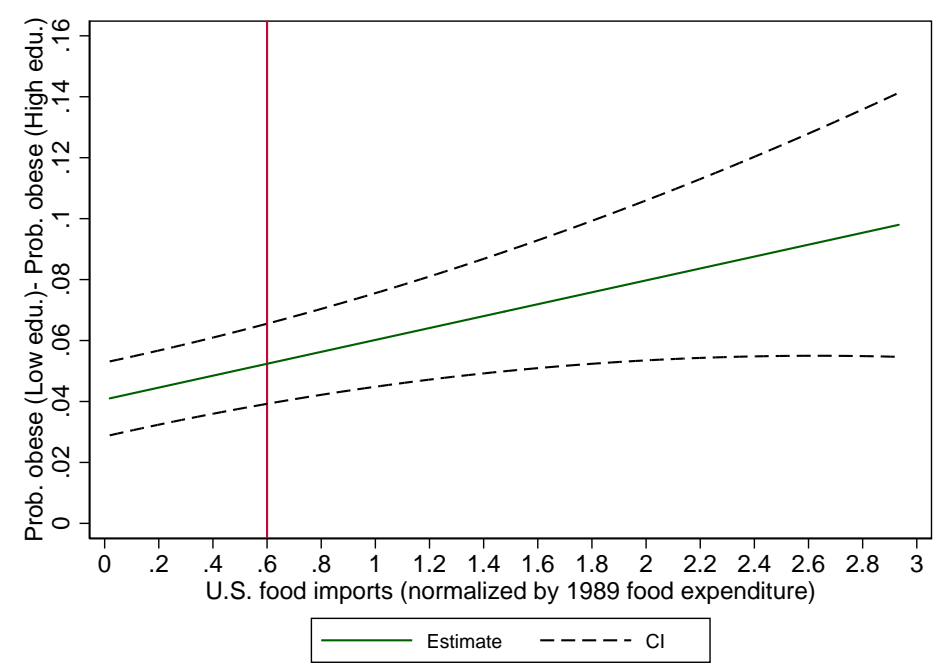

Note: The vertical line indicates the sample average of the USimp variable. Estimates from column (1) of Table A5 are used to generate the graph.

\section{Potential mechanisms}

The empirical findings point to a sizeable and robust effect of food imports from the U.S. on obesity prevalence - an effect that is mainly driven by imports of unhealthy foods. In this sub-section, we explore potential mechanisms that might explain this impact.

Greater penetration of food imports can affect nutrition and body weight by altering domestic food markets. This channel can be rationalized in standard obesity models following Philipson and Posner (2003); Lakdawalla et al. (2005); and Lakdawalla and Philipson (2009). Assume the utility of an individual $U(f, c, w)$ relates positively to food consumption $f$ and other consumption $c$; and non-linearly to body weight $w$. An individual's utility increases (decreases) in body weight when weight is below (above) a weight target $w_{o}$. In other words, if $w>w_{o}$ the individual will diet, and gain weight otherwise. Weight in turn depends positively on food consumption $w(f)$ (with $w^{\prime}>0$ ), where for simplicity we hold physical activity constant. When $U(f, c, w)$ is separable in its arguments and maximised with respect to the budget constraint $I=c+P f$, then the price of food $P$ has a negative effect and income $I$ a positive effect on $f$ and hence weight $w$. This model motivates us to examine if changes in relative food prices and income can explain the effect of food imports on body weight. ${ }^{36}$ Extensions of this simple framework introducing taste

\footnotetext{
${ }^{36}$ Increasing income and falling food prices will only initially lead to weight gains and not-monotonically so due to the ideal weight $w_{o}$. We focus on the linear relationships as ideal weight may change over time (Strulik, 2014), thus making tests for non-monotonicity problematic.
} 
(or habit) formation (e.g., in Atkin (2013); and Dragone and Ziebarth (2017)) beg the additional question of whether prolonged exposure to imported foods can have reinforcing effects on food consumption and hence body weight.

(a) Price mechanism

Greater openness to imports may lower relative prices of imported and import-competing goods through several channels (see Goldberg and Pavcnik (2016) for a detailed discussion). In our setting, American food exporters become more competitive through lower export prices and greater market access (e.g., due to the NAFTA-induced reduction in trade barriers). Both lead to an expansion in the U.S. export supply and a lower domestic price of imported U.S. foods. ${ }^{37}$ Holding constant the price of local foods, the overall consumer price of a food product (including both local and foreign varieties) decreases with the price of imports, although the strength of this relationship depends on the market structure and demand conditions (e.g., on the substitutability between foreign and domestic varieties).

Greater import penetration in food markets might further reduce consumer prices by exerting competitive pressure on local food producers. This pro-competitive effect emerges in models with imperfect competition and variable markups as domestic firms lower markups and prices in order to accommodate a downward shift in the residual demand curve and greater price elasticity of demand (Krugman, 1979; Edmond et al., 2015). These mechanisms clearly suggest a negative relationship between U.S. export supply of foods to Mexico and Mexican consumer food prices, which could in turn explain the reduced-form effect of exposure to U.S. foods on obesity prevalence. ${ }^{38}$

We test if Mexican consumer food prices decrease with U.S. food exports both at the national and sub-national level using the CPI microdata made available by Gagnon (2009) (for details see section 3). We compute the annual price for each food product that could be matched with the ENIGH (and trade) classification as the average of the (log) monthly price quotes - a monthly quote is identified by a store, city, and food product. These national prices are regressed on (logs of) annual U.S. food exports to other countries than Mexico

\footnotetext{
${ }^{37}$ Under the small country assumption, the export price $\left(p_{g}^{*}\right)$ and trade costs $\left(t_{g}\right)$ pin down the consumer price of a given food product $g$. With perfect competition or monopolistic competition and CES demand, changes in the domestic price of imported goods are proportional to changes in the export price or in multiplicative (iceberg or ad-valorem) trade costs $\left(\ln p_{g}=\ln p_{g}^{*}+\ln t_{g}\right)$.

${ }^{38}$ Trade liberalisation can reduce the price of domestically produced foods by providing domestic firms with access to a greater variety of (cheap) intermediate inputs (see Amiti and Konings (2007) and Goldberg et al. (2010) for evidence from Indonesia and India across all manufacturing industries). This channel is however likely to be weak in our setting where most of the food products considered are for final consumption.
} 
- our instrument for product-specific U.S. food supply -, controlling for product and year fixed effects, from 1995 to 2010 (the period when the CPI data are available). The negative and significant elasticity in column (1) of Table 7 supports the prediction of a price-reducing effect of exposure to greater U.S. export supply of foods. Since food prices went up during this period along with prices of other goods ${ }^{39}$, the estimates suggest that the rise in food prices was dampened by U.S. food export supply.

In columns (2) to (4) of Table 7 we verify the robustness of these results to the inclusion of other trade variables that might affect relative food prices. Standard comparative advantage arguments would predict that the relative (producer) price of exported foods from Mexico should increase as producers gain market access to the U.S. and other countries. To isolate exogenous (in this case, demand-side) determinants of Mexican food exports, we use total food imports by the U.S. (a major destination of Mexican food exports) from all origins except Mexico. As shown in column (2), the elasticity of Mexican food prices with respect to this instrument for Mexican export opportunities is negative, close to zero and imprecisely estimated. While not conclusive, this piece of evidence indicates that exposure to exports markets did not have significant effects on food consumption (and hence body weight) through local food prices. Importantly, the negative elasticity with respect to U.S. food exports remains unchanged (see column (3)). Further controlling for Mexican food imports from other countries (ROW) in column (4) does alter the elasticity of interest.

Greater exposure to U.S. food supply should affect Mexican food prices through higher food imports from the U.S.. We investigate this casual chain from U.S. food exports to consumer food prices more closely by estimating IV models. U.S. food exports to other countries serve as an instrument for the value of Mexican food imports from the U.S., while food imports by the U.S. from other countries than Mexico is the instrument for Mexican food exports to the U.S. The results, reported in columns (5) to (7) of Table 7, confirm the price-reducing effect of greater exposure to U.S. foods. Food products become relatively less expensive to Mexican consumers as penetration of U.S. foods increases - a result of the expanding U.S. food export supply.

The magnitudes implied by the elasticities of consumer food prices with respect to shocks in U.S. food exports are in line with the findings of the literature on the price effects of import liberalisation. As reported at the bottom of Table 7, the average increases in U.S. food exports to other countries (in columns (1),(3) and (4)) and to Mexico (in columns (5)

\footnotetext{
39 Following the Mexican peso crisis at the end of 1994, inflation skyrocketed to $40 \%$ during 1995 and much of 1996 (Gagnon, 2009). Prices increased steadily thereafter, although at a lower pace. The official CPI for foods, beverages and tobacco products in 2010 was about three times its value in 1996 - a similar increase is observed for the overall CPI (data from the INEGI website).
} 
to (7)) observed between 1995 and 2010 mandate 3 to 14 percent reductions (depending on the specification used) in the consumer prices of foods in our sample, which were on average 120 percent higher in 2010 than in 1995 (overall inflation was even higher during the same period - see footnote no.39). Incidentally, these magnitudes are in the ballpark of the 10 percent decline in domestic prices due to import tariff liberalisation in India found by Topalova (2010); and De Loecker et al. (2016). The attenuated price response that we find is consistent with different theoretical mechanisms (Goldberg and Pavcnik, 2016), and can be related to our empirical setting. Unlike the aforementioned papers exploiting direct changes in trade costs, we identify an indirect effect of an export supply shock that should be matched by a drop in the domestic price of imported foods and in turn transmit to overall consumer prices. Persistence in food consumption habits as in the model of Atkin (2013) can further diminish price responses to trade liberalisation, if Mexican consumers hold tastes for local food varieties that were available before U.S. ones. In spite of these limitations, findings corroborate a price channel behind the impact of exposure to U.S. foods on obesity. ${ }^{40}$

\footnotetext{
${ }^{40}$ The dependent variable of the price regressions, computed from the CPI microdata as average across price quotes, should encompass the price effect of new and disappearing food varieties as quotes are added and dropped from the dataset. Importantly though, the CPI microdata do not allow us to distinguish domestic from imported varieties, nor to follow price quotes after 2002 (see section 3). Furthermore, lack of data on expenditures at the variety (i.e., price quote) level prevents us from computing exact price indices that formally incorporate the influence of changes at the extensive margin (e.g., as in Feenstra (1994); and Broda and Weinstein (2006)).
} 
Table 7: Food prices and U.S. food exports to Mexico

\begin{tabular}{|c|c|c|c|c|c|c|c|}
\hline & $(1)$ & $\begin{array}{c}(2) \\
\text { Reduced }\end{array}$ & $\begin{array}{c}(3) \\
\text { form OLS }\end{array}$ & $(4)$ & $(5)$ & $\begin{array}{l}(6) \\
\text { IV }\end{array}$ & $(7)$ \\
\hline Ln(U.S. food exports to ROW) & $\begin{array}{c}-0.0436^{* * *} \\
(0.0157)\end{array}$ & & $\begin{array}{c}-0.0429^{* * *} \\
(0.0152)\end{array}$ & $\begin{array}{c}-0.0452^{* * *} \\
(0.0153)\end{array}$ & & & \\
\hline Ln(U.S. food imports from ROW) & & $\begin{array}{r}-0.00892 \\
(0.0188)\end{array}$ & $\begin{array}{r}-0.00472 \\
(0.0189)\end{array}$ & $\begin{array}{l}0.00441 \\
(0.0175)\end{array}$ & & & \\
\hline Ln(food imports from U.S.) & & & & & $\begin{array}{c}-0.0633^{* *} \\
(0.0308)\end{array}$ & $\begin{array}{r}-0.0732^{*} \\
(0.0438)\end{array}$ & $\begin{array}{r}-0.0824^{*} \\
(0.0442)\end{array}$ \\
\hline Ln(Mex. exports to U.S.) & & & & & & $\begin{array}{l}-0.0153 \\
(0.0550)\end{array}$ & $\begin{array}{l}-0.0360 \\
(0.0581)\end{array}$ \\
\hline Ln(food imports from ROW) & & & & $\begin{array}{c}-0.00488 \\
(0.00388)\end{array}$ & & & $\begin{array}{l}-0.00285 \\
(0.00581)\end{array}$ \\
\hline \multicolumn{8}{|c|}{ First-stage results - food imports from U.S.: } \\
\hline Ln(U.S. food exports to ROW) & & & & & $\begin{array}{c}0.688^{* * *} \\
(0.236)\end{array}$ & $\begin{array}{c}0.657^{* * *} \\
(0.216)\end{array}$ & $\begin{array}{c}0.661^{* * *} \\
(0.214)\end{array}$ \\
\hline Ln(U.S. food imports from ROW) & & & & & & $\begin{array}{c}0.188 \\
(0.133)\end{array}$ & $\begin{array}{c}0.207 \\
(0.155)\end{array}$ \\
\hline F-stat excluded instr. & & & & & 8.48 & 4.63 & 4.78 \\
\hline \multicolumn{8}{|c|}{ Percent impact of 2010 - 1995 ave. change in: } \\
\hline Ln(U.S. food exports to ROW) & $\begin{array}{c}-3.398^{* * *} \\
(1.220)\end{array}$ & & $\begin{array}{c}-3.341^{* * *} \\
(1.182)\end{array}$ & $\begin{array}{c}-3.523^{* * *} \\
(1.191)\end{array}$ & & & \\
\hline Ln(food imports from U.S.) & & & & & $\begin{array}{c}-10.74^{* *} \\
(5.222)\end{array}$ & $\begin{array}{c}-12.42^{*} \\
(7.422)\end{array}$ & $\begin{array}{c}-13.98^{*} \\
(7.501)\end{array}$ \\
\hline Obs & 1,848 & 1,880 & 1,848 & 1,738 & 1,840 & 1,756 & 1,661 \\
\hline $\mathrm{R}^{2}$ & 0.977 & 0.977 & 0.977 & 0.976 & 0.974 & 0.973 & 0.969 \\
\hline
\end{tabular}

Note: The dependent variable is the annual average of price quotes (in logs) by food product. All regressions include product and year fixed effects. The product expenditure share in 1995 is used as weight. First-stage results are estimates on the excluded instruments only. Robust standard errors clustered at the product level are in parentheses. Significant at: ${ }^{*} 10 \%,{ }^{*} 5 \%$, $* * * 1 \%$ level.

Similar patterns emerge when we exploit variation within Mexico. For each state and year, we take the expenditure-weighted average of food prices across products (where product-level prices equal in turn the mean of price quotes, in logs), holding the expenditure weights fixed at their values in 1995. This annual food price index for each state is regressed on U.S. food exports and other trade variables, allocated across states and normalized by total state's food expenditure using expenditure values in 1995 (see equation 2). The state-year panel specification further controls for state and year fixed effects, so as to identify the price effect of exposure to U.S. foods from variations within states over time and across food products. The estimates, reported in columns (1) to (4) of Table A4 in the Appendix, show a negative effect of penetration of food imports from the U.S. on state-level food prices, which is unaltered by controlling for exposure to food imports from ROW, shocks to foreign demand for Mexican foods, and other state-level covariates (GDP per capita, FDI over GDP, and migrants - all in logs -, and annual inflation).

The average impact of U.S. food penetration on Mexican consumer prices can mask important variation across food products that are more or less 'obesity-prone'. The simple obesity model described above could be extended to allow for foods with different 
characteristics that are related to their 'healthiness' (see MacInnis and Rausser (2005) for a model with 'unprocessed' and 'processed' foods). Say, unhealthy foods are more intensive in calories than healthy ones and thus more obesity prone as captured in the properties of the body weight production function: $w\left(f^{h}, f^{u n h}\right)$; with $\frac{\partial w(.)}{\partial f^{u n h}}>\frac{\partial w(.)}{\partial f^{h}}-$ where $f^{u n h}$ and $f^{h}$ identify consumption of unhealthy and healthy foods, respectively. When prices of unhealthy relative to healthy foods decline, relative unhealthy consumption goes up and body weight increases - for any given level of total food consumption.

Table 8 reports aggregate results of reduced-form and IV price regressions (akin to Table 7), estimated on the separate samples of healthy and unhealthy food products defined according to the USDA classification and our more conservative 'vegs+' grouping. Both splits deliver strong and consistent findings across reduced-form OLS and IV models: the price-reducing effect of greater exposure to U.S. foods is concentrated in unhealthy foods. In the healthy foods sample, the effect is insignificant and the first-stage linking U.S. food exports to ROW and Mexican imports from the U.S. is weak. These patterns accord well with trends in Figures 3 and 4 showing how U.S. food exports to Mexico became increasingly specialised in unhealthy foods. They also match up with the findings from the obesity regressions in Table 6 suggesting that the pro-obesity effect of total food imports from the U.S. is largely due to the increase in unhealthy imports. The correspondence with the obesity results is further enhanced by estimates of state-year panel regressions where the price and trade variables are computed separately for healthy and unhealthy foods (see columns (5) to (8) of Table A4, reporting reduced-form estimates). ${ }^{41}$ Again, the negative effect of exposure to U.S. food supply on consumer prices is robust only with unhealthy foods.

\footnotetext{
${ }^{41}$ The IV estimates are consistent with the reduced-form results reported in Table A4 and available upon request. The instrumental variable strategy is again weak when considering healthy foods only.
} 
Table 8: Food prices and U.S. food exports to Mexico - unhealthy vs. healthy products

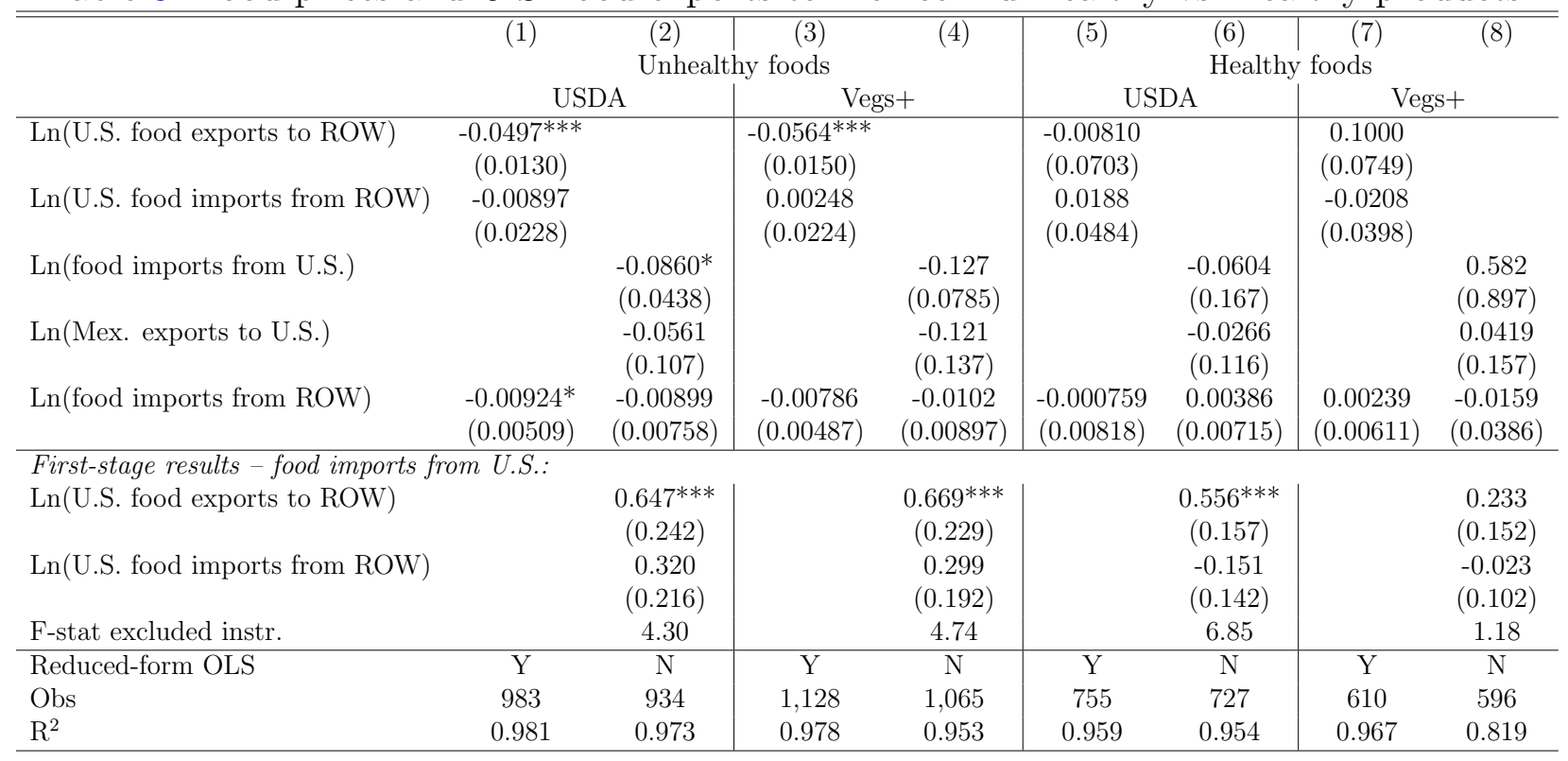

Note: The dependent variable is the annual average of price quotes (in logs), by food product. Odd-numbered columns report reduced-form OLS results, even-numbered columns report IV results. See text for descriptions of the unhealthy vs. healthy classifications. All regressions include product and year fixed effects. The product expenditure share in 1995 is used as weight. First-stage results are estimates on the excluded instruments only. Robust standard errors clustered at the product level are in parentheses. Significant at: $* 10 \%, * * 5 \%, * * * 1 \%$ level.

In sum, variations both within food products and states over time reveal a robust negative effect of U.S. food exports on Mexican consumer prices. These price-reducing influences might well explain part of the documented weight gains due to trade in (unhealthy) foods.

\section{(b) Income effects}

Trade liberalisation can affect food consumption and obesity prevalence through changes in individuals' income. As shown above, body weight is expected to increase with income (as long as $w<w_{o}$ ). In our obesity regressions, the relationship between obesity and income per capita is however insignificant (see Table 1), and controlling for this variable does not affect the pro-obesity effect of exposure to U.S. foods. More generally, our focus on food imports and our empirical strategy geared towards a nutrition channel (i.e., through the use of expenditure shares to capture exposure) makes it unlikely that income changes can explain the obesity effects that we find.

The empirical literature on local income effects of increased import competition and export opportunities relies on exposure through industry of employment (see Topalova (2010); McCaig (2011); Kis-Katos and Sparrow (2015); McCaig and Pavcnik (2018) for 
evidence from developing countries). Our empirical strategy leverages differences in exposure through initial expenditure to imports across more than 150 food and beverages products. The significance of employment variations at such level of detail remains unclear. ${ }^{42}$ When we do control for labour market characteristics of our sample of adult women in our regressions (see Table 1), the positive and significant effect of food imports from the U.S. on obesity rates is unaltered. Furthermore, results from the price regressions do not show significant effects of exposure to food export markets, although the negative effects on the consumer prices of import competing foods could lead to lower labour earnings for workers employed in the production of those foods. ${ }^{43}$ These different pieces of evidence tentatively show that income changes do not affect or relate to our main finding. A different empirical setup (e.g., leveraging exposure through local employment) from the one used in this paper might be better suited to identify the income effects of trade shocks.

(c) Changes in tastes and U.S. foods

A final mechanism that we explore is related to changing tastes following increased exposure to U.S. foods. In the theoretical model proposed by Atkin (2013) explaining nutrition patterns across India, individuals form habits in consumption and buy more of a food product if its past prices were low (relative to other foods). Such a model can also rationalise an expansion in food consumption (leading to higher body weight) if U.S. foods complement pre-existing food preferences by Mexican consumers. Therefore, our empirical strategy that allocates changes in food imports according to expenditure shares at the start of the period is consistent with a reinforcing relationship between penetration of U.S. foods and habits in food consumption. ${ }^{44}$

Since we find that higher U.S. food exports are significantly correlated with lower consumer prices, we would expect that, under habit formation, Mexican households devote larger shares of expenditure to foods that were relatively cheaper in the past because of exposure to U.S. supply. To shed light on this mechanism, we adapt the empirical approach

\footnotetext{
${ }^{42}$ Industry employment by Mexican state could be computed using data the Economic Censuses (see Chiquiar et al. (2017) for an application), where the NAICS industry classification is used.

${ }^{43}$ Greater import competition in the food sector can proxy for penetration of foreign retailers, as it could be the case of Walmart in Mexico (see subsection 4.2). Atkin et al. (2018) however find little evidence for a significant effect of retail FDI on local income or employment in Mexico, and our results show that controlling for the local presence of Walmart stores had no important impact of the relationship between obesity and exposure to food imports from the U.S..

${ }^{44}$ Notably, the utility function discussed above could for instance feature past exposure to foods $F$, allowing for their interactions with current consumption $f$ through a non-zero cross partial $U_{F, f}$ (for such a model of food consumption and weight gains see Dragone and Ziebarth (2017)).
} 
of Atkin (2013). In a first stage, we regress household food expenditure shares by nine food aggregates on total real food expenditure, household-level controls, and state-year fixed effects. The estimated state-year fixed effects from the first step varying across food aggregates are then regressed on exposure to U.S. food exports to the ROW (our instrument), controlling for current own and cross-product price effects, as well as state-product and state-year fixed effects. ${ }^{45}$

Table A6 summarizes the results (the notes at the bottom of the table provide more details on the estimation). We first include our contemporaneous trade variable by itself (column (1)), which correlates positively with expenditure shares by product aggregate. As one would expect and in line with the aforementioned price mechanism, this correlation vanishes once we control for prices (column 2). In columns (3),(5) and (7), we include lags of the trade variable without controlling for prices. The average effect across lags is positive and significant (as reported in a separate row below the individual point estimates), suggesting that past exposure to U.S. foods leads to persistence in food consumption. Given the arbitrary choice of the number of lags, we also report a Bayesian Information Criterion (BIC), which indicates that the model with just one lag is preferred to including several lags. ${ }^{46}$ However, once we control for current prices (see columns 4, 6 and 8), the average effect on the lags is insignificant and small. In sum, we find some evidence of a persistent effect of exposure to U.S. food supply on budget shares, which is however driven by current prices, in turn leaving little room for the identification of a taste mechanism. One important caveat to notice is that changes in tastes are likely slow moving and we are restricted to a relatively short period of analysis (1995 - 2010).

\section{Concluding remarks}

A handful but growing set of studies has documented the adverse effects of trade liberalisation on health through income and labour market channels (Colantone et al., 2018; Adda and Fawaz, 2017; Pierce and Schott, 2017; Hummels et al., 2016; Lang et al., 2019; McManus and Schaur, 2016).

\footnotetext{
${ }^{45}$ See equation n. 5 of Atkin (2013) for a similar specification. The household budget regression is motivated by a linear approximation of the Almost Ideal Demand System (AIDS) (Deaton and Muellbauer, 1980), under the assumption of weak separability between food expenditure $(f)$ and expenditure on other goods $(c)$ - justifying the use of real food expenditure instead of total real expenditure. Unlike in Atkin (2013), our price data can be matched with the expenditure data only at the state level - i.e., the same spatial level of our trade variables. For this reason, we include the price variables only in the second step of our estimation, where household-level characteristics are netted out from the state-level budget shares.

${ }^{46}$ We stop at three lags as in any case the BIC increases as we add more lags.
} 
We contribute to this literature by providing novel evidence on the effects of trade in foods on obesity. Our results advance the idea that the U.S. has exported some of its obesity epidemic to Mexico. Our causal estimates suggest that plausibly exogenous variation in U.S. food exports to Mexico explains one tenth of the total rise in obesity prevalence among Mexican women observed between 1988 and 2012. This effect amounts to one million additional obese women over the period. The magnitudes are comparable to the obesity effects found in other studies examining the role of changes in the food environment in different contexts (Courtemanche and Carden, 2011). U.S. exports of unhealthy foods are driving the pro-obesity impact of exposure to U.S. foods, thus corroborating a nutritional channel. We also find evidence for a price-reducing effect of exposure to U.S. food supply, which might rationalize the findings on obesity.

In combining health, expenditure, and trade data over a long period of time, our empirical analysis faces some limitations - future work might address some of these. First, the results stem from a relatively small number of observations (32 states observed over four periods). The large variations in obesity and food imports observed over the period and across states, and the robustness of our findings to a host of checks (e.g., lead tests, dropping single states, and alternative outcome variables) alleviate this concern to some extent. Second, we find no evidence for an income mechanism, in part as our empirical strategy is geared towards identifying a consumption channel. Finally, the relatively short period under consideration might not allow us to pinpoint the effect of prolonged exposure to U.S. foods on tastes, which might take decades to manifest itself.

With these caveats in mind, the baseline findings still imply a significant and sizeable contribution of U.S. food exports to the ongoing nutrition transition and associated spread of the obesity epidemic in Mexico. Like other emerging economies, the country would have attained high levels of obesity prevalence even without increasing exposure to American (unhealthy) foods. Our empirical analysis - which controls for trends in obesity prevalence across Mexican states - shows that the rising penetration of U.S. food exports has moved Mexican consumers on a steeper obesity trajectory.

Our paper supports the idea that health concerns should matter for the determination of trade policies, especially when it comes to unhealthy food products. Our paper is consistent with anecdotal evidence of a positive link between trade and investment liberalisation and the observed rise in obesity in Mexico (Jacobs and Richtel, 2017). As the UN Special Rapporteur on the Right to Food stated in 2012, the widespread belief is that at least part of the obesity emergency could have been avoided if "the health concerns linked to shifting diets had been integrated into the design of the country's trade policies" (Guardian, 2015). 
That said, future work should investigate further the health consequences of trade liberalisation in the food sector. There are possible negative health externalities associated with trade integration, especially when trading partners have a comparative advantage in unhealthy foods. Yet, it remains unclear how these health externalities measure up to the much heralded consumers' welfare gains from trade due to access to new and less expensive varieties. 


\section{References}

Acemoglu, D., Autor, D., Dorn, D., Hanson, G.H., Price, B., 2016. Import Competition and the Great US Employment Sag of the 2000s. Journal of Labor Economics 34(S1), 141-198.

Adda, J., Fawaz, Y., 2017. The Health Toll of Import Competition. Working Paper.

Alcott, H., Diamond, R., Dube, J.P., Handbury, J., Rahkovsky, I., Schnell, M., 2018. Food Deserts and the Causes of Nutritional Inequality. Working Paper.

Amiti, M., Konings, J., 2007. Trade Liberalization, Intermediate Inputs, and Productivity: Evidence from Indonesia. American Economic Review 97(5), 1611-1638.

Atkin, D., 2013. Trade, tastes, and nutrition in India. American Economic Review 103(5), 1629-1663.

Atkin, D., Donaldson, D., 2015. Who's Getting Globalized? The Size and Implications of Intra-national Trade Costs. Working Paper Series 21439. National Bureau of Economic Research.

Atkin, D., Faber, B., Gonzalez-Navarro, M., 2018. Retail Globalization and Household Welfare: Evidence from Mexico. Journal of Political Economy 126(1), 1-73.

Autor, D.H., Dorn, D., Hanson, G.H., 2013. The China Syndrome: Local Labor Market Effects of Import Competition in the United States. American Economic Review 103(6), 2121-68.

Barlow, P., McKee, M., Basu, S., Stuckler, D., 2017a. Impact of the North American Free Trade Agreement on high-fructose corn syrup supply in Canada: A natural experiment using synthetic control methods. Canadian Medical Association Journal 189(26), 881-887.

Barlow, P., McKee, M., Basu, S., Stuckler, D., 2017b. The health impact of trade and investment agreements: A quantitative systematic review and network co-citation analysis. Globalization and Health 13(1), 13.

Barlow, P., McKee, M., Stuckler, D., 2018. The Impact of U.S. Free Trade Agreements on Calorie Availability and Obesity: A Natural Experiment in Canada. American Journal of Preventive Medicine 54(5), 637 - 643.

Broda, C., Weinstein, D.E., 2006. Globalization and the Gains From Variety. The Quarterly Journal of Economics 121(2), 541-585. 
Cawley, J., 2015. An economy of scales: A selective review of obesity's economic causes, consequences, and solutions. Journal of Health Economics 43, 244-268.

Chiquiar, D., Covarrubias, E., Salcedo, A., 2017. Labor market consequences of trade openness and competition in foreign markets. Working Paper 01. Banco de México.

Colantone, I., Crinò, R., Ogliari, L., 2018. Globalization and Mental Distress. Working Paper.

Costa-Font, J., Mas, N., 2016. 'Globesity'? The effects of globalization on obesity and caloric intake. Food Policy 64, 121 - 132.

Courtemanche, C., Carden, A., 2011. Supersizing supercenters? The impact of Walmart Supercenters on body mass index and obesity. Journal of Urban Economics 69(2), 165-181.

Courtemanche, C.J., Pinkston, J.C., Ruhm, C.J., Wehby, G.L., 2016. Can Changing Economic Factors Explain the Rise in Obesity? Southern Economic Journal 82(4), 1266-1310.

Currie, J., DellaVigna, S., Moretti, E., Pathania, V., 2010. The effect of fast food restaurants on obesity and weight gain. American Economic Journal: Economic Policy 2(3), 32-63.

Cutler, D.M., Glaeser, E.L., Shapiro, J.M., 2003. Why have Americans become more obese? Journal of Economic Perspectives 17(3), 93-118.

De Loecker, J., Goldberg, P.K., Khandelwal, A.K., Pavcnik, N., 2016. Prices, Markups, and Trade Reform. Econometrica 84(2), 445-510.

Deaton, A., Muellbauer, J., 1980. An almost ideal demand system. American Economic Review 70(3), 312-326.

DGA, 2010. USDA Dietary Guidelines for Americans. Report. Available at: https://health.gov/dietaryguidelines/dga2010/DietaryGuidelines2010.pdf.

Dix-Carneiro, R., Kovak, B.K., 2017. Trade Liberalization and Regional Dynamics. American Economic Review 107(10), 2908-46.

Dragone, D., Ziebarth, N.R., 2017. Economic Development, Novelty Consumption, and Body Weight: Evidence from the East German Transition to Capitalism. Journal of Health Economics (51), 41-65. 
Edmond, C., Midrigan, V., Xu, D.Y., 2015. Competition, Markups, and the Gains from International Trade. American Economic Review 105(10), 3183-3221.

Feenstra, R.C., 1994. New Product Varieties and the Measurement of International Prices. The American Economic Review 84(1), 157-177.

Gagnon, E., 2009. Price Setting during Low and High Inflation: Evidence from Mexico. The Quarterly Journal of Economics 124(3), 1221-1263.

Gagnon, E., Lopez-Salido, D., Vincent, N., 2013. Individual Price Adjustment along the Extensive Margin. NBER Macroeconomics Annual 27(1), 235-281.

Goldberg, P., Pavcnik, N., 2016. Chapter 3 - The Effects of Trade Policy, in: Bagwell, K., Staiger, R.W. (Eds.), Handbook of Commercial Policy. North-Holland. volume 1, pp. 161 $-206$.

Goldberg, P.K., Khandelwal, A.K., Pavcnik, N., Topalova, P., 2010. Imported Intermediate Inputs and Domestic Product Growth: Evidence from India. The Quarterly Journal of Economics 125(4), 1727-1767.

Grossman, M., 1972. On the concept of health capital and the demand for health. Journal of Political Economy 80(2), 223-255.

Guardian, 2015. The Global South has free trade to thank for its obesity and diabetes epidemic. Newspaper article. By Ramon Vera Herrera, Monday 6th April 2015.

Hanson, G.H., 2003. What Has Happened to Wages in Mexico since NAFTA? Working Paper 9563. National Bureau of Economic Research.

Hanson, G.H., 2007. Globalization, Labor Income, and Poverty in Mexico, in: Globalization and Poverty. National Bureau of Economic Research, Inc. NBER Chapters, pp. 417-456.

Hanson, G.H., 2010. Why Isn't Mexico Rich? Journal of Economic Literature 48(4), 987-1004.

Hummels, D., Munch, J., Xiang, C., 2016. No Pain, No Gain: The Effects of Exports on Effort, Injury, and Illness. Working Paper 22365. National Bureau of Economic Research.

Hut, S., Oster, E., 2018. Diabetes and diet: Purchasing behavior change in response to health. Working Paper. 
Iacovone, L., Javorcik, B., Keller, W., Tybout, J., 2015. Supplier responses to Walmart's invasion in Mexico. Journal of International Economics 95(1), 1-15.

Jacobs, A., Richtel, M., 2017. A Nasty, NAFTA-Related Surprise: Mexico's Soaring Obesity. The New York Times .

Keats, S., Wiggins, S., 2014. Future diets: Implications for agriculture and food prices. Report. Overseas Development Institute (ODI).

Kis-Katos, K., Sparrow, R., 2015. Poverty, labor markets and trade liberalization in Indonesia. Journal of Development Economics 117(C), 94-106.

Krugman, P.R., 1979. Increasing returns, monopolistic competition, and international trade. Journal of International Economics 9(4), 469-479.

Lakdawalla, D., Philipson, T., 2009. The growth of obesity and technological change. Economics \& Human Biology 7(3), 283 - 293.

Lakdawalla, D., Philipson, T., Bhattacharya, J., 2005. Welfare-enhancing technological change and the growth of obesity. American Economic Review 95(2), 253-257.

Lang, M., McManus, T.C., Schaur, G., 2019. The effects of import competition on health in the local economy. Health Economics 28(1), 44-56.

Lopez, A.M., Loopstra, R., McKee, M., Stuckler, D., 2017. Is trade liberalisation a vector for the spread of sugar-sweetened beverages? A cross-national longitudinal analysis of 44 low- and middle-income countries. Social Science and Medicine 172, $21-27$.

MacInnis, B., Rausser, G., 2005. Does Food Processing Contribute to Childhood Obesity Disparities? American Journal of Agricultural Economics 87(5), 1154-1158.

McCaig, B., 2011. Exporting out of poverty: Provincial poverty in Vietnam and U.S. market access. Journal of International Economics 85(1), 102-113.

McCaig, B., Pavcnik, N., 2018. Export Markets and Labor Allocation in a Low-Income Country. American Economic Review 108(7), 1899-1941.

McManus, T.C., Schaur, G., 2016. The effects of import competition on worker health. Journal of International Economics 102, 160 - 172.

Mendez, O., 2015. The effect of chinese import competition on mexican local labor markets. The North American Journal of Economics and Finance 34(Suppl. C), 364 - 380. 
Miljkovic, D., Shaik, S., Miranda, S., Barabanov, N., Liogier, A., 2015. Globalisation and Obesity. The World Economy 38(8), 1278-1294.

Ng, M., et al., 2014. Global, regional, and national prevalence of overweight and obesity in children and adults during 1980-2013: a systematic analysis for the global burden of disease study 2013. The Lancet 384(9945), 766 - 781.

Oberlander, L., Disdier, A.C., Etilé, F., 2017. Globalisation and national trends in nutrition and health: A grouped fixed-effects approach to intercountry heterogeneity. Health Economics 0, 1-16.

OECD, 2017. Obesity Update 2017. Report. Organisation for Economic Cooperation and Development (OECD).

Omran, A.R., 1971. The epidemiologic transition: a theory of the epidemiology of population change. The Milbank Memorial Fund Quarterly 49(4), 509-538.

Philipson, T.J., Posner, R.A., 2003. The long-run growth in obesity as a function of technological change. Perspective in Biology and Medicine 46(3).

Pierce, J.R., Schott, P.K., 2017. Trade Liberalization and Mortality: Evidence from U.S. Counties. Technical Report 22849. National Bureau of Economic Research.

Popkin, B.M., Adair, L.S., Ng, S.W., 2012. Global nutrition transition and the pandemic of obesity in developing countries. Nutrition Reviews 70(1), 3-21.

Popkin, B.M., Gordon-Larsen, P., 2004. The nutrition transition: worldwide obesity dynamics and their determinants. International Journal of Obesity 28, S2-S9.

Rivera, J.A., Barquera, S., Gonzalez-Cossio, T., Olaiz, G., Sepulveda, J., 2004. Nutrition transition in Mexico and in other Latin American countries. Nutrition Reviews 62(suppl 2), S149-S157.

Rosenzweig, M.R., Schultz, T.P., 1983. Estimating a household production function: Heterogeneity, the demand for health inputs, and their effects on birth weight. Journal of Political Economy 91(5), 723-746.

Rtveladze, K., Marsh, T., Barquera, S., Romero, L.M.S., Levy, D., Melendez, G., Webber, L., Kilpi, F., McPherson, K., Brown, M., 2014. Obesity prevalence in mexico: impact on health and economic burden. Public Health Nutrition 17(1), 233-239. 
Silva, J.M.C.S., Tenreyro, S., 2006. The Log of Gravity. The Review of Economics and Statistics 88(4), 641-658.

Strulik, H., 2014. A mass phenomenon: The social evolution of obesity. Journal of Health Economics 33, 113 - 125 .

Thow, A.M., 2009. Trade liberalisation and the nutrition transition: mapping the pathways for public health nutritionists. Public Health Nutrition 12(11), 2150-2158.

Todd, J.E., Mancino, L., Lin, B.H., 2010. The Impact of Food Away from Home on Adult Diet Quality. Economic Research Report 58298. United States Department of Agriculture, Economic Research Service.

Topalova, P., 2007. Trade Liberalization, Poverty and Inequality: Evidence from Indian Districts, in: Globalization and Poverty. National Bureau of Economic Research. NBER Chapters, pp. 291-336.

Topalova, P., 2010. Factor Immobility and Regional Impacts of Trade Liberalization: Evidence on Poverty from India. American Economic Journal: Applied Economics 2(4), $1-41$.

Utar, H., Ruiz, L.B.T., 2013. International competition and industrial evolution: Evidence from the impact of chinese competition on mexican maquiladoras. Journal of Development Economics 105(Supplement C), $267-287$.

Verhoogen, E.A., 2008. Trade, Quality Upgrading, and Wage Inequality in the Mexican Manufacturing Sector. The Quarterly Journal of Economics 123(2), 489-530.

Vogli, R.D., Kouvonen, A., Elovainio, M., Marmot, M., 2014. Economic globalization, inequality and body mass index: a cross-national analysis of 127 countries. Critical Public Health 24(1), 7-21.

Volpe, R., Okrent, A., Leibtag, E., 2013. The Effect of Supercenter-format Stores on the Healthfulness of Consumers' Grocery Purchases. American Journal of Agricultural Economics 95(3), 568-589.

WHO, 2015. Trade and Health: Towards building a national strategy. Technical Report eds. R. Smith, C. Blouin, Z. Mirza, P. Beyer and N. Drager.. World Health Organization. 


\section{Appendix}

Figure A1: Changes in normalized imputed food imports from the U.S. ( $\Delta U$ Simp) between 1988 and 2012

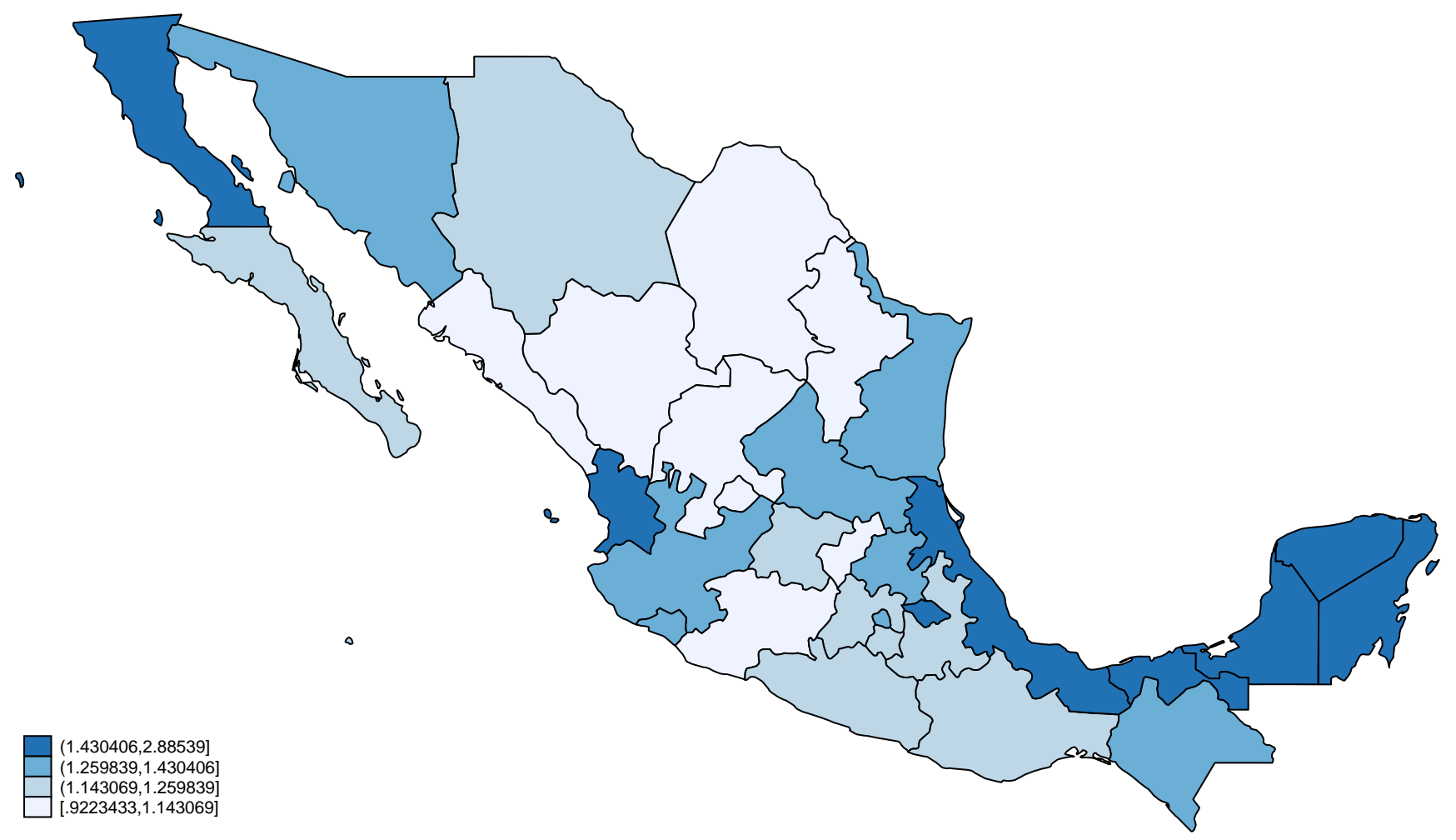

Figure A2: Relationship between actual and imputed food imports between 2006 and 2012

Panel (a): Controlling for year fixed effects

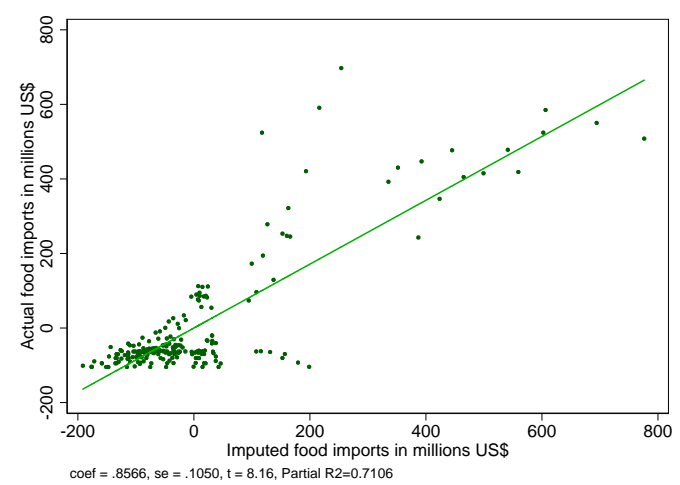

Panel (b): Controlling for state and year fixed effects

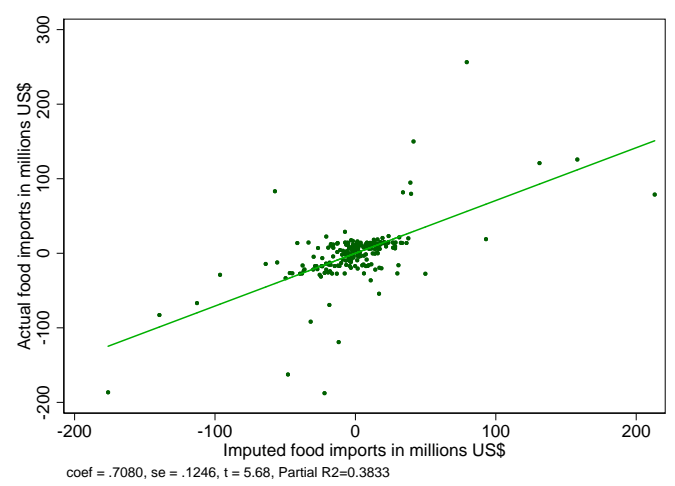


Figure A3: Obesity prevalence and food imports from the U.S. - Excluding one state at a time

Panel (a): Long-difference (2012 - 1988)

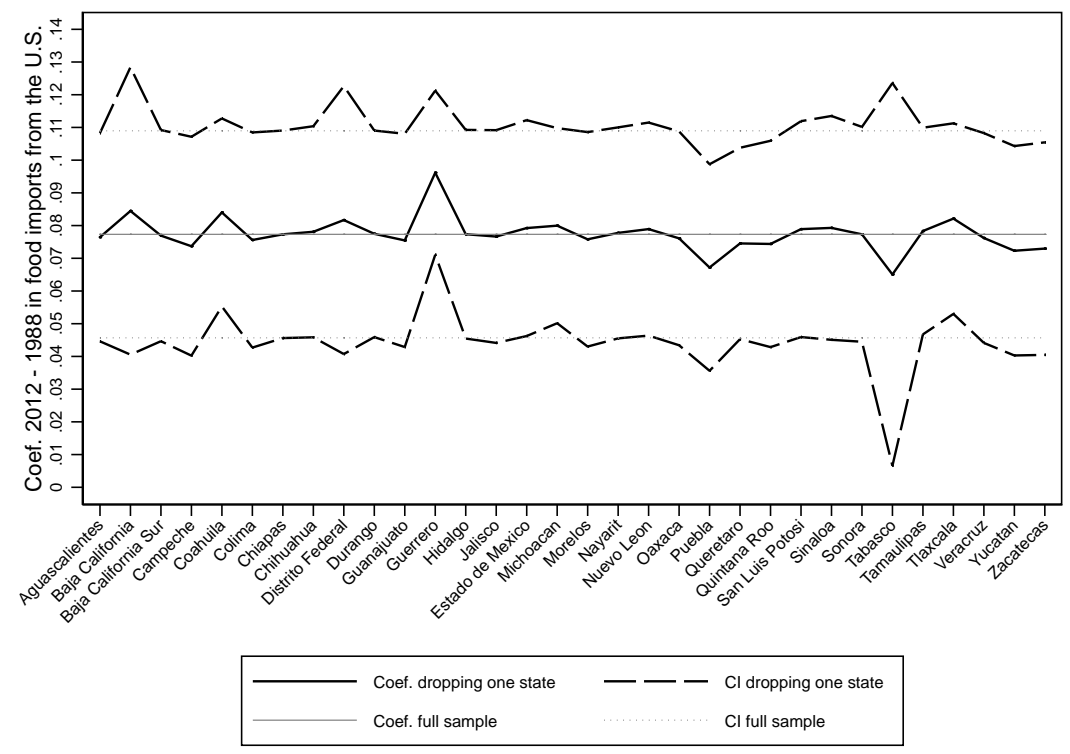

Panel (b): Stacked first-difference

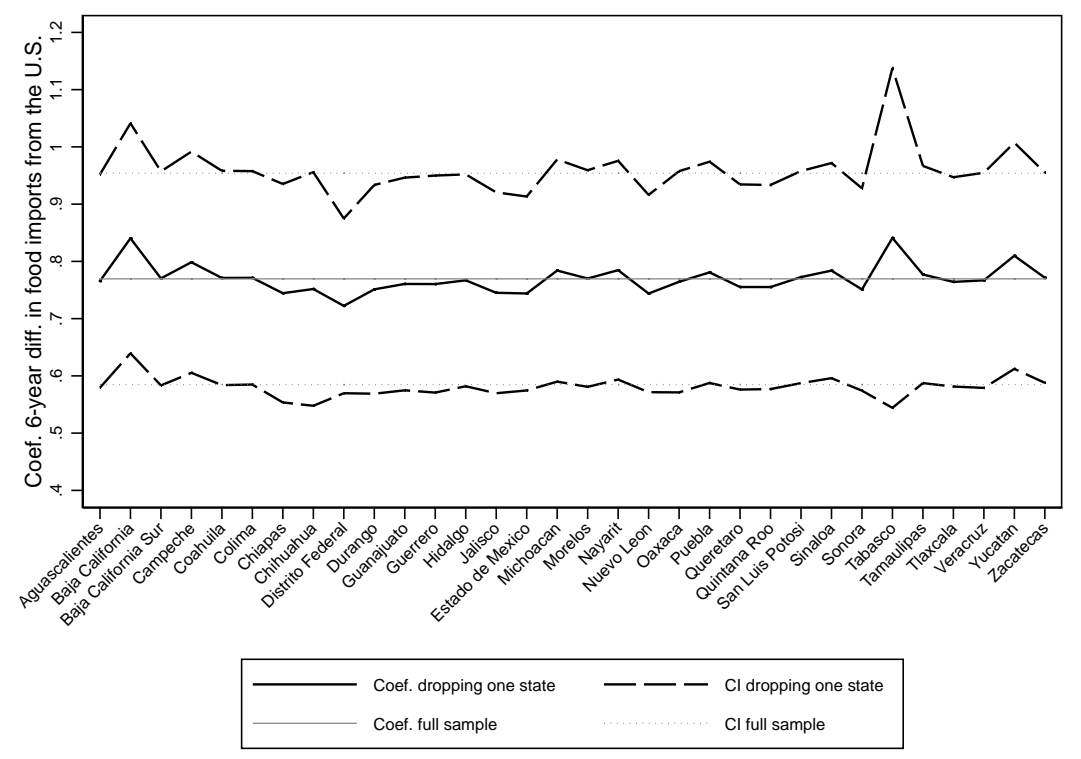

Note: Both panels use the specifications in column (4) of Table 1. 
Figure A4: Obesity prevalence, Walmart, food imports from the U.S.

Panel (a): Obesity and Walmart, unconditional

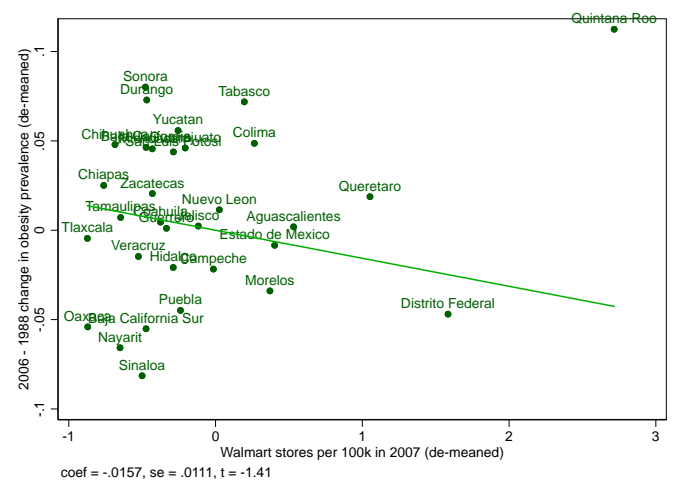

Panel (c): U.S. foods imports and Walmart, unconditional

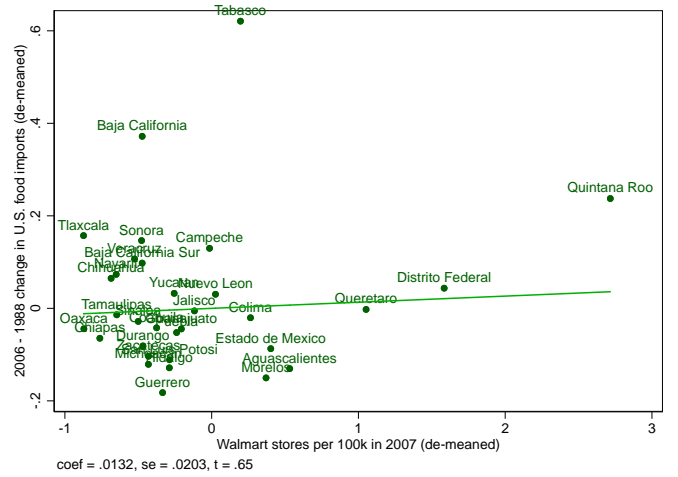

Panel (b): Obesity and Walmart, with

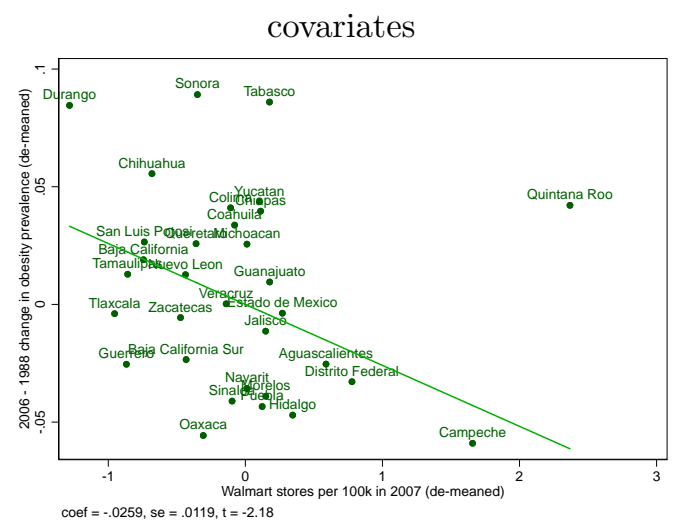

Panel (d): U.S. foods imports and Walmart, with covariates

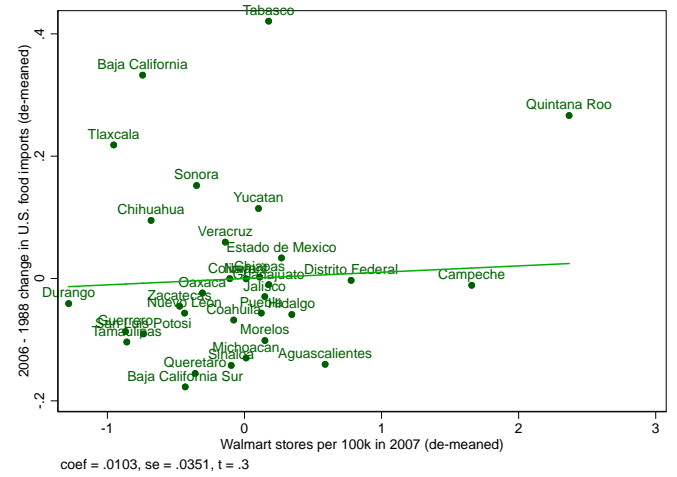

Note: Variables on the vertical and horizontal axis are 'partialled out' of the constant term and controls. The state share of national female population between 18 and 59 years of age in 1990 is used as weight. 
Table A1: List of Food and Beverages products

\begin{tabular}{|c|c|c|c|}
\hline $\begin{array}{l}\text { Product } \\
\end{array}$ & QRFAHPD category & (Healthy (USDA) & ( Healthy (Vegs+) \\
\hline Pineapple & 1 & 1 & 1 \\
\hline Apple & 1 & 1 & 1 \\
\hline Lemon & 1 & 1 & 1 \\
\hline Strawberry & 1 & 1 & 1 \\
\hline Grape & 1 & 1 & 1 \\
\hline Avocado & 1 & 1 & 1 \\
\hline Peach and apricot & 1 & 1 & 1 \\
\hline Tabascan banana & 1 & 1 & 1 \\
\hline Orange & 1 & 1 & 1 \\
\hline Mammee apple & 1 & 1 & 1 \\
\hline Pear & 1 & 1 & 1 \\
\hline Watermelon & 1 & 1 & 1 \\
\hline Mango & 1 & 1 & 1 \\
\hline Other citrus fruits: lime, grapefruit & 1 & 1 & 1 \\
\hline Melon & 1 & 1 & 1 \\
\hline Other: soursop, fig, coconut, tamarind & 1 & 1 & 1 \\
\hline Papaya & 1 & 1 & 1 \\
\hline Guava & 1 & 1 & 1 \\
\hline Boxed juices & 3 & 1 & 0 \\
\hline Cucumber & 4 & 1 & 1 \\
\hline Coriander & 4 & 1 & 1 \\
\hline Parsley & 4 & 1 & 1 \\
\hline Mixed bagged vegetables & 4 & 1 & 1 \\
\hline Cabbage & 4 & 1 & 1 \\
\hline Lettuce & 4 & 1 & 1 \\
\hline Courgette & 4 & 1 & 1 \\
\hline Epazote, celery, papalo & 4 & 1 & 1 \\
\hline Spinach, algae & 4 & 1 & 1 \\
\hline Carrot & 6 & 1 & 1 \\
\hline Sweetcorn & 8 & 1 & 1 \\
\hline Corn & 8 & 1 & 0 \\
\hline Potato & 8 & 1 & 0 \\
\hline Other: yam, sweet potato, beetroot & 8 & 1 & 1 \\
\hline Other bananas: plantain etc. & 8 & 1 & 1 \\
\hline Pea & 8 & 1 & 1 \\
\hline Nixtamal (boiled maize/corn) and others & 9 & 1 & 0 \\
\hline Nopales & 10 & 1 & 1 \\
\hline Serrano pepper and jalapeno & 10 & 1 & 1 \\
\hline Dried and powdered chillis & 11 & 1 & 1 \\
\hline Pepper & 12 & 1 & 1 \\
\hline Green tomato & 12 & 1 & 1 \\
\hline Red tomato & 12 & 1 & 1 \\
\hline Garlic & 14 & 1 & 1 \\
\hline Bean & 14 & 1 & 1 \\
\hline Chickpea & 14 & 1 & 1 \\
\hline Other: lentil, broad bean & 14 & 1 & 1 \\
\hline Green bean & 14 & 1 & 1 \\
\hline Onion & 14 & 1 & 1 \\
\hline Chayote & 14 & 1 & 1 \\
\hline Other: artichoke, radishes & 14 & 1 & 1 \\
\hline Bean (tinned or boxed) & 15 & 1 & 1 \\
\hline Grains of rice & 16 & 1 & 0 \\
\hline Corn tortilla & 16 & 1 & 0 \\
\hline Oats & 16 & 1 & 0 \\
\hline Other cereals: barley, rye & 16 & 1 & 0 \\
\hline Wheat tortilla & 16 & 1 & 0 \\
\hline Corn dough & 16 & 1 & 0 \\
\hline Corn flour & 17 & 1 & 0 \\
\hline Other: yoghurt, sour cream & 17 & 0 & 0 \\
\hline Sliced bread & 19 & 0 & 0 \\
\hline Other wheat products: flakes, prepared & 19 & 0 & 0 \\
\hline Other rice products: flour, toasted & 19 & 0 & 0 \\
\hline Pasta for soup & 19 & 0 & 0 \\
\hline White bread & 19 & 0 & 0 \\
\hline Wheat flour (refined and wholemeal) & 20 & 0 & 0 \\
\hline Evaporated milk & 22 & 1 & 0 \\
\hline Formula milk & 22 & 1 & 0 \\
\hline Fresh cheese & 23 & 1 & 0 \\
\hline Other milk: goat, donkey & 25 & 0 & 0 \\
\hline Powdered milk (whole or skimmed) & 25 & 0 & 0 \\
\hline Condensed milk & 25 & 0 & 0 \\
\hline Pasteurised milk & 25 & 0 & 0 \\
\hline Other: Chillied, Gruyere, Parmesan & 26 & 0 & 0 \\
\hline Manchego & 26 & 0 & 0 \\
\hline Oaxaca & 26 & 0 & 0 \\
\hline Chihuahua cheese & 26 & 0 & 0 \\
\hline
\end{tabular}

Table A1: List of Food and Beverages products (continued)

\begin{tabular}{|c|c|c|c|}
\hline Product & QFAHPD category & " Healthy (USDA) & 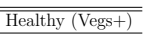 \\
\hline Butter & 26 & 0 & 0 \\
\hline Mature cheese & 26 & 0 & 0 \\
\hline Cream & 27 & 0 & 0 \\
\hline Goat & 28 & 1 & 0 \\
\hline Mutton and lamb & 28 & 1 & 0 \\
\hline Pork: mince, steak, piece & 29 & 0 & 0 \\
\hline Beef: stew/stock with bone & 29 & 0 & 0 \\
\hline Beef: chop and rib & 29 & 0 & 0 \\
\hline Beef: fillet & 29 & 0 & 0 \\
\hline Sausage & 29 & 0 & 0 \\
\hline Other beef: offal (liver), tongue, heart & 29 & 0 & 0 \\
\hline Lard & 29 & 0 & 0 \\
\hline Beef: steak and breaded & 29 & 0 & 0 \\
\hline Beef: round (piece or ground) & 29 & 0 & 0 \\
\hline Other: rabbit, iguana, venison & 29 & 0 & 0 \\
\hline Pork: chop and rib & 29 & 0 & 0 \\
\hline Other pork: insides (liver, kidney), to & 29 & 0 & 0 \\
\hline Pork: fillet and leg & 29 & 0 & 0 \\
\hline Beef: special cuts: t-bone, roast & 29 & 0 & 0 \\
\hline Other: chicken pie, salami, mortadella & 30 & 0 & 0 \\
\hline Bacon & 30 & 0 & 0 \\
\hline Chillied or smoked meats & 30 & 0 & 0 \\
\hline Ham & 30 & 0 & 0 \\
\hline Chorizo and longaniza & 30 & 0 & 0 \\
\hline Dried beef, cured meat, machaca & 30 & 0 & 0 \\
\hline Other birds: turkey, duck, pigeon & 31 & 1 & 0 \\
\hline Whole hen or in pieces & 31 & 1 & 1 \\
\hline Roast chicken & 31 & 1 & 1 \\
\hline Chicken insides: heart, liver & 32 & 1 & 1 \\
\hline Chicken in pieces & 32 & 1 & 1 \\
\hline Sardines & 33 & 1 & 1 \\
\hline Other: oyster, octopus, abalone & 33 & 1 & 1 \\
\hline Dried: cod, prawn & 34 & 1 & 1 \\
\hline Tuna & 34 & 1 & 1 \\
\hline Jam, jelly, peanut butter & 36 & 1 & 1 \\
\hline Hen egg & 37 & 1 & 1 \\
\hline Vegetable oil & 38 & 1 & 1 \\
\hline Vinegar & 38 & 1 & 1 \\
\hline Other: olive oil & 38 & 1 & 1 \\
\hline Mole & 39 & 0 & 0 \\
\hline Margarine & 39 & 0 & 0 \\
\hline Vegetable fat & 39 & 0 & 0 \\
\hline Other condiments: dressings & 39 & 0 & 0 \\
\hline Other: corn syrup, powdered brown sugar & 40 & 0 & 0 \\
\hline Honey & 40 & 0 & 0 \\
\hline Compote or conserve & 40 & 0 & 0 \\
\hline White or brown sugar & 40 & 0 & 0 \\
\hline Soft drinks (sparkling or still) & 41 & 0 & 0 \\
\hline Mineral water (flavoured or unflavoured) & 41 & 0 & 0 \\
\hline Beer & 42 & 0 & 0 \\
\hline Tequila & 42 & 0 & 0 \\
\hline Wine & 42 & 0 & 0 \\
\hline Aguardiente, mescal, sotol & 42 & 0 & 0 \\
\hline Other: cider, eggnog, sherry, vodka & 42 & 0 & 0 \\
\hline 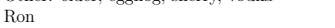 & 42 & 0 & 0 \\
\hline Pulque & 42 & 0 & 0 \\
\hline Brandy & 42 & 0 & 0 \\
\hline Purified water & 43 & 1 & 0 \\
\hline Ice creams and ices & 44 & 0 & 0 \\
\hline Jellies, flans and puddings & 45 & 0 & 0 \\
\hline Toffee and caramel & 45 & 0 & 0 \\
\hline Sweet biscuits & 46 & 0 & 0 \\
\hline Sweets and lollipops & 46 & 0 & 0 \\
\hline Powdered chocolate or chocolate bar & 46 & 0 & 0 \\
\hline Sweet bread & 47 & 0 & 0 \\
\hline Savoury biscuits & 47 & 0 & 0 \\
\hline Other: soup, salad, pizza, pie & 48 & 0 & 0 \\
\hline Mayonnaise & 49 & 0 & 0 \\
\hline Mustard & 49 & 0 & 0 \\
\hline Other: soup and tinned vegetables, olives & 49 & 0 & 0 \\
\hline Spicy sauces & 49 & 0 & 0 \\
\hline Instant tea & 49 & 0 & 0 \\
\hline Instant coffee & 49 & 0 & 0 \\
\hline Chicken and tomato stock & 51 & 0 & 0 \\
\hline Barbecued pork and pork rind (carnitas & 52 & 0 & 0 \\
\hline Barbeque & 52 & 0 & 0 \\
\hline
\end{tabular}

Note: See Volpe et al. (2013), Table 1 for a list of the QFAHPD categories. The USDA healthy categorization is read from column (3) of their Table. The "Healthy (vegs+)" classification classifies all vegetables, fruits, fish and poultry products as healthy. 
Table A2: Summary statistics for state-level variables

\begin{tabular}{|c|c|c|c|c|c|c|c|c|}
\hline & (1) & $(2)$ & $(3)$ & (4) & $(5)$ & $(6)$ & $(7)$ & $(8)$ \\
\hline & \multicolumn{4}{|c|}{ Long difference (2012 - 1988) } & \multicolumn{4}{|c|}{ Stacked first-diff. } \\
\hline & Mean & Std. Dev. & Min & Max & Mean & Std. Dev. & Min & $\operatorname{Max}$ \\
\hline$\Delta$ Obesity & 0.26 & 0.03 & 0.19 & 0.37 & 0.06 & 0.04 & -0.06 & 0.19 \\
\hline$\Delta$ Overw. & 0.38 & 0.06 & 0.28 & 0.53 & 0.08 & 0.07 & -0.11 & 0.25 \\
\hline$\Delta \mathrm{BMI}$ & 4.67 & 0.58 & 3.63 & 5.94 & 1.04 & 0.71 & -0.90 & 2.86 \\
\hline$\Delta$ USimp & 1.32 & 0.30 & 0.92 & 2.89 & 0.08 & 0.04 & 0.04 & 0.24 \\
\hline$\Delta$ USimp unh. (USDA) & 0.86 & 0.17 & 0.62 & 1.41 & 0.05 & 0.03 & 0.02 & 0.15 \\
\hline$\Delta$ USimp h. (USDA) & 0.46 & 0.24 & 0.18 & 1.88 & 0.03 & 0.02 & 0.01 & 0.13 \\
\hline$\Delta$ USimp unh. (cons.) & 1.00 & 0.29 & 0.72 & 2.48 & 0.06 & 0.03 & 0.03 & 0.19 \\
\hline$\Delta$ USimp h. (cons.) & 0.33 & 0.08 & 0.15 & 0.41 & 0.02 & 0.01 & 0.00 & 0.05 \\
\hline$\Delta$ U.S. food exports & 7.08 & 1.25 & 4.84 & 11.80 & 0.48 & 0.33 & 0.04 & 1.59 \\
\hline$\Delta$ Obesity $_{t-1}$ & 0.10 & 0.03 & 0.04 & 0.23 & 0.08 & 0.03 & -0.01 & 0.23 \\
\hline$\Delta$ Overw $_{t-1}$ & 0.35 & 0.07 & 0.20 & 0.53 & 0.19 & 0.13 & -0.07 & 0.53 \\
\hline$\Delta \mathrm{BMI}_{t-1}$ & 23.94 & 0.79 & 22.34 & 26.21 & 8.92 & 10.69 & -0.35 & 26.21 \\
\hline Food expen. share $t_{t-1}$ & 0.22 & 0.05 & 0.13 & 0.34 & 0.18 & 0.05 & 0.10 & 0.34 \\
\hline$\Delta$ ROWimp & 0.45 & 0.09 & 0.23 & 0.60 & 0.03 & 0.02 & 0.01 & 0.08 \\
\hline$\Delta \operatorname{Ln}($ GDP per cap.) & 3.35 & 0.21 & 3.02 & 4.35 & 1.12 & 0.81 & 0.13 & 2.46 \\
\hline$\Delta \operatorname{Ln}(\mathrm{FDI} / \mathrm{GDP})$ & 1.48 & 1.96 & -3.20 & 5.95 & 0.49 & 1.26 & -4.21 & 6.16 \\
\hline$\Delta \operatorname{Ln}($ Migrant/Pop) & 0.72 & 0.79 & -1.81 & 2.75 & 0.24 & 1.16 & -2.68 & 3.25 \\
\hline$\Delta$ High educ. share & 0.27 & 0.06 & 0.14 & 0.49 & 0.09 & 0.06 & -0.09 & 0.32 \\
\hline$\Delta$ Unemp. share & -0.16 & 0.04 & -0.35 & -0.03 & -0.05 & 0.10 & -0.31 & 0.20 \\
\hline$\Delta$ Malls share food expen. & 0.03 & 0.10 & -0.12 & 0.42 & 0.01 & 0.06 & -0.21 & 0.22 \\
\hline$\Delta$ Restaurant share food expen. & 0.09 & 0.05 & -0.09 & 0.23 & 0.03 & 0.08 & -0.21 & 0.16 \\
\hline Walmart stores per 100k persons (2007) & 1.14 & 0.74 & 0.26 & 3.85 & & & & \\
\hline
\end{tabular}

Note: Long-difference statistics are based on 32 observations. Stacked first-difference statistics are based on 96 observations. $\Delta$ Obesity $_{t-1}, \Delta$ Overw $_{t-1}$ and $\Delta \mathrm{BMI}_{t-1}$ equal their respective values in 1988 for the long-difference statistics. The state share of national female population between 18 and 59 years of age in 1990 is used as weight. 
Table A3: Values of $\Delta$ USimp

\begin{tabular}{|c|c|c|c|c|}
\hline State & $1999-1988$ & $2006-1999$ & $2012-2006$ & $2012-1988$ \\
\hline Aguascalientes & 0.10 & 0.04 & 0.06 & 0.94 \\
\hline Baja California & 0.20 & 0.08 & 0.07 & 2.00 \\
\hline Baja California Sur & 0.16 & 0.04 & 0.04 & 1.18 \\
\hline Campeche & 0.14 & 0.11 & 0.08 & 1.70 \\
\hline Chiapas & 0.12 & 0.07 & 0.05 & 1.29 \\
\hline Chihuahua & 0.14 & 0.09 & 0.05 & 1.15 \\
\hline Coahuila & 0.13 & 0.07 & 0.06 & 1.12 \\
\hline Colima & 0.12 & 0.06 & 0.04 & 1.26 \\
\hline Distrito Federal & 0.13 & 0.05 & 0.07 & 1.33 \\
\hline Durango & 0.11 & 0.06 & 0.05 & 0.92 \\
\hline Estado de Mexico & 0.11 & 0.05 & 0.07 & 1.17 \\
\hline Guanajuato & 0.12 & 0.04 & 0.05 & 1.26 \\
\hline Guerrero & 0.09 & 0.07 & 0.05 & 1.15 \\
\hline Hidalgo & 0.11 & 0.04 & 0.07 & 1.33 \\
\hline Jalisco & 0.12 & 0.05 & 0.06 & 1.37 \\
\hline Michoacan & 0.10 & 0.04 & 0.05 & 1.10 \\
\hline Morelos & 0.10 & 0.05 & 0.07 & 1.15 \\
\hline Nayarit & 0.14 & 0.06 & 0.11 & 1.50 \\
\hline Nuevo Leon & 0.15 & 0.05 & 0.08 & 1.12 \\
\hline Oaxaca & 0.12 & 0.06 & 0.08 & 1.18 \\
\hline Puebla & 0.12 & 0.05 & 0.05 & 1.17 \\
\hline Queretaro & 0.14 & 0.04 & 0.04 & 1.12 \\
\hline Quintana Roo & 0.15 & 0.06 & 0.06 & 1.57 \\
\hline San Luis Potosi & 0.12 & 0.04 & 0.05 & 1.34 \\
\hline Sinaloa & 0.12 & 0.05 & 0.05 & 1.13 \\
\hline Sonora & 0.16 & 0.07 & 0.06 & 1.41 \\
\hline Tabasco & 0.24 & 0.11 & 0.15 & 2.89 \\
\hline Tamaulipas & 0.13 & 0.04 & 0.05 & 1.31 \\
\hline Tlaxcala & 0.15 & 0.04 & 0.05 & 1.87 \\
\hline Veracruz & 0.15 & 0.04 & 0.06 & 1.74 \\
\hline Yucatan & 0.10 & 0.10 & 0.08 & 1.45 \\
\hline Zacatecas & 0.11 & 0.04 & 0.05 & 1.14 \\
\hline
\end{tabular}

Table A4: State food prices and exposure to U.S. foods from the U.S.

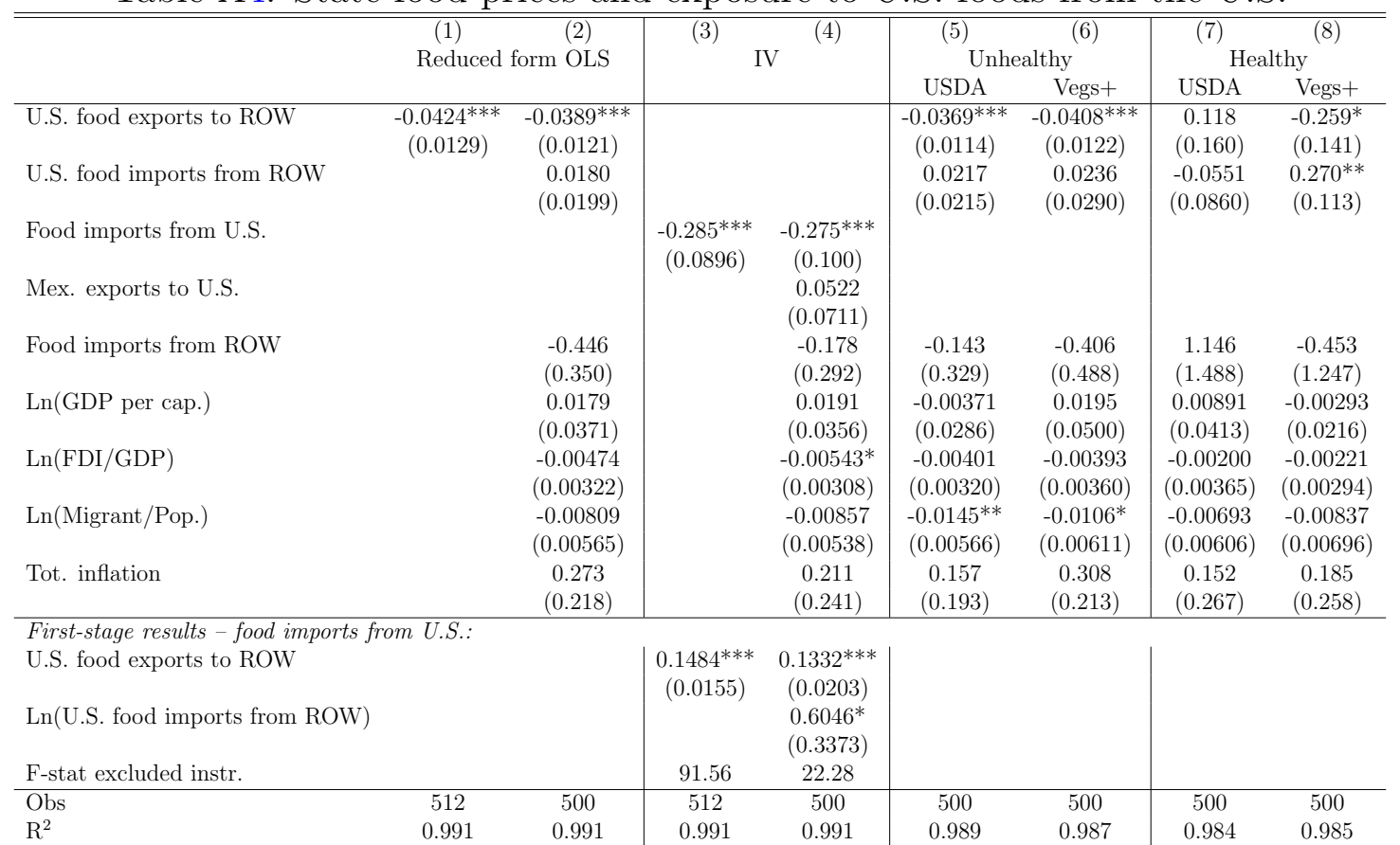

Note: The dependent variable is the expenditure-weighted average of price across food products (with weights fixed at their values in 1995), for each state and year. All regressions include state and year fixed effects. Columns (5) to (8) are reduced-form OLS estimates. First-stage results report estimates associated with the excluded instruments only. Robust standard errors clustered at the state level are in parentheses. Significant at: *10\%,**5\%,***1\% level. 
Table A5: Food imports from the U.S. and health disparities

\begin{tabular}{lccc|cc}
\hline \hline & $(1)$ & $(2)$ & $(3)$ & $(4)$ & $(5)$ \\
U.S. food var.: & & Total & & Unh. & H. \\
\hline U.S. foods $\times$ High educ. & $-0.0195^{* *}$ & & $-0.0199^{* * *}$ & $-0.0350^{* * *}$ & -0.0328 \\
& $(0.00722)$ & & $(0.00684)$ & $(0.0102)$ & $(0.0198)$ \\
High educ. & $-0.0407^{* * *}$ & $-0.0501^{* * *}$ & $-0.0406^{* * *}$ & $-0.0392^{* * *}$ & $-0.0446^{* * *}$ \\
& $(0.00628)$ & $(0.00639)$ & $(0.00655)$ & $(0.00638)$ & $(0.00699)$ \\
U.S. foods $\times$ Unemp. & & -0.00855 & $-0.0130^{* *}$ & -0.0165 & $-0.0357^{* * *}$ \\
& & $(0.00654)$ & $(0.00612)$ & $(0.0101)$ & $(0.0127)$ \\
Unemp. & 0.00257 & 0.00657 & 0.00916 & 0.00816 & 0.00861 \\
& $(0.00515)$ & $(0.00616)$ & $(0.00639)$ & $(0.00640)$ & $(0.00605)$ \\
U.S. foods $\times$ Middle inc. & & & 0.00254 & 0.00176 & 0.00961 \\
& & & $(0.00924)$ & $(0.0151)$ & $(0.0223)$ \\
U.S. foods $\times$ High inc. & & & -0.0141 & -0.0280 & -0.0121 \\
& & & $(0.0123)$ & $(0.0201)$ & $(0.0255)$ \\
Middle inc. & $0.0547^{* * *}$ & $0.0543^{* * *}$ & $0.0535^{* * *}$ & $0.0543^{* * *}$ & $0.0528^{* * *}$ \\
& $(0.00793)$ & $(0.00805)$ & $(0.00841)$ & $(0.00859)$ & $(0.00830)$ \\
High inc. & 0.0165 & 0.0171 & 0.0229 & 0.0250 & 0.0184 \\
& $(0.0155)$ & $(0.0160)$ & $(0.0156)$ & $(0.0157)$ & $(0.0156)$ \\
\hline Obs & 56,713 & 56,713 & 56,713 & 56,713 & 56,713 \\
$\mathrm{R}^{2}$ & 0.111 & 0.111 & 0.111 & 0.111 & 0.111 \\
\hline
\end{tabular}

Note: All regressions include state-year fixed effects and the following individual level covariates: age and age squared; an indicator for women who speak indigenous languages; a dummy for chronic diseases, and one for being the household head. The variable "U.S. foods" equals USimp in "Tot." columns and its unhealthy and healthy parts in the "Unh." and "H." columns, respectively. The state share of national female population between 18 and 59 years of age in 1990 is used as weight. Standard errors clustered at the state level are in parentheses. Significant at: ${ }^{*} 10 \%,{ }^{*}{ }_{5} \%,{ }^{* * *} 1 \%$ level.

Table A6: Contemporary tastes and past U.S. food exports

\begin{tabular}{|c|c|c|c|c|c|c|c|c|}
\hline & $(1)$ & 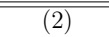 & 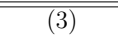 & $\overline{(4)}$ & 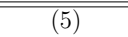 & 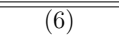 & $\overline{(7)}$ & 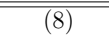 \\
\hline U.S. food exports to $\mathrm{ROW}_{t}$ & $\begin{array}{c}0.00333^{*} \\
(0.00196)\end{array}$ & $\begin{array}{c}0.00125 \\
(0.00323)\end{array}$ & $\begin{array}{c}-0.00425 \\
(0.00312)\end{array}$ & $\begin{array}{c}0.00385 \\
(0.00356)\end{array}$ & $\begin{array}{c}-0.00617^{*} \\
(0.00356)\end{array}$ & $\begin{array}{l}-0.00366 \\
(0.00376)\end{array}$ & $\begin{array}{c}-0.00581^{*} \\
(0.00323)\end{array}$ & $\begin{array}{l}-0.00293 \\
(0.00347)\end{array}$ \\
\hline U.S. food exports to ROW RO- $_{t}$ & & & $\begin{array}{c}0.0102 * * * \\
(0.00326)\end{array}$ & $\begin{array}{l}-0.00357 \\
(0.00354)\end{array}$ & $\begin{array}{c}0.00416 \\
(0.00353)\end{array}$ & $\begin{array}{l}-0.00271 \\
(0.00447)\end{array}$ & $\begin{array}{c}0.00551 \\
(0.00367)\end{array}$ & $\begin{array}{c}-0.00182 \\
(0.00455)\end{array}$ \\
\hline U.S. food exports to $\mathrm{ROW}_{t-2}$ & & & & & $\begin{array}{c}0.0150^{* * *} \\
(0.00409)\end{array}$ & $\begin{array}{c}0.00992^{* *} \\
(0.00462)\end{array}$ & $\begin{array}{c}0.0289^{* * * *} \\
(0.00550)\end{array}$ & $\begin{array}{c}0.0181^{* * *} * \\
(0.00598)\end{array}$ \\
\hline U.S. food exports to $\mathrm{ROW}_{t-3}$ & & & & & & & $\begin{array}{c}-0.0228^{* * *} \\
(0.00408)\end{array}$ & $\begin{array}{c}-0.0152^{* *} \\
(0.00603)\end{array}$ \\
\hline Avg. effect of lags & & & $\begin{array}{c}0.0102^{* * *} \\
(0.00326)\end{array}$ & $\begin{array}{c}-0.00357 \\
(0.00354)\end{array}$ & $\begin{array}{c}0.00958^{* * *} \\
(0.0022\end{array}$ & $\begin{array}{l}0.00360 \\
(0.0026)\end{array}$ & $\begin{array}{c}0.0039^{* * *} \\
(0.0014)\end{array}$ & $\begin{array}{l}0.00037 \\
(0.0019)\end{array}$ \\
\hline Price controls & $\mathrm{N}$ & $\mathrm{Y}$ & $\mathrm{N}$ & $\mathrm{Y}$ & $\mathrm{N}$ & $\mathrm{Y}$ & $\mathrm{N}$ & $\mathrm{Y}$ \\
\hline $\mathrm{BIC}$ & & -12167 & -11268 & -12162 & -10048 & -10995 & -10063 & -11001 \\
\hline Obs & 2,592 & 2,592 & 2,592 & 2,592 & 2,304 & 2,304 & 2,304 & 2,304 \\
\hline $\mathrm{R}^{2}$ & 0.511 & 0.705 & 0.512 & 0.705 & 0.530 & 0.739 & 0.534 & 0.740 \\
\hline
\end{tabular}

Note: The dependent variable is estimated as state-year fixed effects from regressions of households' expenditure shares by food aggregate on real food expenditure and other household characteristics. Years of the expenditure survey are 1996, 1998, 2000, 2002, 2004, 2005, 2006, 2008, and 2010. We use nine food aggregates (obtained by aggregating the QFAHPD categories - see Table A1): fruits; vegetables; grains; dairy products; meats; oils and fats; sugary products; drinks; prepared foods and others. Household controls used in the first step of the empirical strategy include: age (and its square term), sex, occupation, education and sector of employment of the household head, household size (and its square term) and composition. "U.S. food exports to ROW" is exposure to U.S. food exports by food aggregate computed as the average $\frac{E_{g, s, 1994}}{E_{g, 1994}} \ln \left(X_{g, t}^{U S}\right)$ across food product $g$ within the same aggregate $-X_{g, t}$ is the PPP-adjusted value of U.S. food exports to ROW. The set of "price controls" equals the state expenditure-weighted (with 1994 weights) average price of each food aggregate interacted with dummies for all the food aggregates (thus allowing for cross-aggregate price effects). All regressions include food-state and state-year fixed effects. Standard errors clustered at the food-state level are in parentheses. Significant at: ${ }^{*} 10 \%, * * 5 \%,{ }^{* * *} 1 \%$ level. 